Florida International University FIU Digital Commons

7-14-2016

\title{
Qualitative Detection of Selected Designer Drugs and Relevant Metabolites in Environmental Water Samples
}

Marley Pruyn

Florida International University, mpruy001@fiu.edu

DOI: $10.25148 /$ etd.FIDC000751

Follow this and additional works at: https:// digitalcommons.fiu.edu/etd

Part of the Analytical Chemistry Commons, and the Other Chemistry Commons

\section{Recommended Citation}

Pruyn, Marley, "Qualitative Detection of Selected Designer Drugs and Relevant Metabolites in Environmental Water Samples" (2016). FIU Electronic Theses and Dissertations. 2571.

https://digitalcommons.fiu.edu/etd/2571 


\section{FLORIDA INTERNATIONAL UNIVERSITY}

Miami, Florida

QUALITATIVE DETECTION OF SELECTED DESIGNER DRUGS AND RELEVANT METABOLITES IN ENVIRONMENTAL WATER SAMPLES

A thesis submitted in partial fulfillment of the

requirements for the degree of

MASTER OF SCIENCE

in

CHEMISTRY

by

Marley Pruyn 
To: Dean Michael R. Heithaus

College of Arts, Sciences and Education

This thesis, written by Marley Pruyn, and entitled Qualitative Detection of Selected Designer Drugs and Relevant Metabolites in Environmental Water Samples, having been approved in respect to style and intellectual content, is referred to you for judgment.

We have read this thesis and recommend that it be approved.

Jose Almirall

Anthony DeCaprio

Piero Gardinali, Major Professor

Date of Defense: July 14, 2016

The thesis of Marley Pruyn is approved.

Dean Michael R. Heithaus

College of Arts, Sciences and Education

Andrés G. Gil

Vice President for Research and Economic Development and Dean of the University Graduate School

Florida International University, 2016 


\begin{abstract}
OF THE THESIS
QUALITATIVE DETECTION OF SELECTED DESIGNER DRUGS AND RELEVANT METABOLITES IN ENVIRONMENTAL WATER SAMPLES

Marley Pruyn
\end{abstract}

Florida International University, 2016

Miami, Florida

Professor Piero Gardinali, Major Professor

Designer drugs are compounds which have been synthetically derived from illicit drugs. After consumption, drugs and their metabolites are introduced into the sewage water which is treated and disposed into the environment. A combined target, suspect and nontarget workflow was created to detect designer drugs in environmental water samples. Multiple water samples were spiked with an unknown mixture of drugs and metabolites to assess the efficiency of the method. Samples were collected from sewage influent and effluent pipes, downstream from a sewage outfall and reclaimed water. Analysis was conducted with high resolution MS using the QExactive Orbitrap. Screening was performed using a database compiled in-house using TraceFinder EFS. Structure confirmation was achieved using MassFrontier. Target drugs and their metabolites were detected in sewage influent but not in sewage effluent, downstream of the effluent pipe, or in reclaimed water. The workflow was adequate to detect designer drugs in multiple water matrices at concentrations as low as $20 \mathrm{ppt}$. 
TABLE OF CONTENTS

CHAPTER

PAGE

1 INTRODUCTION

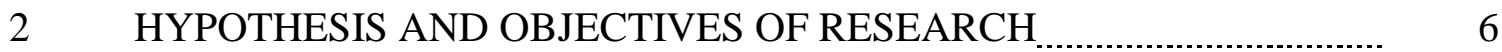

3 EXPERIMENTAL

$3.1 \quad$ RESEARCH TASKS _ _ _

3.2 REAGENTS AND CHEMICALS _..................................... 10

3.3 SAMPLE COLLECTION AND PREPARATION $\ldots$

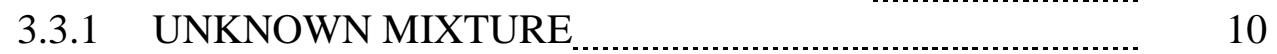

3.3.2 SEWAGE INFLUENT ………………………..............

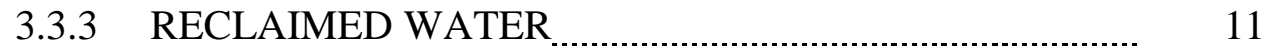

3.3.4 ENVIRONMENTAL SAMPLES ……………...................

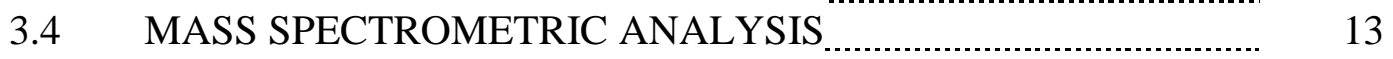

$4 \quad$ RESULTS

4.1 CONFIRMATION OF UNKNOWN MIXTURE

4.2 DETERMINATION OF LIMIT OF DETECTION _......................... 27

4.3 ASSESSMENT OF MATRIX EFFECTS _............................................. 29

4.4 DETECTION OF PARENT COMPOUNDS AND METABOLITES

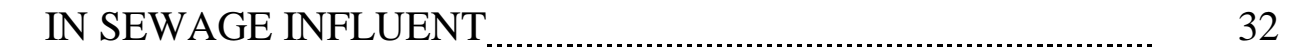

4.5 COMPARSION OF ACQUISITION MODES …............................. 41

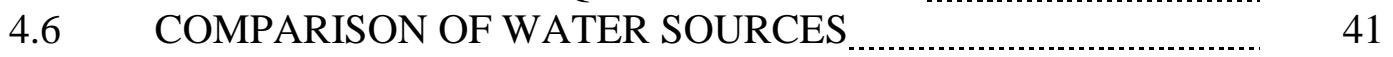

$5 \quad$ DISCUSSION

REFERENCES

APPENDICES _ _ $\quad 50$ 


\section{LIST OF TABLES}

TABLES

PAGE

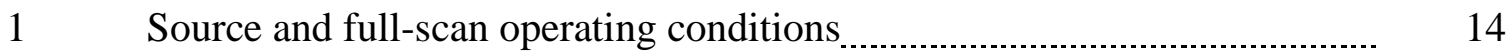

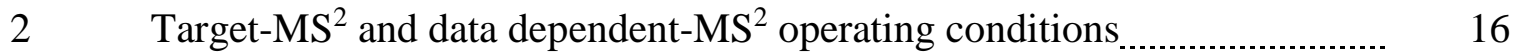

3 HPLC gradient for pumps 1 and 2: solvent A (water), solvent B (methanol), solvent $\mathrm{C}$ (acetonitrile), solvent $\mathrm{D}(0.1 \%$ formic acid)

4 Compounds detected in $\mathrm{MS}^{2}$ analysis of unknown spiked samples at $20 \mathrm{ppt}$

$5 \quad$ Parent compounds detected in sewage influent and observed

fragmentation

$6 \quad$ Suspect compounds unconfirmed with $\mathrm{MS}^{2}$

$7 \quad$ Metabolites detected and observed fragmentation

8 Comparison of target- $\mathrm{MS}^{2}$ and data dependent-MS ${ }^{2}$ analyses 


\section{LIST OF FIGURES}

FIGURES

PAGE

1 Comparison of phenethylamine (left), 2,5-dimethoxy-4ethylphenethylamine aka 2C-E (center) and 2,5-dimethoxy-4iodophenethylamine aka 2C-I (right)

2 Map of collection locations of environmental samples

3 Full scan chromatogram of unknown mixture in deionized water at $20 \mathrm{ppt}$

4 Full scan chromatogram of identified compounds in deionized water at $20 \mathrm{ppt}$

$5 \mathrm{MS}^{2}$ spectra of the individual components of the unknown mixture (35 NCE)

6 Comparison of $\mathrm{MS}^{2}$ spectra of isopentedrone at $20 \mathrm{ppt}$ (top), $10 \mathrm{ppt}$ (second), 5 ppt (third), and 1 ppt (bottom)

7 Comparison of 4-fluoroethcathinone in deionized water (top), tap water (second), reclaimed water (third) and filtered raw sewage (bottom)

8 Graph of the effect of the dilution factor of raw sewage on the peak intensity of the $[\mathrm{M}+\mathrm{H}]^{+}$peak for each component of the unknown mixture present at $20 \mathrm{ppt}$

9 Fragmentation spectra of confirmed suspect compounds in sewage influent

10 Fragmentation spectra of confirmed metabolites 


\section{LIST OF ABBREVIATIONS}

4-MAR

2-methylaminorex

3,4-MDMA

3,4-methylenedioxymethamphetamine

3,4-DMMC 3,4-dimethylmethcathinone

$\operatorname{ddMS}^{2}$ Data Dependent-MS ${ }^{2}$

HESI Heated Electrospray Ionization

HPLC High Performance Liquid Chromatography HRMS High Resolution Mass Spectrometry MDA Methylenedioxyamphetamine MDPV Methylenedioxypyrovalerone

MMA 3-methoxy-4-methylamphetamine SPE Solid Phase Extraction $\mathrm{tMS}^{2}$ Target-MS ${ }^{2}$

UNODC United Nation Office on Drugs and Crime

UPLC Ultra-High Performance Liquid Chromatography 


\section{INTRODUCTION}

Designer drugs are defined as compounds which are synthetically derived analogs of drugs which are currently banned or controlled. The primary law for the regulation of drugs is known as the Controlled Substances Act. The act divides drugs into specific categories based on accepted medical uses and the potential for abuse, and regulates them accordingly. Laws regarding production and consumption of drugs are written to regulate specific chemical structures, thus modifications to the regulated structures allow drug manufacturers to circumvent current drug laws. The modifications of the parent structure can include the addition, modification or subtraction of a functional group. The resulting structure is not regulated under the Controlled Substances Act. As new drug laws are written to ban emerging designer drugs, newer compounds are created. In this manner, the production of designer drugs can stay ahead of regulations and the number of designer drugs available increases exponentially. In 2014, 69 new compounds were seen on the market for the first time, and were added to the United Nations Office on Drugs and Crime (UNODC) drug monitoring system. By the end of 2014, a total of 450 designer drugs were recorded in the UNODC system, which is more than triple the number of designer drugs recorded in 2009 (UNODC 2015).

Many designer drugs are produced overseas and sold online or smuggled into the United States to be sold on the streets, but some are produced domestically. In 2012, MDMA seizures were reported at 2 tons in East and South-East Asia but only 0.7 tons seized in the Americas (UNODC 2015.) Recipes to produce designer drugs are available online and in published literature, such as $P i H K A L$ and TiHKAL, which means manufacturers have easy access to the information. In an attempt to restrict the manufacturing of illicit 
and designer drugs, many precursors for the production of illicit drugs have been regulated under the Controlled Substances Act. In 2011 and 2012, enough MDMA precursors were seized worldwide to have produced approximately 44 tons of MDMA, while only 9 tons of MDMA itself were seized worldwide (UNODC 2015.) The creation of new designer drugs means that new precursors may be used for production, so manufacturers can avoid regulations and detection. Early warning systems have been implemented in several countries to monitor the use of illicit drugs and emergence of new drugs.

The numbers of designer drugs available on the market increases exponentially as new modifications are developed. For the purposes of this research, information on existing and newly developed designer drugs was gathered, not only from published, peerreviewed articles, but also from government sources, such as the Drug Enforcement Administration and from user forums such as Erowid.org and Drugs-Forum.com. The large number of designer drugs on the market necessitates recognizable drug classifications. The compounds can be divided in the following categories: hallucinogens, empathogens, stimulants, opioids, sedatives, cannabinoids, and anabolic steroids. Drugs which fall into the hallucinogen classification includes psychedelics, lysergamides, and phenethylamines. The empathogen classification includes the group known as the MDxx family (i.e. MDMA) and piperazines. The stimulant classification includes amphetamines, cathinones, pyrollidines, and pyrrolidinophenones. The opioid group primarily consists of fentanyl derivatives. The sedative classification mainly includes GHB (gamma-hydroxybutyrate) derivatives. There are many sub-categories in the 
cannabinoid group. They are commonly thought of as synthetic THC, but they can have a wide variety of pharmacological effects. The drugs in the anabolic steroid class are a relatively new group which contains primarily testosterone-derived performance enhancing compounds and "dietary supplements." A single drug or sub-category of drugs may be responsible for a variety of effects and may technically fit into multiple classifications but are typically sorted based on the primary effect seen when the drug is consumed. Of the new compounds reported in 2014, $39 \%$ were synthetic cannabinoids and $18 \%$ were phenethylamines, but new compounds were seen from each of the major classes of designer drugs (UNODC 2014.)

When structural modifications are performed, the original drug and the new compound typically share pharmacological effects. Due to these similarities, many of the drugs within a particular category share a common structural backbone. There is common backbone for the phenethylamine series, shown in Figure 1. There a several sub-classes within the phenethylamine group, and each group has its own common scaffold, to which further modifications can be made to produce new compounds. For example, the members of the $2 \mathrm{C}$ series, a phenethylamine sub-class, share a common dimethoxyphenethylamine backbone. Each member of the $2 \mathrm{C}$ series has a different, additional substituent, such as a chlorine, a methyl group, an ethyl group, or an iodine. These additional functional groups are used in the naming system of the $2 \mathrm{C}$ series. $2 \mathrm{C}-\mathrm{E}$ has an ethyl group, while 2C-I has an iodine, as shown in Figure 1 (Shulgin, 1991.) 

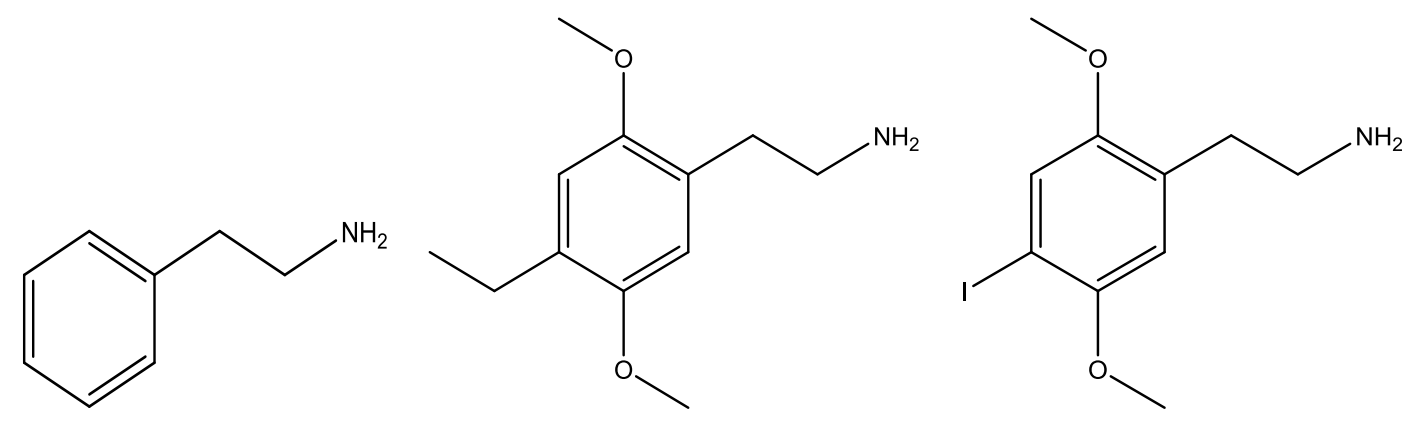

Figure 1. Comparison of phenethylamine (left), 2,5-dimethoxy-4-ethylphenethylamine aka $2 C$-E (center) and 2,5-dimethoxy-4-iodophenethylamine aka 2C-I (right)

Each sub-class of the phenethylamine group are classified in a similar manner. The members of the DOx series and the NBOMe series each share common structural features in addition to the common phenethylamine backbone. There are also common backbones shared within the tryptamines, cathinones, and many of other classifications.

When drugs are consumed, they are excreted as metabolites, the unchanged parent compound, or a combination of both. Once the drugs have been deposited into the sewage system, they are transported to the wastewater treatment plant. The wastewater undergoes three stages of treatment before being released into the environment. The primary treatment involves the removal of large waste items such as bottles, stick and other objects that may have been deposited into the sewers. The secondary stage of treatment removes up to $90 \%$ of the organic matter that is contained in wastewater through biological treatment with microbes. The tertiary stage of treatment is the chemical treatment stage, in which chemical additives are added to the wastewater causing pollutants to clump together, making them easier to remove by physical means (EPA, 2004.) Treatment protocols are developed to remove specific chemicals and contaminants which are regulated by law. Even the most sophisticated treatment protocols are not 
capable of removing $100 \%$ of all contaminants present, some contaminants are released into the environment with the treated wastewater. Illicit drugs and their metabolites are among the compounds which survive the sewage treatment process (Heuett et. al., 2014.)

Public concern began to rise when it was observed that surface water contained trace amounts of pharmaceutical compounds and other personal care products. Researchers began to examine the level of exposure and the long-term health effects that these compounds may have on the ecosystem. Following the determination of the presence of standard pharmaceuticals, researchers began to examine the presence of illicit drugs, such as cocaine and THC, in surface water. It has been determined that many common illicit drugs will survive the sewage treatment process and be introduced into the environment via outfalls (Baker et. al., 2012; Castiglioni et. al., 2006; Chiaia et. al., 2008; Ostan et. al., 2014; Pal et. al., 2013; Senta et. al., 2014; Thomas et. al., 2012; Yargeau et. al., 2014). Concentrations of illicit drugs have been reported in influent and effluent streams, outfalls and surface water samples at levels as high as $27,500 \mathrm{ng} / \mathrm{L}$ (Heuett et. al., 2014). These findings indicate that drugs can survive the sewage treatment process and will be deposited into the environment via treated effluent outfalls. MDMA and several of its derivatives have been detected in raw and treated wastewater and in water collected from rivers located throughout Europe (Bartelt-Hunt et. al., 2009; Postigo et. al., 2010; Valcartel et. al., 2012; Zuccato et. al., 2008b). Studies were conducted in the Ebro and Targus Rivers in Spain which detected MDMA in the ranges of 0.2 to $180.0 \mathrm{ng} / \mathrm{L}$ (Postigo et. al., 2010) and 0.63 to $2.51 \mathrm{ng} / \mathrm{L}$ (Valcarcel et. al., 2012), respectively. Prior to this 
examination, no study has been conducted which searches for a comprehensive list of designer drugs in environmental water samples.

\section{HYPOTHESIS AND OBJECTIVES OF RESEARCH}

The hypothesis of this research was that a wide variety of designer drugs and their metabolites could be detected in sewage influent and effluents, and environmental water samples, allowing for the assessment of environmental prevalence. The intent of this research was to implement a single protocol for the detection of a wide variety of designer drugs and their metabolites to determine their prevalence in environmental water samples. The first aim of this study was to determine the efficacy of the method by identifying the components of a mixture of unknown parent drugs and metabolites. The second aim was to establish that designer drugs and their metabolites were present in raw sewage in detectable concentrations. The final aim was to determine if designer drugs were present in detectable concentrations in environmental water samples.

\section{EXPERIMENTAL}

The ThermoScientific QExactive Orbitrap was used to conduct this research paired with the EQuan Online SPE system. The online SPE system utilized a pair of pumps to push the sample through a pre-concentration column and an analytical column. The preconcentration column retained the analyte compounds from the sample solution. The analytes were then washed out of the pre-concentration column by the mobile phases. 
The mobile phases pushed the analyte through the rest of the online SPE system and carried the compounds to the analytical column where they were separated before being introduced into the HESI source (Ramirez et. al., 2014.) When the analyte molecules entered the HESI source, they were passed through a charged capillary tube. The analyte compounds in the mobile phase were sprayed out of the end of the capillary tube, where they became charged. The solvent portion of the droplets evaporated leaving only the charged analyte to move into the Orbitrap system. The newly formed ions were aimed into a quadrupole mass analyzer using a curved charged beam guide. The quadrupole is followed by an octopole. After passing through the quadrupole and the octopole, the ions reached the C-trap where they were held before they were introduced into the Orbitrap. The Orbitrap ion trap used a combination of radial and axial oscillations to create separate bands of ions moving tangentially around a curved electrode. Each ion had a specific rotational frequency which was recorded by the detector and translated into the spectrum displayed by the instrument. This system was run first as a full scan analysis, introducing all ions into the Orbitrap. During $\mathrm{MS}^{2}$ analysis, the ions of the selected masses were sent into a collision cell to fragment the ions before they were moved into the C-Trap and into the Orbitrap.

One isolation and analysis protocol was developed and applied which was effective for all categories of designer drugs. The method was optimized in order to accommodate each of the target compounds and simultaneously conduct a screening for metabolites. The combined selectivity and sensitivity of the Orbitrap allowed for low concentrations of designer drugs to be detected with levels of confidence required for positive 
identification (ThermoScientific, 2014). The Orbitrap has been shown to be capable of distinguishing between isotopes with an $\mathrm{m} / z$ difference as low as 0.0109 (Hu et. al., 2005) and has a mass accuracy capable of distinguishing between compounds within 2ppm routinely (Makarov et. al., 2006.) Previously conducted research indicates that the Orbitrap is capable of detecting compounds present in the $\mathrm{ng} / \mathrm{L}$ range, which is sufficient to provide the environmental relevance required for this research (Heuett et. al., 2014.)

This study utilized $\mathrm{MS}^{2}$ analysis. The first dimension of $\mathrm{MS}^{2}$ analysis (full scan) was conducted by creating a spectrum of the ions produced in the HESI source. These ions are typically the $[\mathrm{M}+\mathrm{H}]^{+}$peaks. The second dimension of the $\mathrm{MS}^{2}$ analysis involved the selection of one or more ions which was then fragmented. These fragments were then recorded in a separate but linked spectrum. There are two methods for $\mathrm{MS}^{2}$ analysis: target-MS ${ }^{2}\left(\mathrm{tMS}^{2}\right)$ and data dependent-MS ${ }^{2}\left(\mathrm{ddMS}^{2}\right)$. In this research, both methods were used. Analysis by $\mathrm{tMS}^{2}$ involved creating a target ion inclusion list with known chemical structures, formulae and their accurate masses. Fragmentation occurred only when the instrument detects a $[\mathrm{M}+\mathrm{H}]^{+}$peak with a mass specified in the inclusion list (de Hoffmann, 2007.) Analysis by ddMS ${ }^{2}$ involved the fragmentation of the largest peaks detected during the full scan process. The number of peaks to be analyzed is set prior to analysis using the TOPN selection (de Hoffmann, 2007.) A preliminary scan was conducted to survey the masses present in the analyte sample. The selected number of precursor ions were selected from the results of this scan and underwent $\mathrm{MS}^{2}$ analysis. 


\subsection{RESEARCH TASKS}

This research was composed of four major tasks. The first task was the formation of a database of known designer drugs and the major metabolites associated with each of the drugs. The parent drugs and the associated metabolites were collected from published materials (Blachut et. al., 2012; Boatto et. al., 2005; Brandt et. al., 2010; Concheiro et. al., 2013; de Boer et. al., 2004; de Jager et. al., 2012; De Paoli et. al., 2013; Dean et. al., 2014; ElSohly et. al., 2014; Jankovics et. al., 2011; Lin et. al., 2004; Meyer et. al., 2010a; Meyer et. al., 2012; Meyer et. al., 2010b; Peters et. al., 2005; Sauer et. al., 2006; Seely et. al., 2013; Shulgin 1991; Shulgin 1997; Smolianitski et. al., 2014; Soblevsky et. al., 2012; Springer et. al., 2003; Springer et. al., 2002; Staack et. al., 2003; Swortwood 2013; Theoblad et. al., 2006; Uchiyama et. al., 2013; Wohlfarth et. al., 2014; Wohlfarth et. al., 2013; Zawilska et. al., 2013; Zuba et. al., 2013; Zuba et. al., 2012.) For drugs with no known metabolic pathways, the program MetWorks was used to predict the possible metabolites based on the parent structure. Each of the compounds was entered into the TraceFinder EFS software to create the database. The database contained parent drugs from each major class of designer drugs; a total of 179 parent compounds and 129 metabolites were included. Additionally, the exact masses, pKa values and predicted adducts were entered into the database. This database was used for the initial screening of full-scan data to create a list of target compounds for target-MS'2. The second task involved spiking an unknown mixture of designer drugs into environmental water samples to assess the performance of the method for separating, detecting and identifying designer drugs from different classes. The identification of the parent drugs and their metabolites was based on the parent $[\mathrm{M}+\mathrm{H}]^{+}$peak and the fragmentation pattern 
predicted in silico using the structural information in MassFrontier. The third task involved the analysis of authentic raw sewage samples to determine the presence of designer drugs in raw sewage samples which had been collected from the pumping station of a major university. The fourth task involved the analysis of environmental water samples, including reclaimed water and river water samples.

\subsection{REAGENTS AND CHEMICALS}

The mixture of unknown designer drugs was obtained from the laboratory of Dr. Anthony DeCaprio (Florida International University, Modesto A. Maidique Campus.) The mixture contained 10 compounds, each present at a nominal concentration of $1 \mathrm{ppm}$. No information regarding the identity of the compounds was given prior to analysis. The instrument used was the QExactive Orbitrap from ThermoScientific. The mobile phases consisted of Optima grade water, methanol, and acetonitrile, which are suitable for UPLC, were obtained from Fisher Scientific. $1 \mathrm{~mL}$ ampules of Optima grade formic acid were purchased from Fisher Scientific. Sulfamethoxazole-D 4 , used as an internal standard, was purchased from Fisher Scientific.

\subsection{SAMPLE COLLECTION AND PREPARATION}

\subsubsection{UNKNOWN MIXTURE}

The mixture of unknown designer drugs was prepared by another laboratory and provided for analysis. The mixture contained 10 compounds, at $1 \mathrm{ppm}$ each in methanol. The mixture was stored in a glass vial, at $-20^{\circ} \mathrm{C}$ in the dark. On the day of analysis, the mixture was removed from the freezer and allowed to reach room temperature. The 
mixture was shaken for 10 seconds. A portion of the $1 \mathrm{ppm}$ stock solution was used to create a $100 \mathrm{ppt}$ working solution. Aliquots of the $100 \mathrm{ppt}$ solution were used to create 20 ppt analyte samples. The $20 \mathrm{ppt}$ solutions were prepared in deionized water, tap water, reclaimed water, and filtered raw sewage which was diluted 10 times with deionized water. Additional concentrations of $10 \mathrm{ppt}, 5 \mathrm{ppt}$ and $1 \mathrm{ppt}$ were prepared in both deionized water and filtered sewage. The analytical method required a $5 \mathrm{~mL}$ sample volume, so $10 \mathrm{~mL}$ of each concentration was prepared to allow for both full scan analysis and $\mathrm{MS}^{2}$.

\subsubsection{SEWAGE INFLUENT}

Raw sewage samples were collected from a pump station on the Modesto A. Maidique campus of Florida International University. After collection, the samples were filtered using a $1.0 \mu \mathrm{m}$ PreSep Prefilter glass filter, followed by $0.45 \mu \mathrm{m}$ PreSep Prefilter glass filter. The filtered raw sewage was then stored in polylethylene terephthalate bottles in the dark at $-20^{\circ} \mathrm{C}$. When analysis was conducted, the samples were thawed and then shaken for 10 seconds. The raw sewage was diluted 10 times with deionized water prior to analysis. The diluted sewage influent was spiked with an internal standard prior to analysis.

\subsubsection{RECLAIMED WATER}

Samples of reclaimed water were collected from reclaimed water taps located on Florida International University's Biscayne Bay Campus. Samples were collected twice a day, every day for two weeks. A selection of ten of these samples were analyzed. Samples 
were chosen to represent both morning and afternoon collections, and early and late in the week. The reclaimed water line was allowed to run for several minutes before collection to minimize the presence of sediments in the water samples. The samples were collected and stored in polyethylene terephthalate bottles, in the dark at $-20^{\circ} \mathrm{C}$. At the time of analysis, the samples were thawed and then shaken for 10 seconds.

\subsubsection{ENVIRONMENTAL SAMPLES}

Samples were collected along a river system influenced by treated effluent releases in an undisclosed location and submitted for analysis as a representation of a typical outfall site. Samples were collected upstream from a wastewater treatment plant, as well as at the effluent point of the treatment plant. An additional sample was collected from the mixing zone, downstream of the treatment plant. Final samples were collected from the intake and output locations of a drinking water treatment plant located downstream from the wastewater treatment plant. A map of the collection locations is shown in Figure 2. The samples were stored in the dark at $-20^{\circ} \mathrm{C}$. The samples were thawed at the time of analysis and then shaken for 10 seconds. 
Figure 2. Map of collection locations of environmental samples

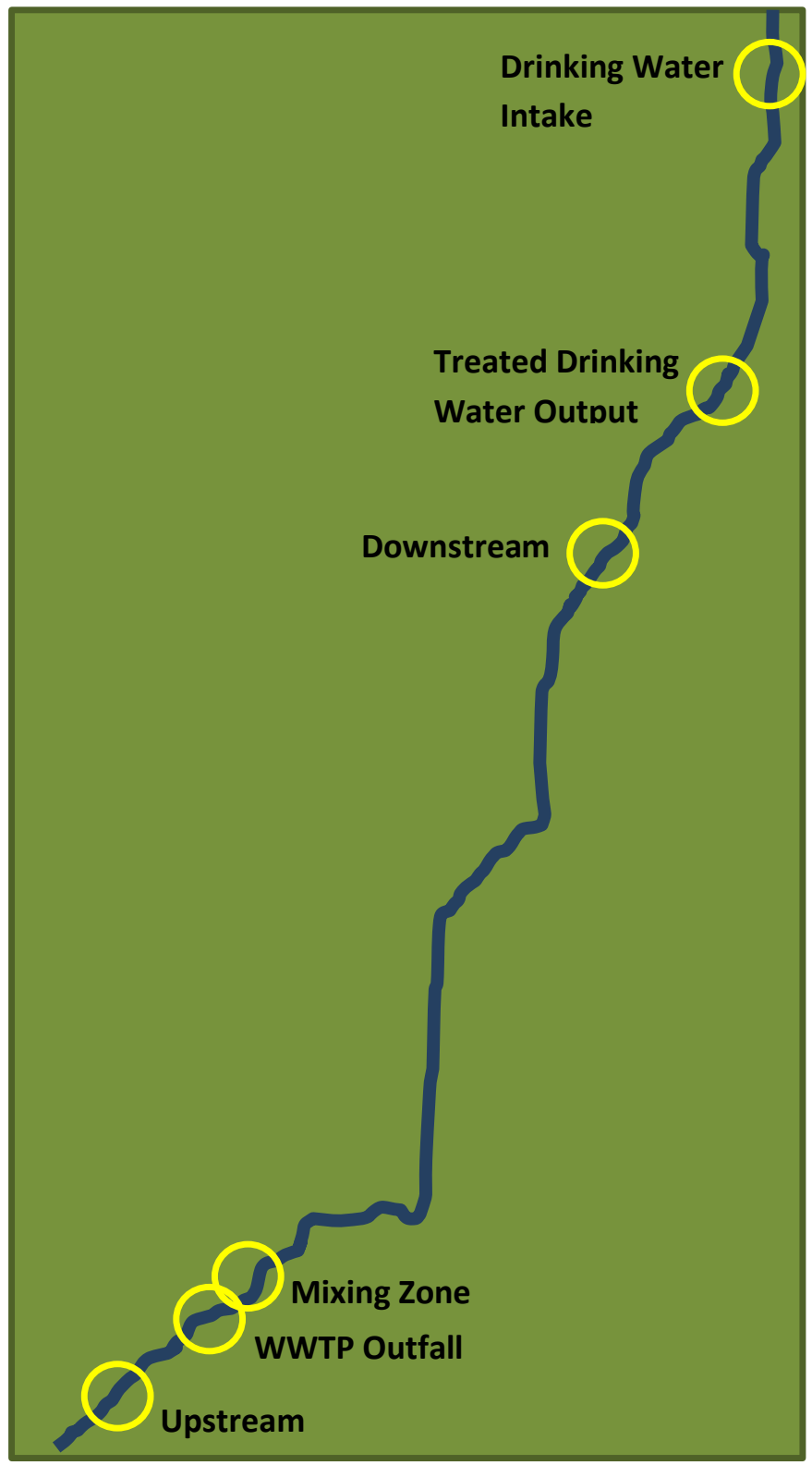

\subsection{MASS SPECTROMETRIC ANALYSIS}

Analysis was conducted using the ThermoScientific QExactive Orbitrap high resolution mass spectrometer in full scan mode, target $\mathrm{MS}^{2}\left(\mathrm{tMS}^{2}\right)$ and data-dependent $\mathrm{MS}^{2}$ $\left(\mathrm{ddMS}^{2}\right.$.) Pre-concentration of the samples was conducted using the EQuan online SPE system. The EQuan online SPE system utilized a pair of pumps to push the analyte and 
mobile phases through a pre-concentration column and an analytical column, leading the analyte to the ionization source. Ionization was achieved using the heated electrospray ionization (HESI II) source in positive polarity mode. Positive ionization mode was selected because the majority of designer drugs will be positively ionized, including drugs in all the major categories. Analysis was conducted using Hypersil Gold PFP $50 \mathrm{x}$ $2.1 \mathrm{~mm} \times 1.9 \mu \mathrm{m}$ (preconcentration) and Hypersep Retain PEP $20 \times 2.1 \mathrm{~mm} \times 12 \mu \mathrm{m}$ (analytical) columns (both from ThermoScientific.) The Hypersil Gold PFP column was a reverse phase column with a C18 and pentafluorophenyl stationary phase. The Hypersep Retain PEP column was a reverse phase column, hydrophobic phase packed with polystyrene divinylbenzene with urea groups (ThermoScientific, 2011.) The hydrophobic column leads to non-polar non-polar interactions and Van der Waals interactions. The mobile phases used were Optima grade water, methanol, acetonitrile and $0.1 \%$ formic acid. Samples were spiked with sulfamethoxazole- $\mathrm{D}_{4}$ as an internal standard, at a concentration of 20 ppt. This concentration was selected so that it was at the limit of detection, but not so high as to overwhelm the peaks of the target compounds. The settings for full-scan analysis are listed in Table 1.

Table 1. Source and full-scan operating conditions

\begin{tabular}{ll}
\hline Parameter & Setting \\
\hline Ionization Source & HESI II \\
\hline Ionization Mode & Positive \\
\hline Run time (minutes) & 15 \\
\hline $\begin{array}{l}\text { Capillary } \\
\text { temperature }\left({ }^{\circ} \mathbf{C}\right)\end{array}$ & 300 \\
\hline $\begin{array}{l}\text { Aux gas heater } \\
\text { temperature }\left({ }^{\circ} \mathbf{C}\right)\end{array}$ & 300 \\
\hline S-lens voltage & 50 \\
\hline Source voltage $(\mathbf{k V})$ & 3 \\
\hline Sheath gas flow rate & 35 \\
\hline
\end{tabular}




\begin{tabular}{ll}
\hline Aux gas flow rate & 30 \\
\hline Sweep gas flow rate & 5 \\
& \\
\hline Full $\mathbf{M S}$ parameters \\
\hline Mass range (m/z) & $\begin{array}{l}80- \\
1000\end{array}$ \\
\hline Resolution settings & 70,000 \\
\hline AGC target & $1 \times 10^{6}$ \\
\hline $\begin{array}{l}\text { Max injection time } \\
\text { (ms) }\end{array}$ & 200 \\
\hline
\end{tabular}

After the completion of the full-scan analysis, the raw data was screened using the database created in TraceFinder EFS. The database is shown in Appendix 1. TraceFinder EFS was used to search the full-scan spectra generated by the Orbitrap against a compiled database. The program indicated all possible matches between the spectra and the database, and the matches were assessed for consistency. The compounds were considered to be tentatively identified during screening based on the quality of the shape of the peak, the height of the peak and the scored isotopic pattern match. The peak shape had to be clean, without significant noise, and the peak height was required to be tall enough to be distinguishable from the background signal. As a general guideline, the height of the called peak was required to be at least five times the height of the background noise. The scored isotopic pattern was required to be $90 \%$ or higher. This value was based on the mass of the isotopes observed in the full scan data compared to the mass of the isotopes predicted from the chemical formula. The screened compounds were used to create the inclusion list for $\mathrm{MS}^{2}$ analysis. The settings for the $\mathrm{MS}^{2}$ and $\mathrm{ddMS}^{2}$ analyses are listed in Table 2. 
Table 2. Target-MS $S^{2}$ and data dependent- $M S^{2}$ operating conditions

\begin{tabular}{ll}
\hline Target-MS $^{\mathbf{2}}$ & \\
\hline Resolution & 17,500 \\
\hline NCE & 35 \\
\hline $\begin{array}{l}\text { Isolation window } \\
(\boldsymbol{m} / \boldsymbol{z})\end{array}$ & 2.0 \\
\hline \multicolumn{2}{l}{ Data Dependent-MS } \\
\hline Resolution \\
\hline NCE & 35,000 \\
\hline $\begin{array}{l}\text { Isolation window } \\
(\boldsymbol{m} / \boldsymbol{z})\end{array}$ & 35 \\
\hline TOPN & 2.0 \\
\hline
\end{tabular}

The UPLC operation was conducted using the gradient program detailed in Table 3.

Pump 1 controlled the mobile phases which moved the analytes through the pre-

concentration column. Pump 2 was responsible for the movement of the mobile phase and analyte compounds through the analytical column. Solvent A was water, solvent B was methanol, solvent $\mathrm{C}$ was acetonitrile and solvent $\mathrm{D}$ was $0.1 \%$ formic acid.

Table 3. HPLC gradient for pumps 1 and 2: solvent $A$ (water), solvent B (methanol), solvent $C$ (acetonitrile), solvent $D(0.1 \%$ formic acid $)$

\begin{tabular}{|l|l|l|l|l|l|}
\hline \multicolumn{7}{|c|}{ Pump 1 } \\
\hline Time & $\mathrm{A} \%$ & $\mathrm{~B} \%$ & $\mathrm{C} \%$ & $\mathrm{D} \%$ & $\mu \mathrm{L} / \mathrm{min}$ \\
\hline 0.00 & 0.0 & 97.0 & 0.0 & 3.0 & 500.0 \\
\hline 1.50 & 0.0 & 97.0 & 0.0 & 3.0 & 500.0 \\
\hline 4.50 & 94.0 & 3.0 & 0.0 & 3.0 & 500.0 \\
\hline 8.30 & 94.0 & 3.0 & 0.0 & 3.0 & 500.0 \\
\hline 8.80 & 37.0 & 60.0 & 0.0 & 3.0 & 500.0 \\
\hline 9.30 & 22.0 & 75.0 & 0.0 & 3.0 & 500.0 \\
\hline 9.80 & 12.0 & 85.0 & 0.0 & 3.0 & 500.0 \\
\hline 10.30 & 7.0 & 90.0 & 0.0 & 3.0 & 500.0 \\
\hline 10.80 & 3.0 & 94.0 & 0.0 & 3.0 & 500.0 \\
\hline 11.30 & 1.0 & 96.0 & 0.0 & 3.0 & 500.0 \\
\hline 11.80 & 0.0 & 97.0 & 0.0 & 3.0 & 500.0 \\
\hline 12.00 & 0.0 & 97.0 & 0.0 & 3.0 & 500.0 \\
\hline 12.50 & 0.0 & 97.0 & 0.0 & 3.0 & 600.0 \\
\hline 15.00 & 0.0 & 97.0 & 0.0 & 3.0 & 700.0 \\
\hline
\end{tabular}




\begin{tabular}{|c|c|c|c|c|c|}
\hline & 100.0 & 0.0 & 0.0 & \begin{tabular}{|l|}
0.0 \\
\end{tabular} & 700.0 \\
\hline \multicolumn{6}{|c|}{ Pump 2} \\
\hline Time & A\% & B\% & $\mathrm{C} \%$ & $\mathrm{D} \%$ & $\mu \mathrm{L} / \mathrm{min}$ \\
\hline 0.00 & 100.0 & 0.0 & 0.0 & \begin{tabular}{|l|}
0.0 \\
\end{tabular} & 1000.0 \\
\hline 2.50 & 99.0 & 1.0 & 0.0 & \begin{tabular}{|l|}
0.0 \\
\end{tabular} & \begin{tabular}{|l|l}
1000.0 \\
\end{tabular} \\
\hline 3.00 & 94.0 & 3.0 & 0.0 & 3.0 & 1000.0 \\
\hline 3.50 & 94.0 & 3.0 & 0.0 & 3.0 & 1000.0 \\
\hline 5.00 & 0.0 & 100.0 & 0.0 & 0.0 & 1000.0 \\
\hline 8.00 & 0.0 & 100.0 & 0.0 & \begin{tabular}{|l|}
0.0 \\
\end{tabular} & \begin{tabular}{|l|l}
1000.0 \\
\end{tabular} \\
\hline 8.10 & 0.0 & 100.0 & 0.0 & \begin{tabular}{|l|}
0.0 \\
\end{tabular} & 2000.0 \\
\hline 9.16 & 0.0 & 100.0 & 0.0 & 0.0 & 2000.0 \\
\hline 9.17 & 0.0 & 100.0 & 0.0 & \begin{tabular}{|l|}
0.0 \\
\end{tabular} & 1000.0 \\
\hline 10.00 & 0.0 & 100.0 & 0.0 & 0.0 & 100.0 \\
\hline 12.90 & 0.0 & 100.0 & 0.0 & 0.0 & 100.0 \\
\hline 13.00 & 0.0 & 0.0 & 100.0 & 0.0 & 2000.0 \\
\hline 13.50 & 0.0 & 0.0 & 100.0 & 0.0 & 2000.0 \\
\hline 14.20 & 0.0 & 100.0 & 0.0 & \begin{tabular}{|l|} 
\\
\end{tabular} & 2000.0 \\
\hline 14.50 & 100.0 & 0.0 & 0.0 & \begin{tabular}{|l|}
0.0 \\
\end{tabular} & 2000.0 \\
\hline 15.00 & 100.0 & 0.0 & 0.0 & 0.0 & 2000.0 \\
\hline & 100.0 & 0.0 & 0.0 & 0.0 & 2000.0 \\
\hline
\end{tabular}

Data processing was conducted using XCalibur. XCalibur is used to visualize the raw data generated by the instrumentation. Filters were applied to visualize specific masses within the spectrum. Once the desired mass was displayed, the individual $\mathrm{MS}^{2}$ spectra containing that mass were scrolled through to identify the $[\mathrm{M}+\mathrm{H}]^{+}$peak and the associated fragment peaks. The spectra generated by the Orbitrap was compared to the fragmentation patterns generated in silico in MassFrontier for structural confirmation. MassFrontier is capable of predicting the fragmentation pattern of a compound based on its structure. The structures of the compounds which had been tentatively identified through the screening process were entered into MassFrontier and the fragmentation pattern was generated based on the general fragmentation rules included in the program. The fragmentation pattern of the structure was then compared to the spectra generated by 
the Orbitrap to determine if the observed spectrum was consistent with the in silico prediction of the fragmentation pattern.

\section{RESULTS}

\subsection{CONFIRMATION OF UNKNOWN MIXTURE}

Full scan and tMS ${ }^{2}$ analyses were conducted on the samples spiked with the unknown mixture. The compounds were identified based on the consistency of the observed fragmentation pattern with the pattern predicted in MassFrontier. For the fragmentation pattern to be considered consistent, the presence of the parent $[\mathrm{M}+\mathrm{H}]^{+}$ion peak was required, along with fragments which are consistent with the in silico prediction of the fragmentation pattern. The final step in confirmation was to determine the precision of the $\mathrm{m} / \mathrm{z}$ of the parent ion. Identification was only considered to be confirmed if the $\mathrm{m} / \mathrm{z}$ was within $5 \mathrm{ppm}$ of the calculated mass of the chemical formula. This standard was met for all compounds in the unknown mixture. The full chromatogram of the unknown mixture in deionized water is shown in Figure 3. The ion chromatogram of each identified compound using its accurate mass is shown in Figure 4. 
Figure 3. Full scan chromatogram of unknown mixture in deionized water at 20 ppt (positive ionization mode)

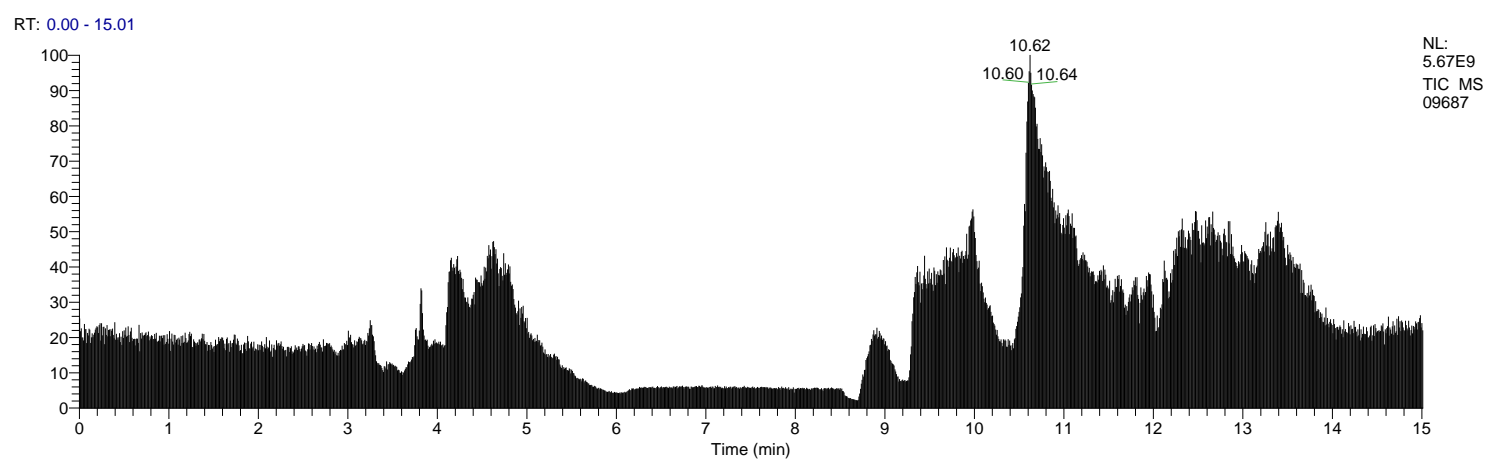

Figure 4. Full scan chromatogram of identified compounds in deionized water at 20 ppt (mass range $\mathrm{m} / \mathrm{z}$ 80 to 1000$)$

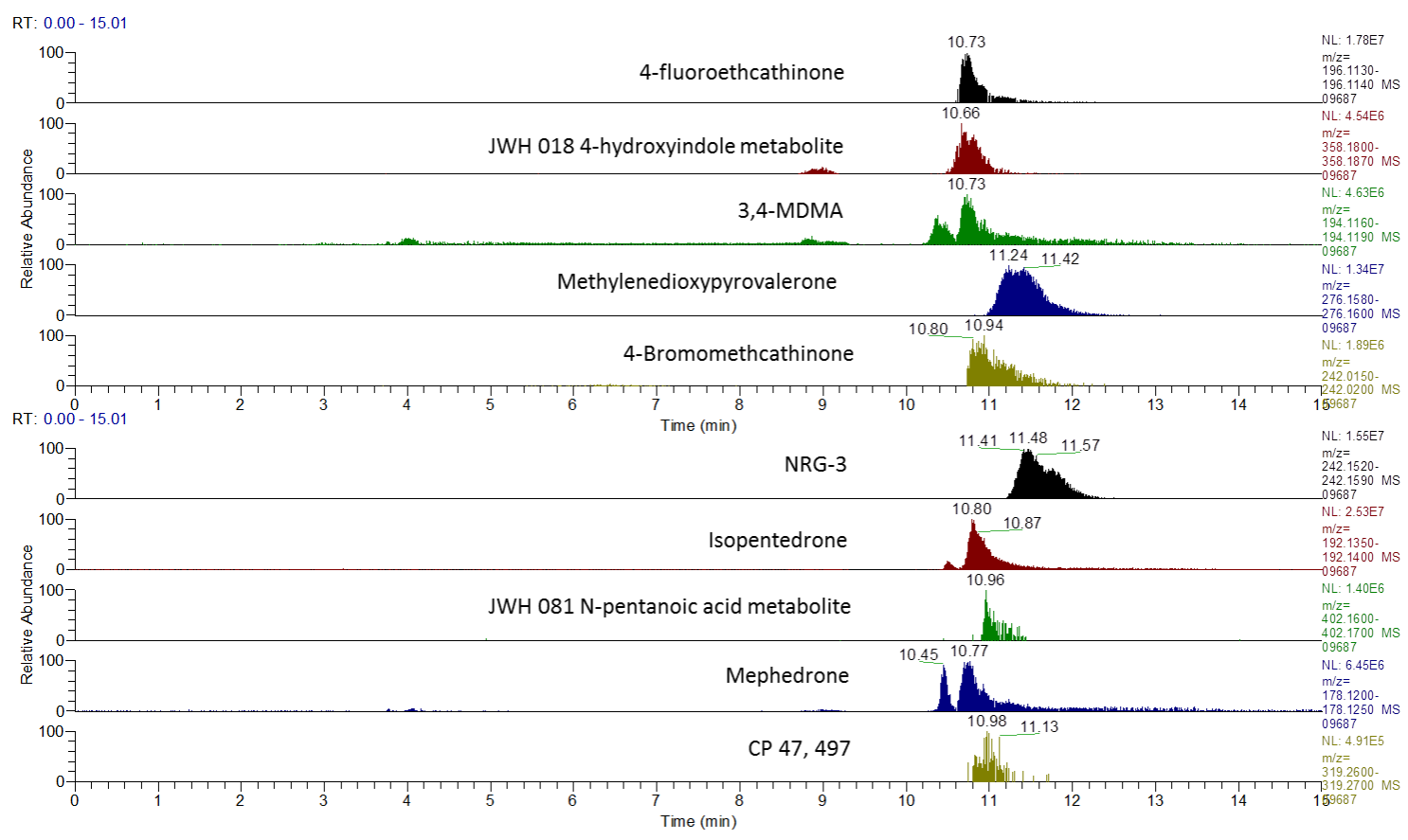


For some of the mass ranges shown in Figure 4, multiple peaks can be seen. This is due to additional compounds with the same mass being present in the sample when the mass filter is applied in XCalibur. The components of the unknown mixture and the additional compound can be easily distinguished when $\mathrm{MS}^{2}$ analysis is conducted. The fragmentation patterns will be different for each compound.

After analysis, the list of compounds contained within the mixture was provided by the preparing laboratory and compared to the results obtained through analysis. The list of identified compounds was consistent with the list of compounds provided. The observed fragmentation patterns were consistent with the in silico prediction of fragmentation of the compounds in the list provided and the generated formula was within 2 ppm for the $[\mathrm{M}+\mathrm{H}]^{+}$peaks all ten compounds. The mass errors of the observed fragments compared to the predicted fragments were all within $3.700 \mathrm{ppm}$. The accepted mass error threshold for identification is $5 \mathrm{ppm}$. The predicted fragmentation patterns are shown in Appendix 2. The $\mathrm{MS}^{2}$ spectra associated with each component of the unknown mixture if shown in Figure 5. The fragments associated with each $\mathrm{m} / \mathrm{z}$ peak are shown. All ten compounds were identified in the each of the water samples (deionized water, tap water, reclaimed water and filtered raw sewage.) The identified compounds, the structure of the compound and the major fragments observed are listed in Table 4.

Table 4. Compounds detected in $M S^{2}$ analysis of unknown spiked samples at 20 ppt

\begin{tabular}{|l|l|l|l|}
\hline Analyte & Structure & {$[\mathbf{M + H}]^{+}$} & tMS $^{2}$ error** $\left.^{*}\right)$ \\
\hline $4-$ & & 196.11322 & $196.11322(0.006)$ \\
fluoroethcathinone & & & $178.10265(-0.024)$ \\
& & & \\
&
\end{tabular}




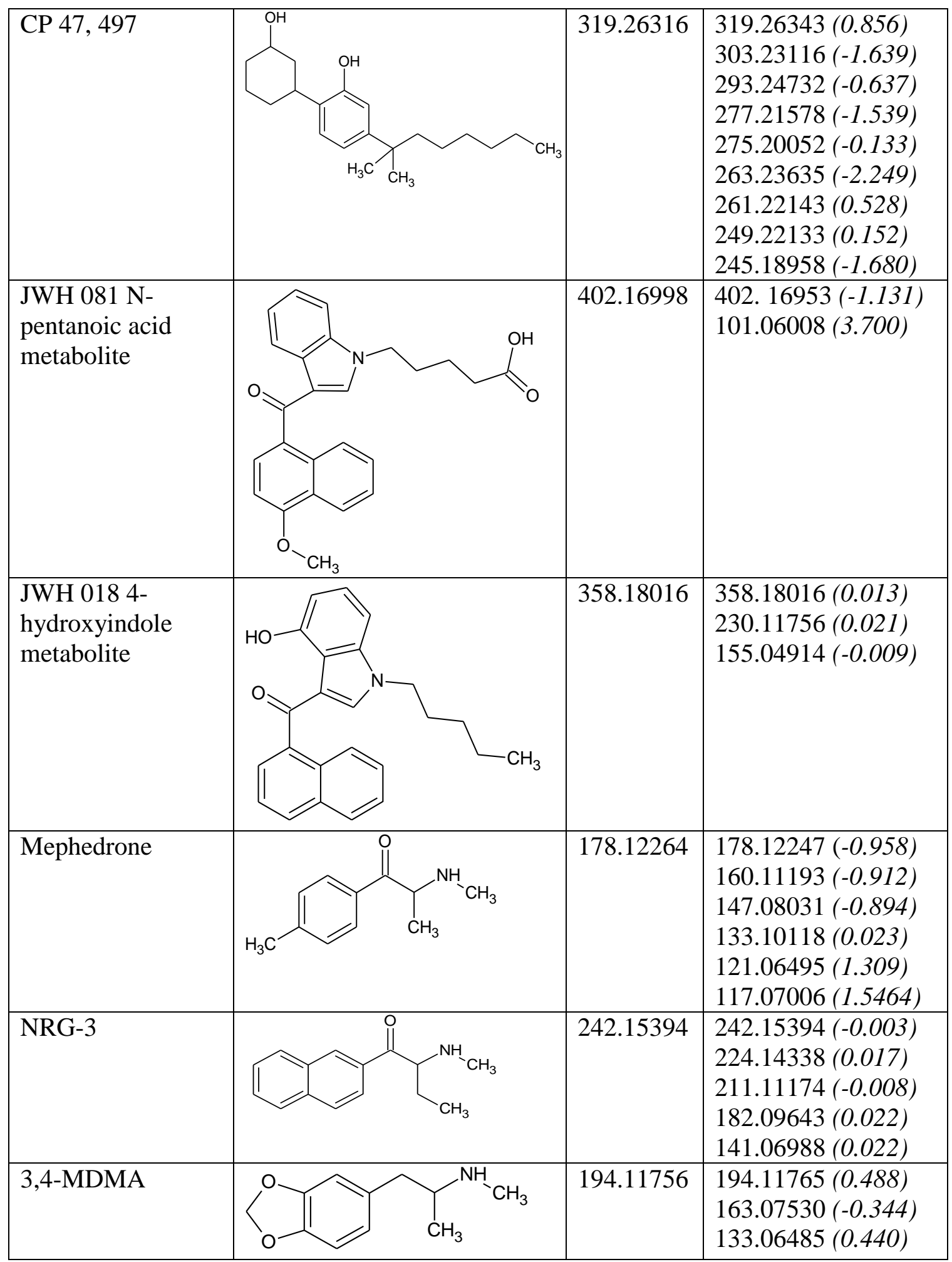




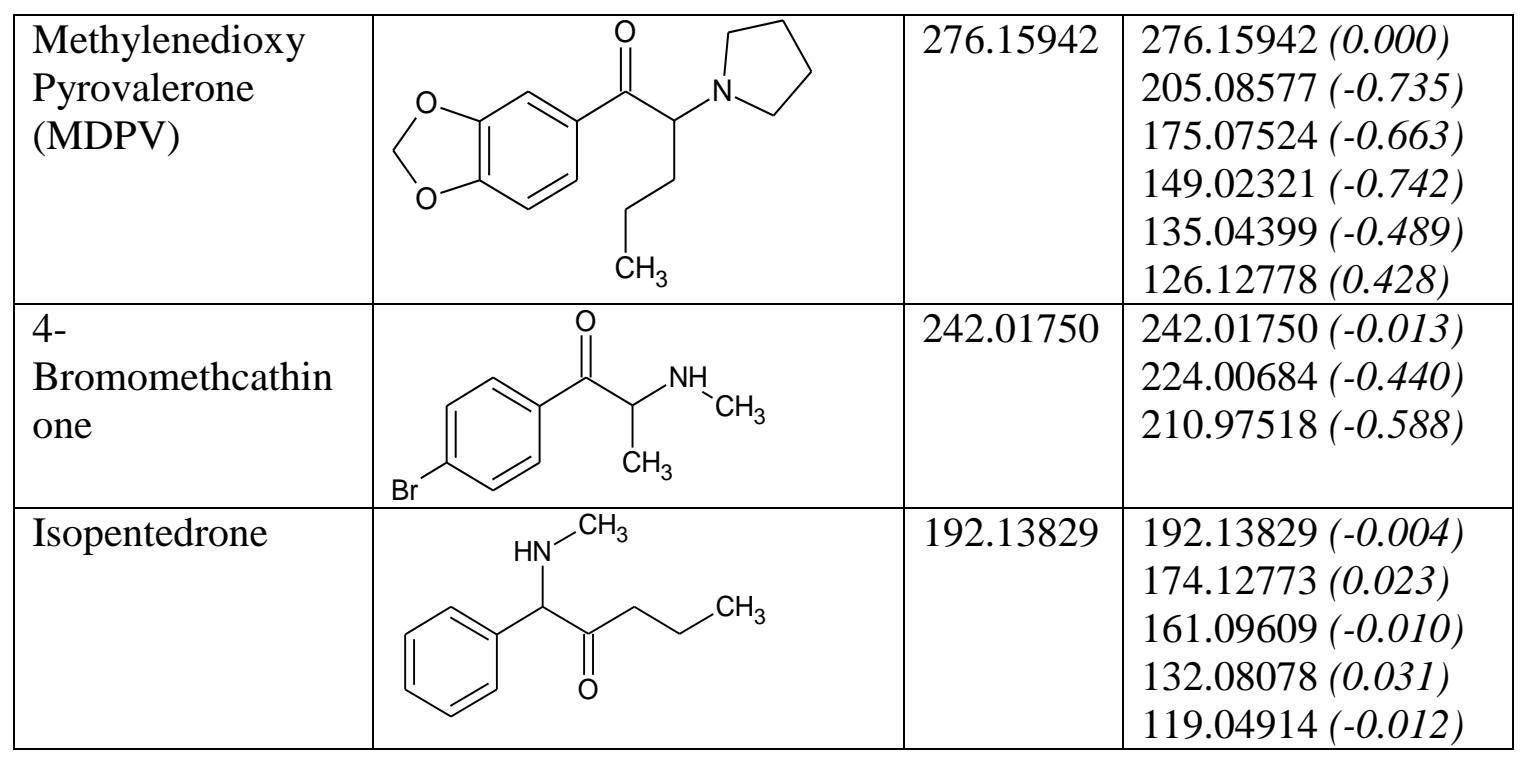

*Error in ppm based on the calculated mass of the chemical formula

Figure 5. $M S^{2}$ Spectra of the individual components of the unknown mixture (35 NCE)

\section{4-fluoroethcathinone}
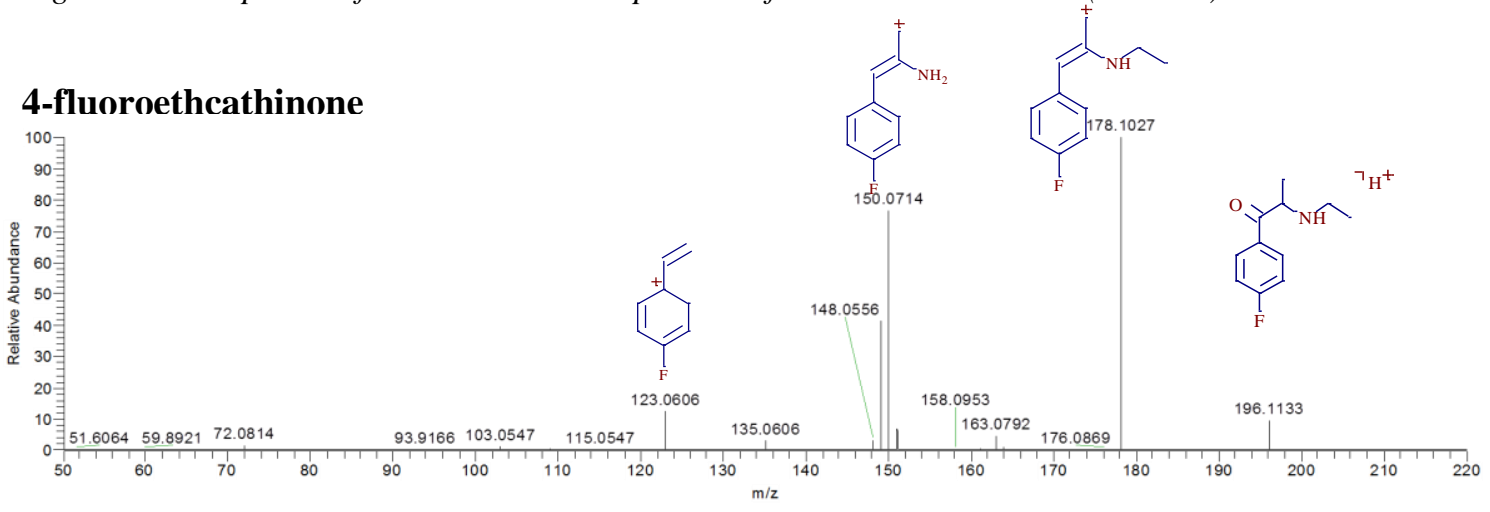

\section{4-MDMA}
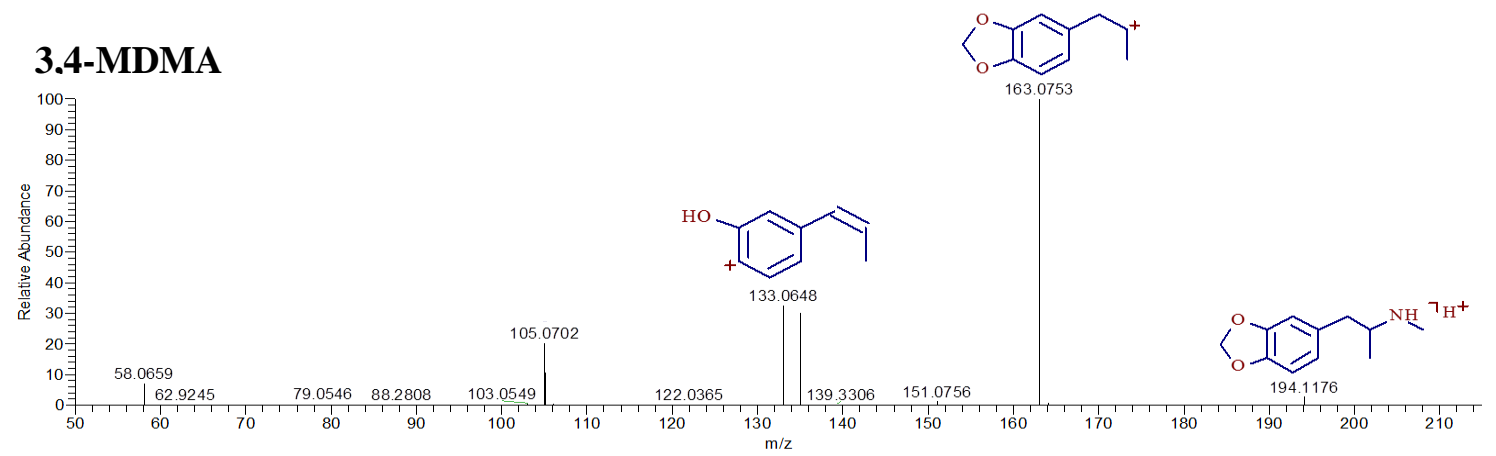

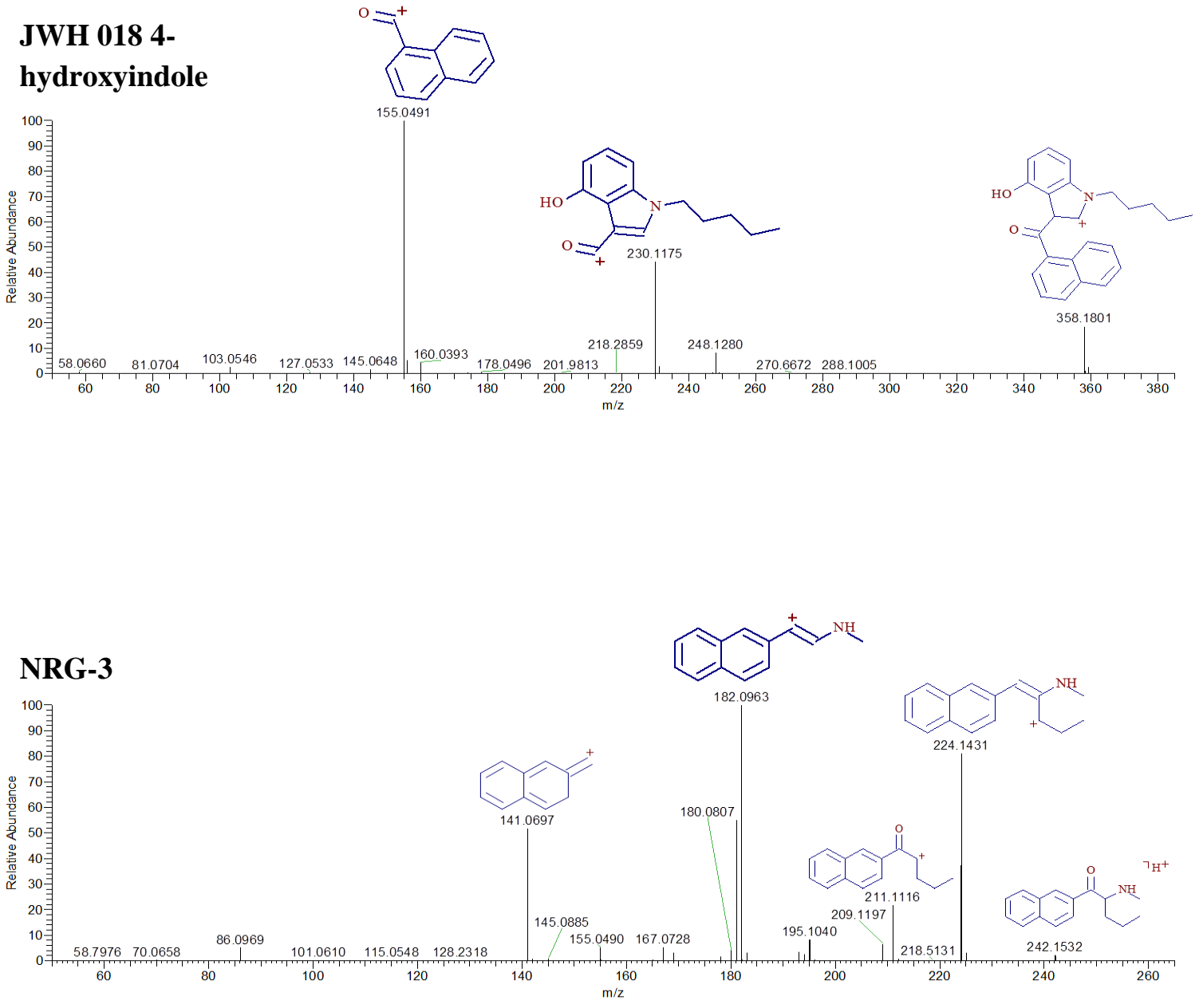

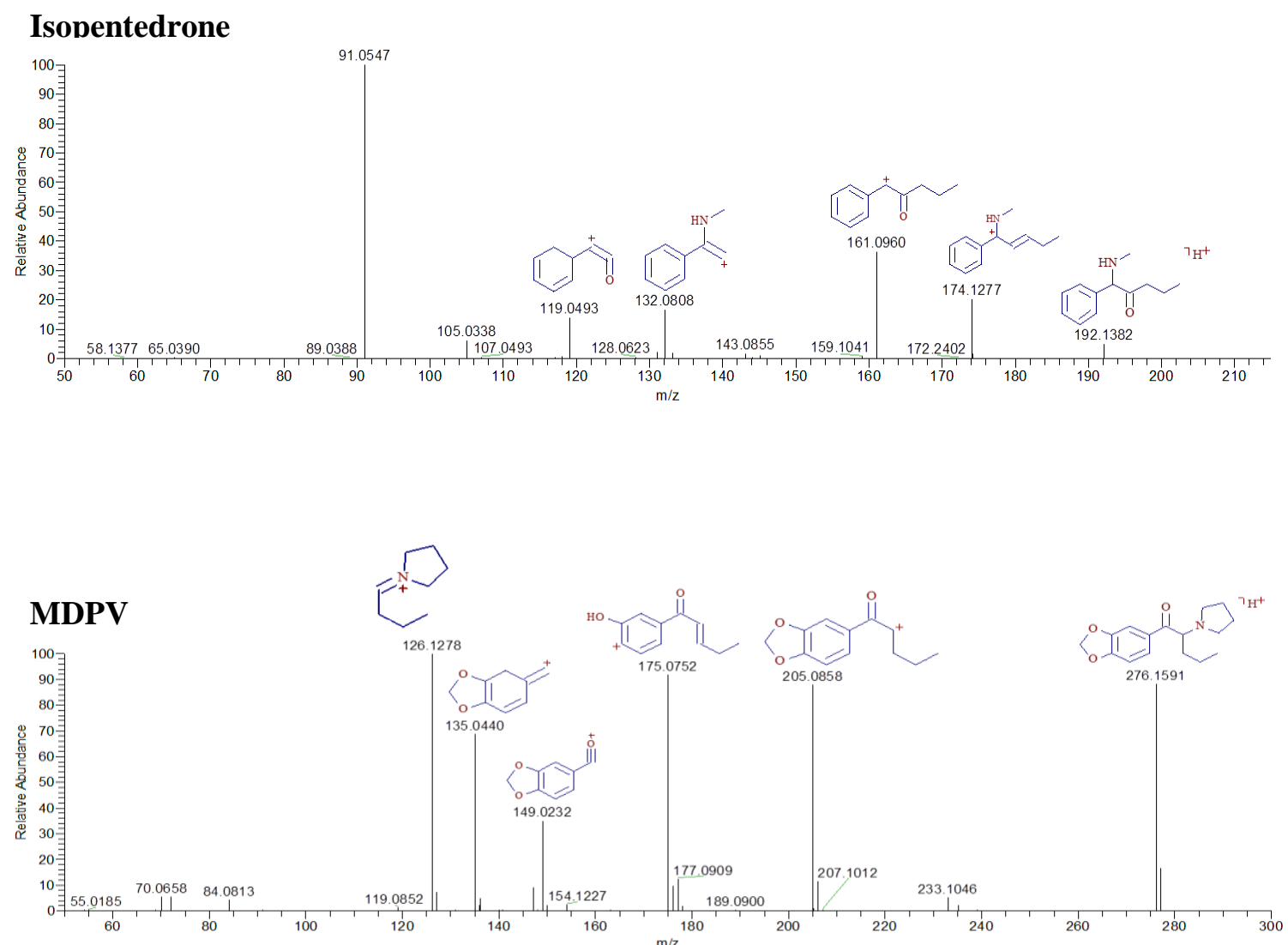

\section{3,4-MDMA}

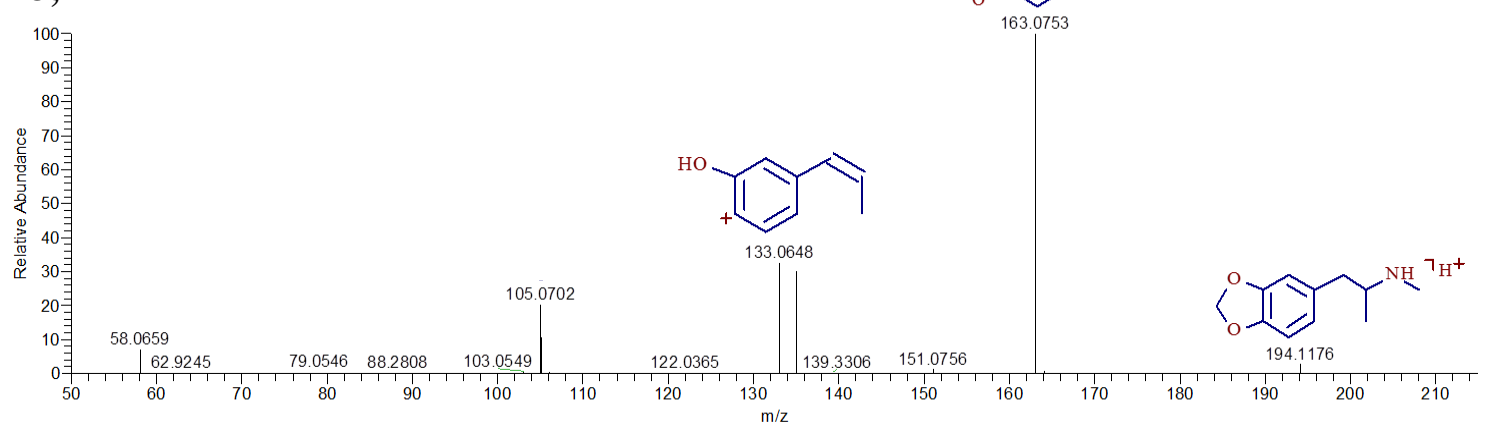



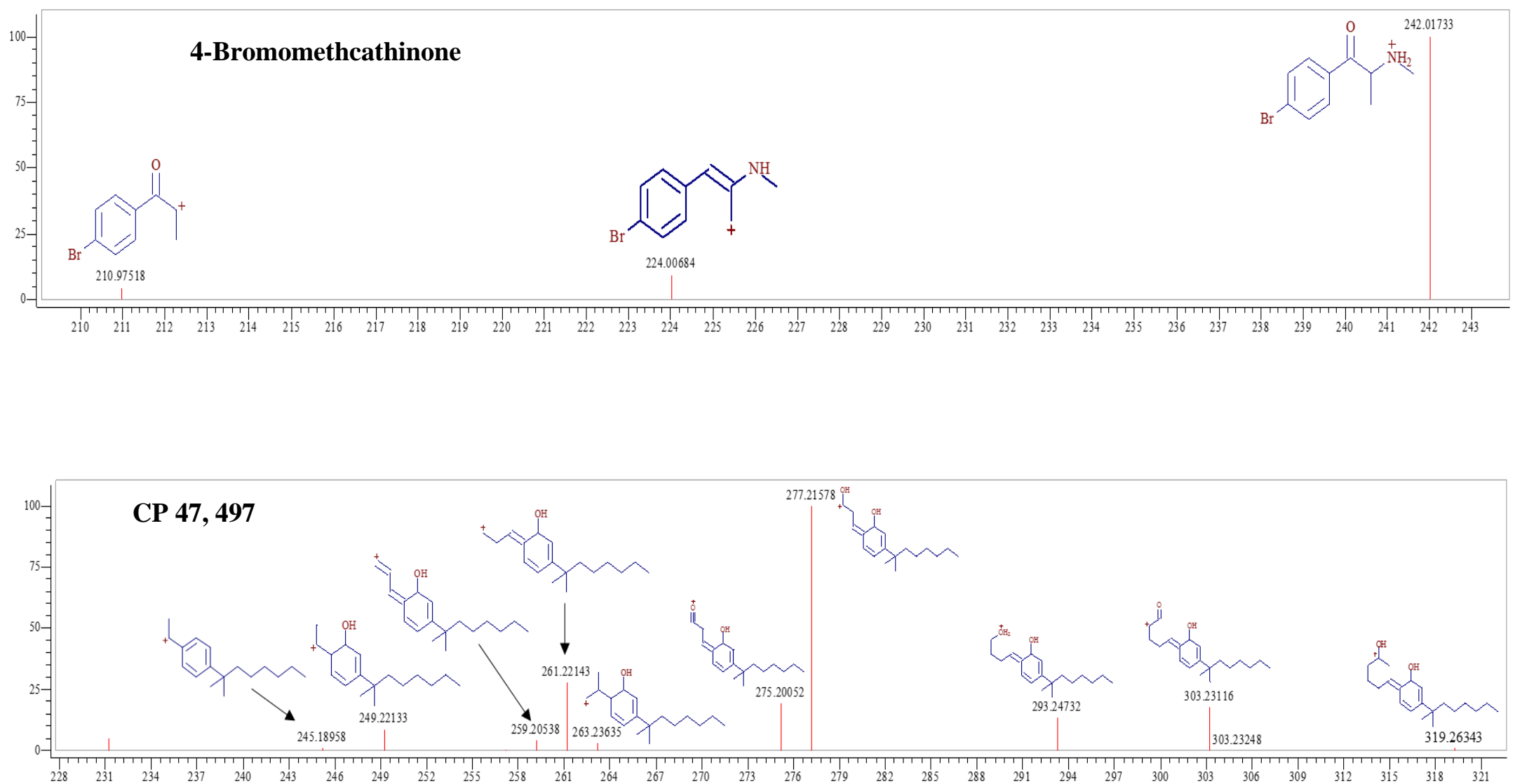

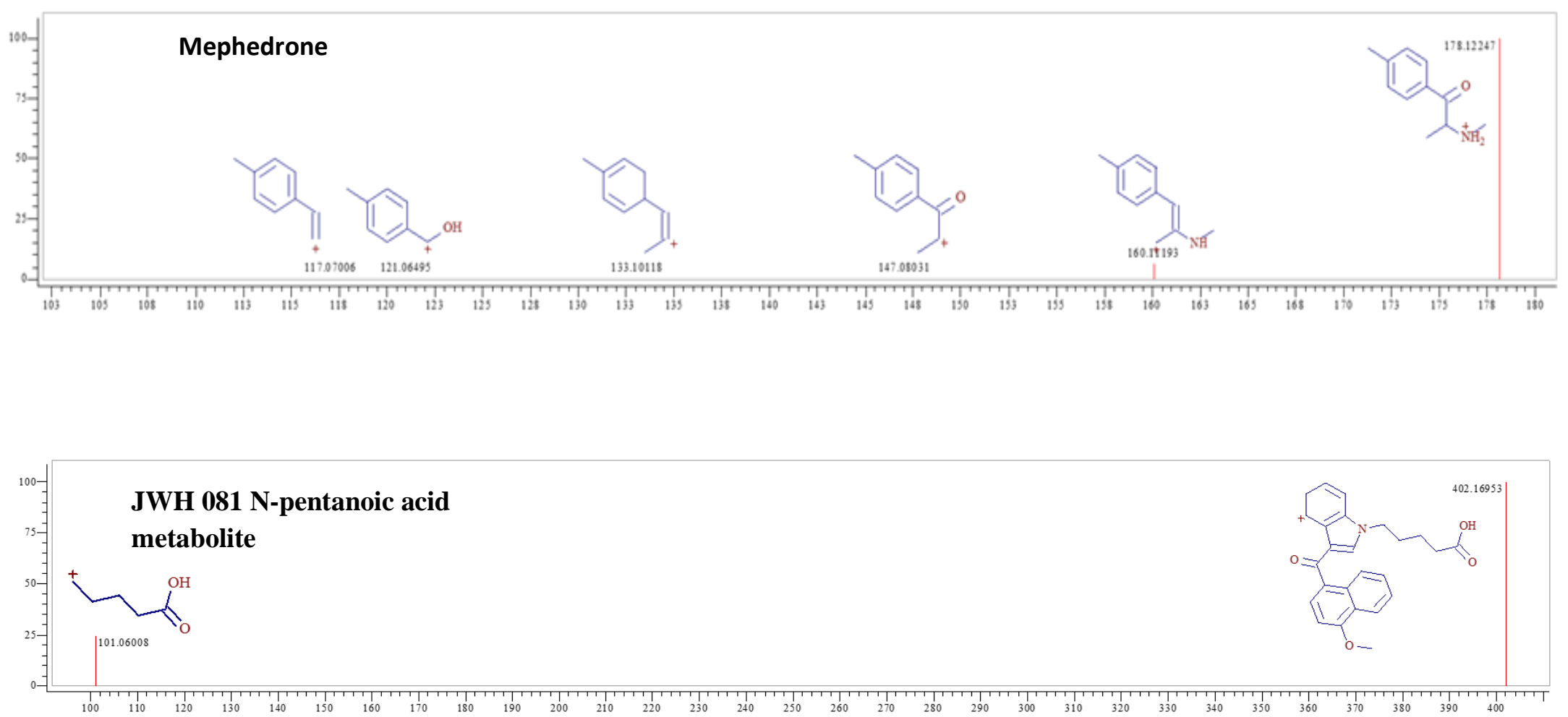


\subsection{DETERMINATION OF LIMIT OF DETECTION}

Limit of detection is traditionally determined by determining at what concentration the signal to noise ratio is above the accepted threshold (ie. 3:1 or 10:1). For the purposes of this research, limit of detection refers to the lowest detectable concentration (above 20 arbitrary intensity units) with environmental relevance independently of the signal to noise ratio. To assess the limits of detection for the method, the unknown mixture was spiked into deionized water at concentrations of $20 \mathrm{ppt}, 10 \mathrm{ppt}, 5 \mathrm{ppt}$ and $1 \mathrm{ppt}$. All ten compounds were detected at $20 \mathrm{ppt}$. Seven compounds (4-fluoroethcathinone, isopentedrone, MDPV, mephedrone, NRG-3, JWH 018 N-pentanoic acid metabolite, and 4-bromomethcathinone) were detected at $10 \mathrm{ppt}$. Only one compound (isopentedrone) was detected at 5 ppt. The same compound was detected at 1ppt, but the background interference was greater in the lowest concentrations. A comparison of a compound detected at $20 \mathrm{ppt}, 10 \mathrm{ppt}, 5 \mathrm{ppt}$, and $1 \mathrm{ppt}$ is shown in Figure 6. As the concentration decreased, the width of the peak increased. Based on these results, the limit of detection for this method was determined to be $20 \mathrm{ppt}$, due to the fact that all of the unknown compounds were detected and positively identified by HRMS and $\mathrm{MS}^{2}$. 
Figure 6. Comparison of $M S^{2}$ spectra of isopentedrone detected at $20 \mathrm{ppt}$ (top), $10 \mathrm{ppt}$ (second), $5 \mathrm{ppt}$ (third), and 1 ppt (bottom)

Isopentedrone at $20 \mathrm{ppt}$

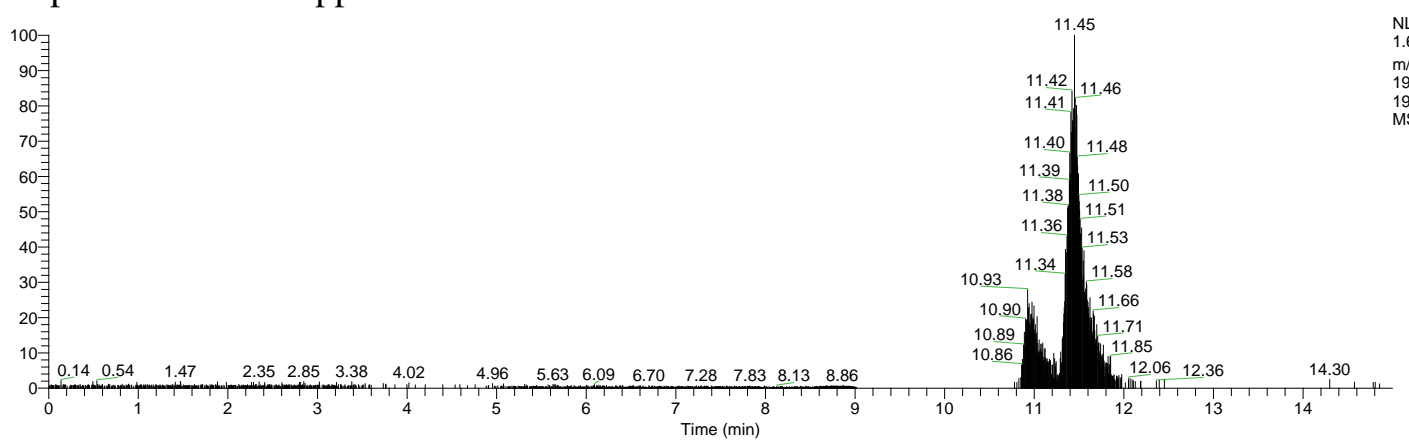

Isopentedrone at $10 \mathrm{ppt}$

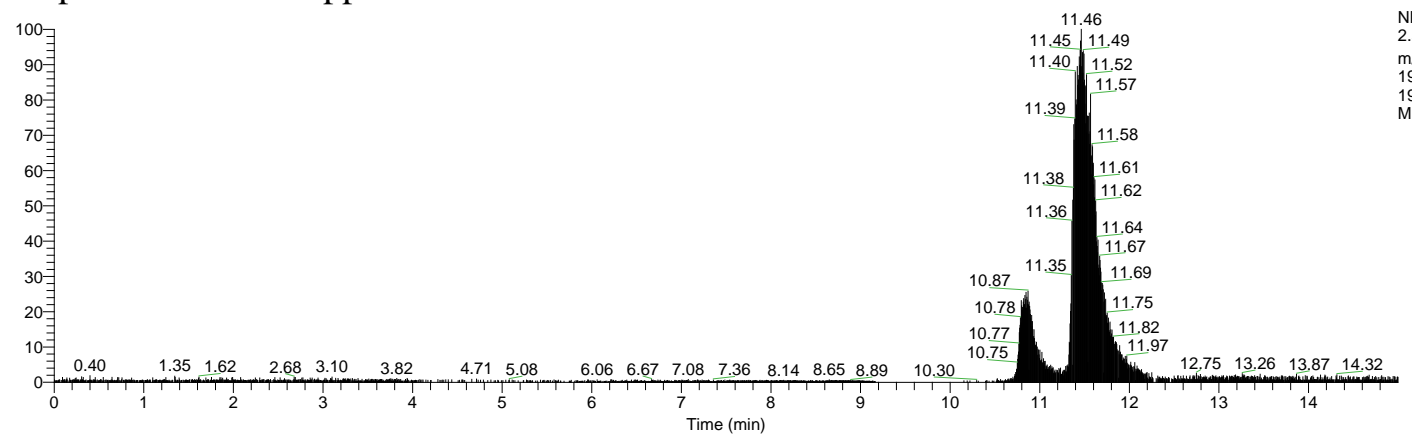

Isopentedrone at $5 \mathrm{ppt}$

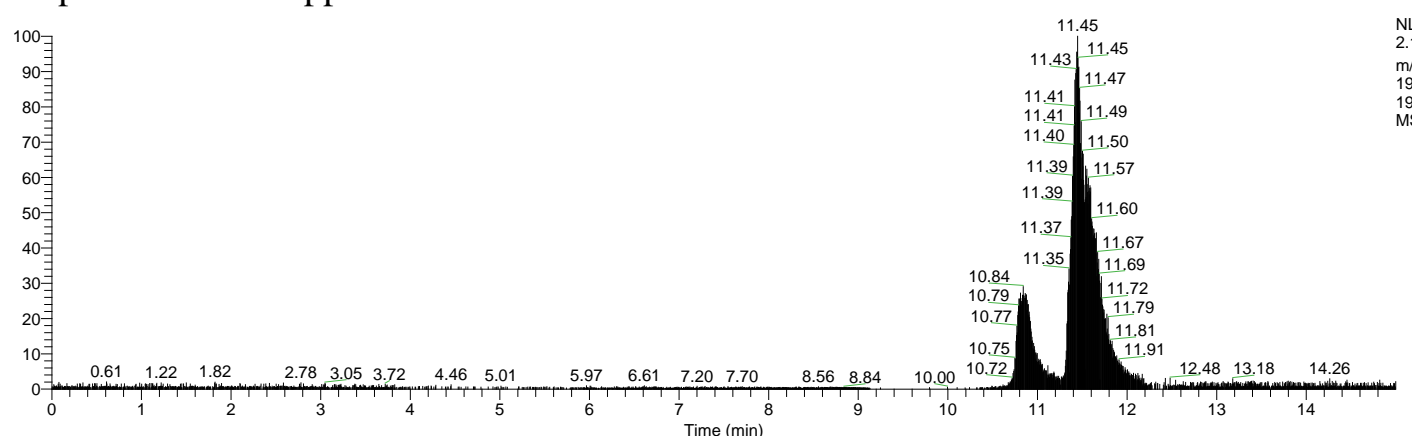

Isopentedrone at $1 \mathrm{ppt}$
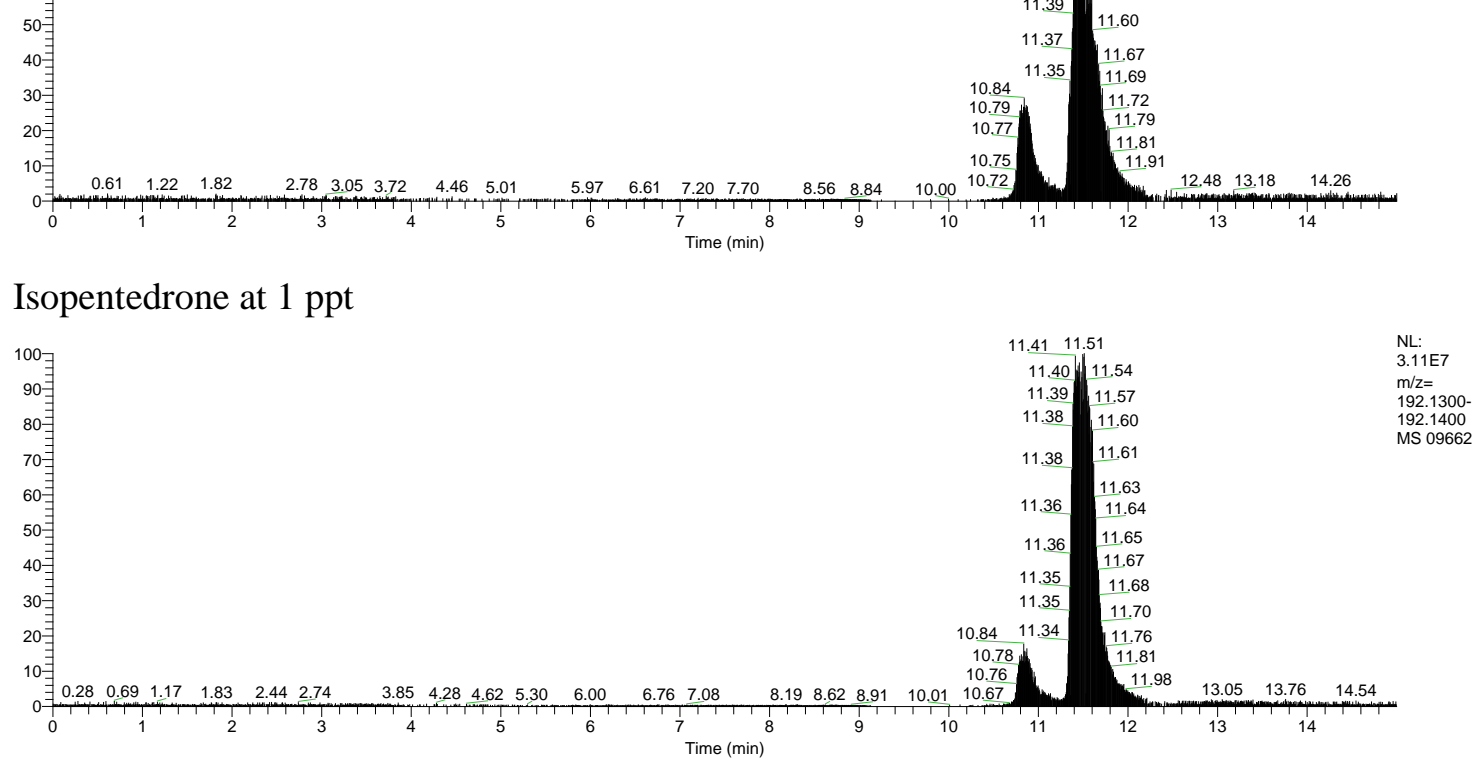


\subsection{ASSESSMENT OF MATRIX EFFECTS}

Matrix effects can be determined mathematically by comparing the peak height in the matrix to the peak height of the same analyte standard in the absence of the matrix. For the purposes of this research, matrix effects were assessed by comparing the peaks detected in the spectra in each matrix and examining the interference of the background signal. To assess the effects of the matrix on the detection of designer drugs, the unknown mixture was spiked into deionized water, tap water, reclaimed water and filtered raw sewage. The mixture was spiked at $20 \mathrm{ppt}$ into each of the water samples. In each water sample, the ten compounds were identified and the major peaks listed in Table 3 were observed for each compounds. The background noise was more prominent in the raw sewage samples, but the $[\mathrm{M}+\mathrm{H}]^{+}$and fragment peaks were identifiable in each sample. A comparison of the fragments observed in the detection of 4-fluoroethcathinone is shown in Figure 7.

Figure 7. Comparison of 4-fluoroethcathinone in deionized water (top), tap water (second), reclaimed water (third), and filtered raw sewage (bottom)

Deionized water
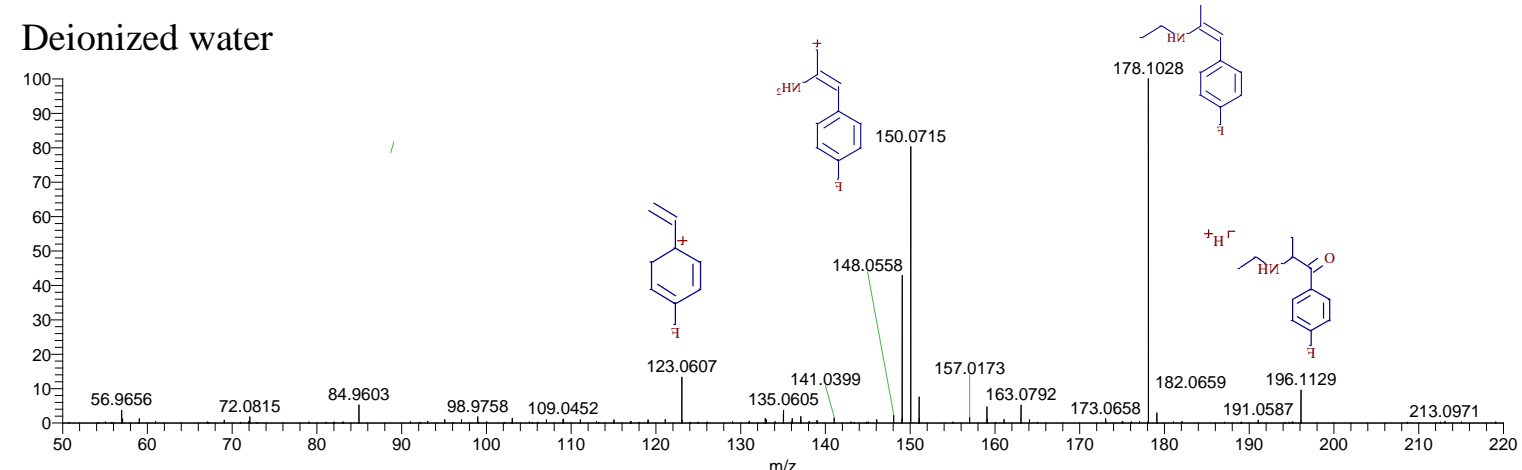


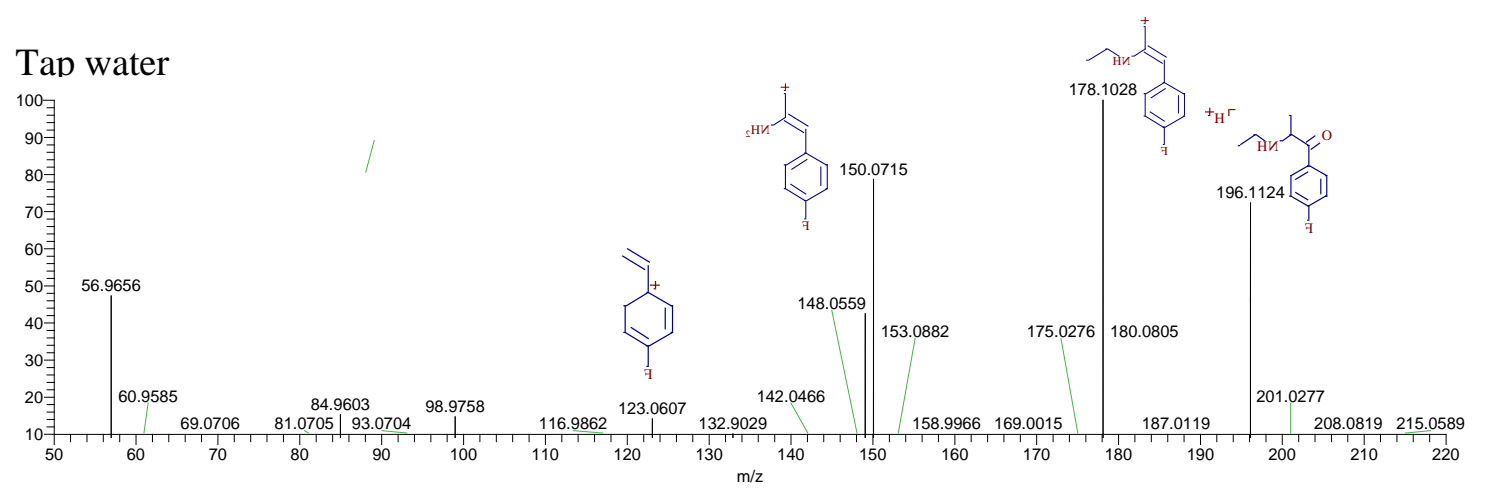

\section{Reclaimed water}

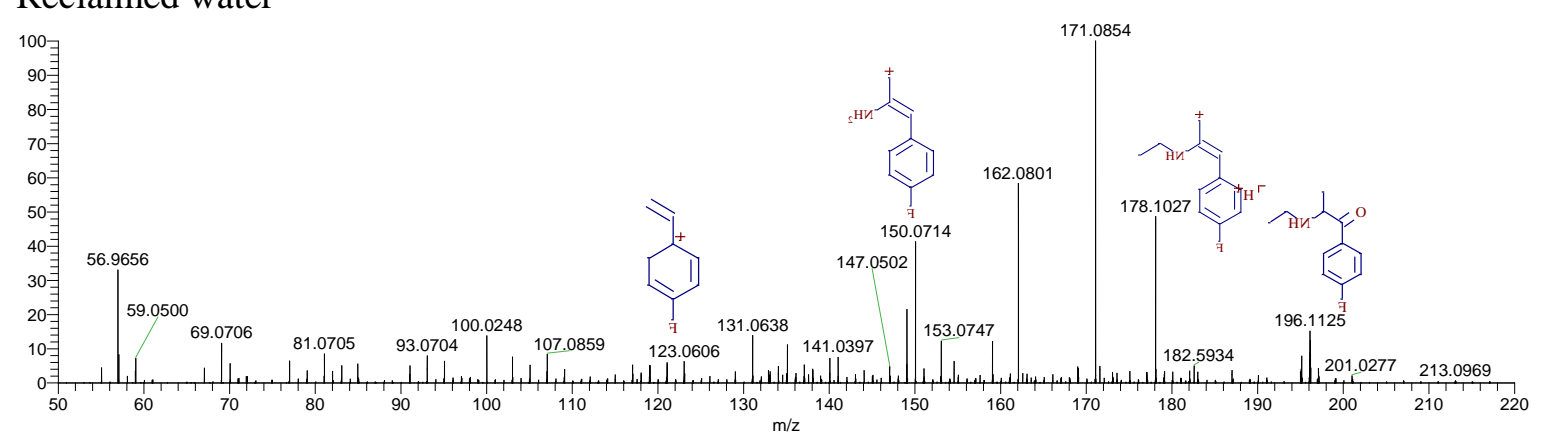

\section{Filtered Raw Sewage}

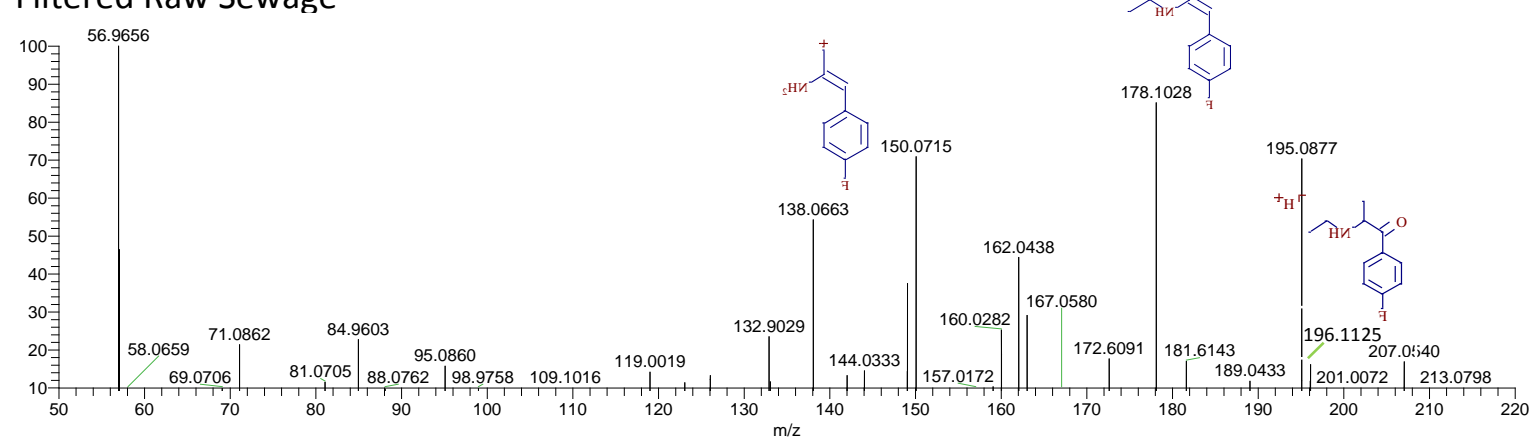


A further assessment of the effect of the matrix of the filtered raw sewage was conducted. The concentration of the unknown mixture was held constant at $20 \mathrm{ppt}$ while the raw sewage was diluted to varying degrees $(1 \mathrm{x}, 10 \mathrm{x}$ and $100 \mathrm{x}$.$) When the sewage was diluted$ 1 time (50:50 deionized water: filtered raw sewage), the background noise made the identification of each compound difficult. Only one compound, isopentedrone, could be identified. It was determined that there was no difference between the 10 and 100 dilution factors. A graph of the peak intensity versus the dilution factor of the raw sewage is shown in Figure 8. Because the concentration of the target compounds is expected to be low in sewage influent, it was decided to dilute the raw sewage by a factor of 10 to avoid over-dilution of the target compounds.

Figure 8. Graph of the effect of the dilution factor of raw sewage on the peak intensity of the $[\mathrm{M}+\mathrm{H}]^{+}$ peak for each component of the unknown mixture present at 20ppt

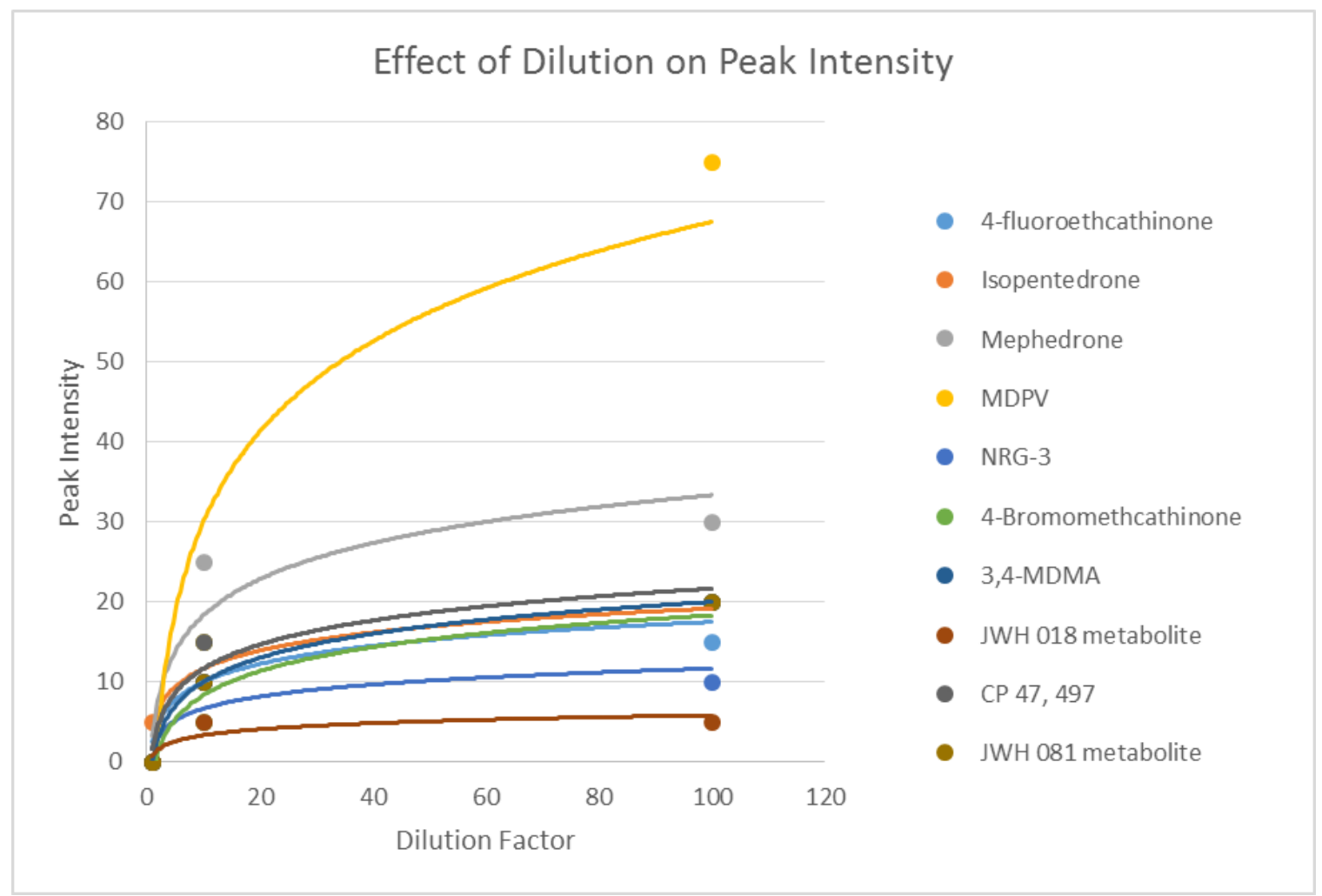


A second set of experiments was done by varying the concentration (20 ppt, $10 \mathrm{ppt}, 5 \mathrm{ppt}$, and $1 \mathrm{ppt}$ ) of the unknown mixture while holding the dilution factor of the raw sewage constant at 10 times. All of the target compounds were detected at $20 \mathrm{ppt}$. The $10 \mathrm{ppt}$ concentration allowed for the identification of five compounds in the mixture, but the background noise begins to obscure some of the major fragmentation peaks. At $1 \mathrm{ppt}$, only one compounds was detectable, with a considerable amount of background noise affecting the identification process. Based on these results, it was determined that the limit of detection in raw sewage was $20 \mathrm{ppt}$, which is consistent with the limit of detection determined in deionized water.

\subsection{DETECTION OF PARENT COMPOUNDS AND METABOLITES IN INFLUENT}

\section{SEWAGE}

Parent compounds and major metabolites were considered confirmed via $\mathrm{MS}^{2}$ when the parent ion was present, and the fragmentation pattern predicted in silico using MassFrontier was consistent with the fragmentation pattern observed in the data. The fragmentation patterns of the identified parent compounds and metabolites are shown in Appendix 2. The parent compounds detected and the observed fragments are listed in Table 5. The $\mathrm{MS}^{2}$ spectra of each of the confirmed parent compounds are shown in Figure 9. The fragments associated with each peak have been overlaid to illustrate the confirmation process. 
Table 5. Parent compounds detected in sewage influent and observed fragmentation

\begin{tabular}{|c|c|c|c|}
\hline $\begin{array}{l}\text { Compound } \\
\text { Name }\end{array}$ & Structure & {$[\mathbf{M}+\mathbf{H}]^{+}$} & tMS $^{2}$ (error*) \\
\hline 3,4-DMMC & $H$ & 192.13829 & $\begin{array}{l}192.13823(-0.316) \\
133.06485(0.440) \\
105.07019(2.980)\end{array}$ \\
\hline CP 55, 244 & & 403.32067 & $\begin{array}{l}403.32118(1.260) \\
385.30974(-0.953) \\
359.29429(-0.465) \\
331.26274(-1.258) \\
301.25221(-1.269) \\
275.20036(-0.714) \\
221.18977(-1.003) \\
183.13788(-0.417) \\
169.12219(-0.688) \\
167.10655(-0.636) \\
155.10652(-0.878) \\
147.11672(-0.728) \\
141.12728(-0.792) \\
125.09617(0.627) \\
113.09631(1.931)\end{array}$ \\
\hline 4-MAR & & 177.10224 & $\begin{array}{l}177.10249(1.414) \\
161.07084(-0.618) \\
159.09154(-0.848) \\
149.07090(-0.265) \\
134.06002(-0.152)\end{array}$ \\
\hline MMA & & 180.13829 & $\begin{array}{l}180.13815(-0.781) \\
164.10692(-0.430) \\
163.11161(-0.807) \\
149.09603(-0.413) \\
121.06492(1.062)\end{array}$ \\
\hline MDA & & 180.10191 & $\begin{array}{l}180.10178(-0.695) \\
163.07522(-0.835) \\
137.05966(-0.336) \\
133.06479(-0.011) \\
121.06492(1.062) \\
117.07005(1.479) \\
107.04942(2.602)\end{array}$ \\
\hline
\end{tabular}

*Error in ppm based on the calculated mass of the chemical formula 
MMA and MDA have very similar $[\mathrm{M}+\mathrm{H}]^{+}$masses. They can be distinguished based on the fragments which are unique to each of the structures. Additionally, the two different masses observed for the $[\mathrm{M}+\mathrm{H}]^{+}$are within the mass errors threshold when compared to the respective masses based on the chemical formulae. MDA is a more commonly used designer drug than MMA. This corresponds with the fact that the MDA showed a peak that was approximately three times the size of the MMA in the raw sewage spectra. Several compounds were detected in sewage influent through the screening process, but were not confirmed through $\mathrm{MS}^{2}$ analysis. These compounds are likely present in concentrations below the limit of detection of $20 \mathrm{ppt}$. The suspect compounds which were detected through screening but were not confirmed are listed in Table 6.

Table 6. Suspect compounds unconfirmed with $M S^{2}$

\begin{tabular}{|l|l|l|}
\hline Compound & Structure & {$[\mathbf{M + H}]^{+}$} \\
\hline 4- methylethcathinone & & 192.13829 \\
\hline Methylbenzodioxolylbutanamine
\end{tabular}


Figure 9. Fragmentation spectra of confirmed suspect compounds in sewage influent
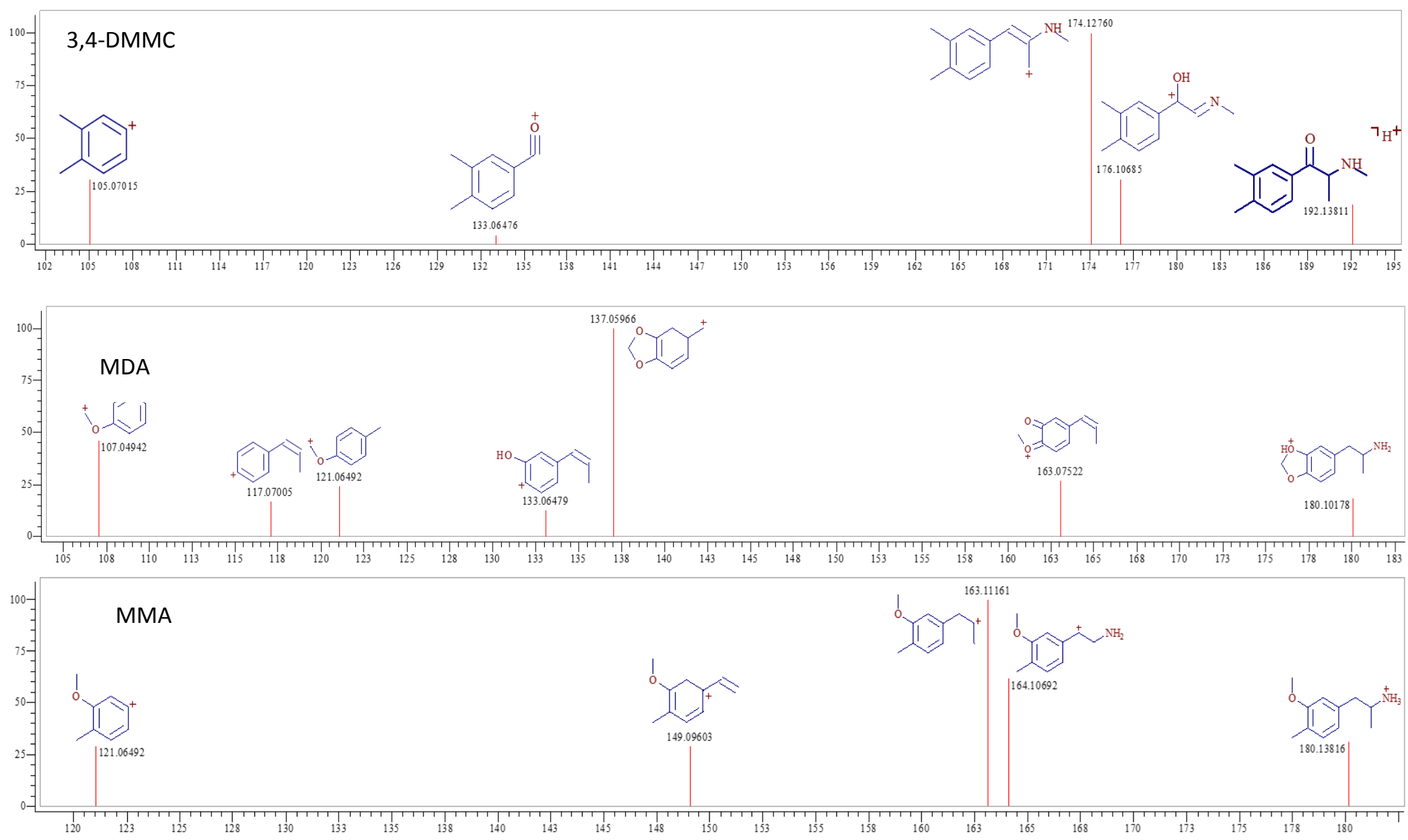

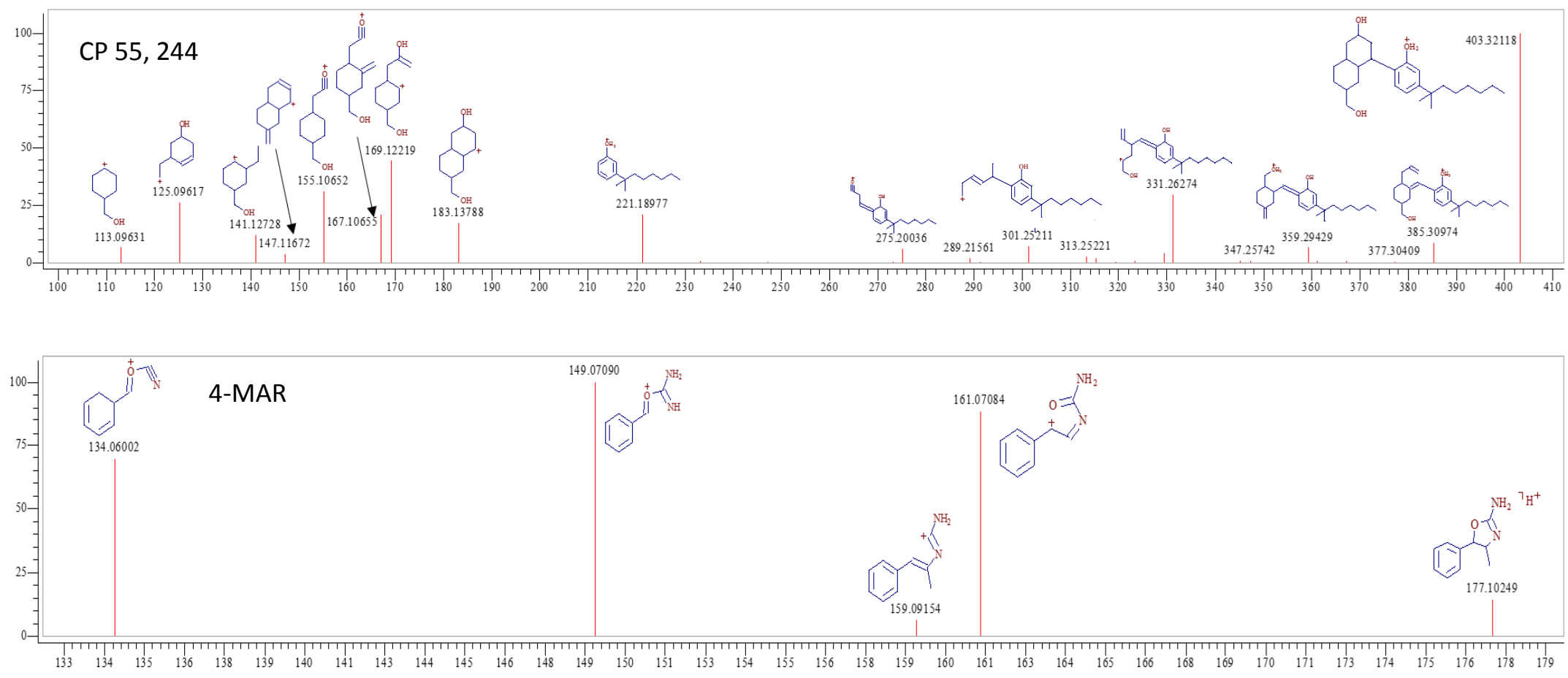
Parent drugs and their major metabolites which were observed and published in previous studies were included in the target screening list (Blachut et. al., 2012; Boatto et. al., 2005; Brandt et. al., 2010; Concheiro et. al., 2013; de Boer et. al., 2004; de Jager et. al., 2012; De Paoli et. al., 2013; Dean et. al., 2014; ElSohly et. al., 2014; Jankovics et. al., 2011; Lin et. al., 2004; Meyer et. al., 2010a; Meyer et. al., 2012; Meyer et. al., 2010b; Peters et. al., 2005; Sauer et. al., 2006; Seely et. al., 2013; Shulgin 1991; Shulgin 1997; Smolianitski et. al., 2014; Soblevsky et. al., 2012; Springer et. al., 2003; Springer et. al., 2002; Staack et. al., 2003; Swortwood 2013; Theoblad et. al., 2006; Uchiyama et. al., 2013; Wohlfarth et. al., 2014; Wohlfarth et. al., 2013; Zawilska et. al., 2013; Zuba et. al., 2013; Zuba et. al., 2012.) For the detected parent compounds which had no published metabolisms, metabolic products were predicted in silico using MetWorks. The major metabolites detected and the observed fragments are listed in Table 7. The $\mathrm{MS}^{2}$ spectra of the identified metabolites are shown in Figure 10. The fragments associated with each peak are shown.

Table 7. Metabolites detected and observed fragmentation

\begin{tabular}{|c|c|c|c|}
\hline Parent & Metabolite & {$[\mathbf{M}+\mathbf{H}]^{+}$} & $\operatorname{ddMS}^{2}$ (error*) \\
\hline 3,4-DMMC & $\mathrm{N}$-demethylation & 178.1226 & $\begin{array}{l}178.12249(-0.846) \\
162.12756(-1.024) \\
162.09118(-0.991) \\
146.09630(-0.862) \\
123.08051(0.556) \\
105.07015(2.600)\end{array}$ \\
\hline
\end{tabular}




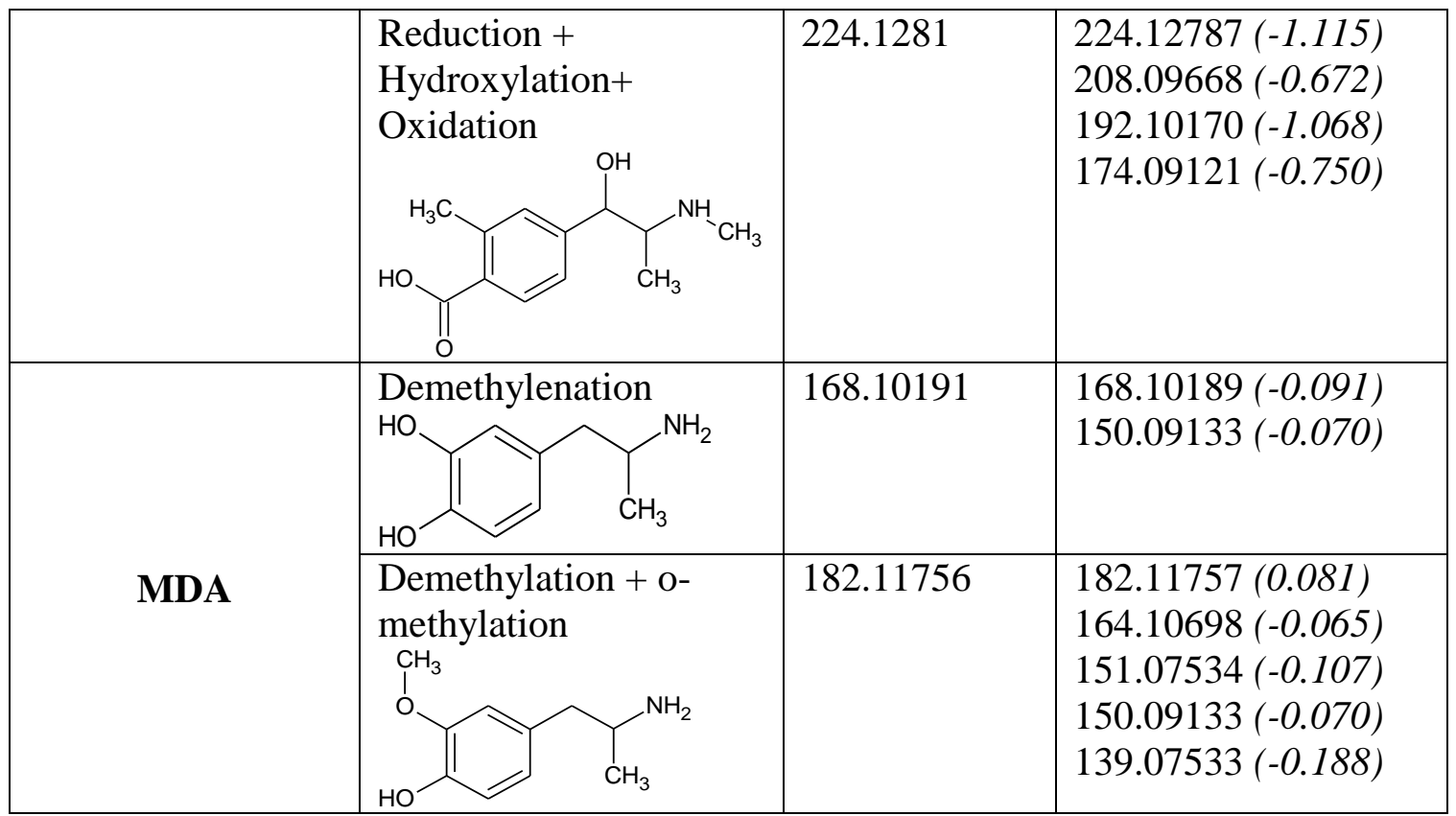

*Error in ppm based on the calculated mass of the chemical formula 
Figure 10. Fragmentation spectra of confirmed metabolites
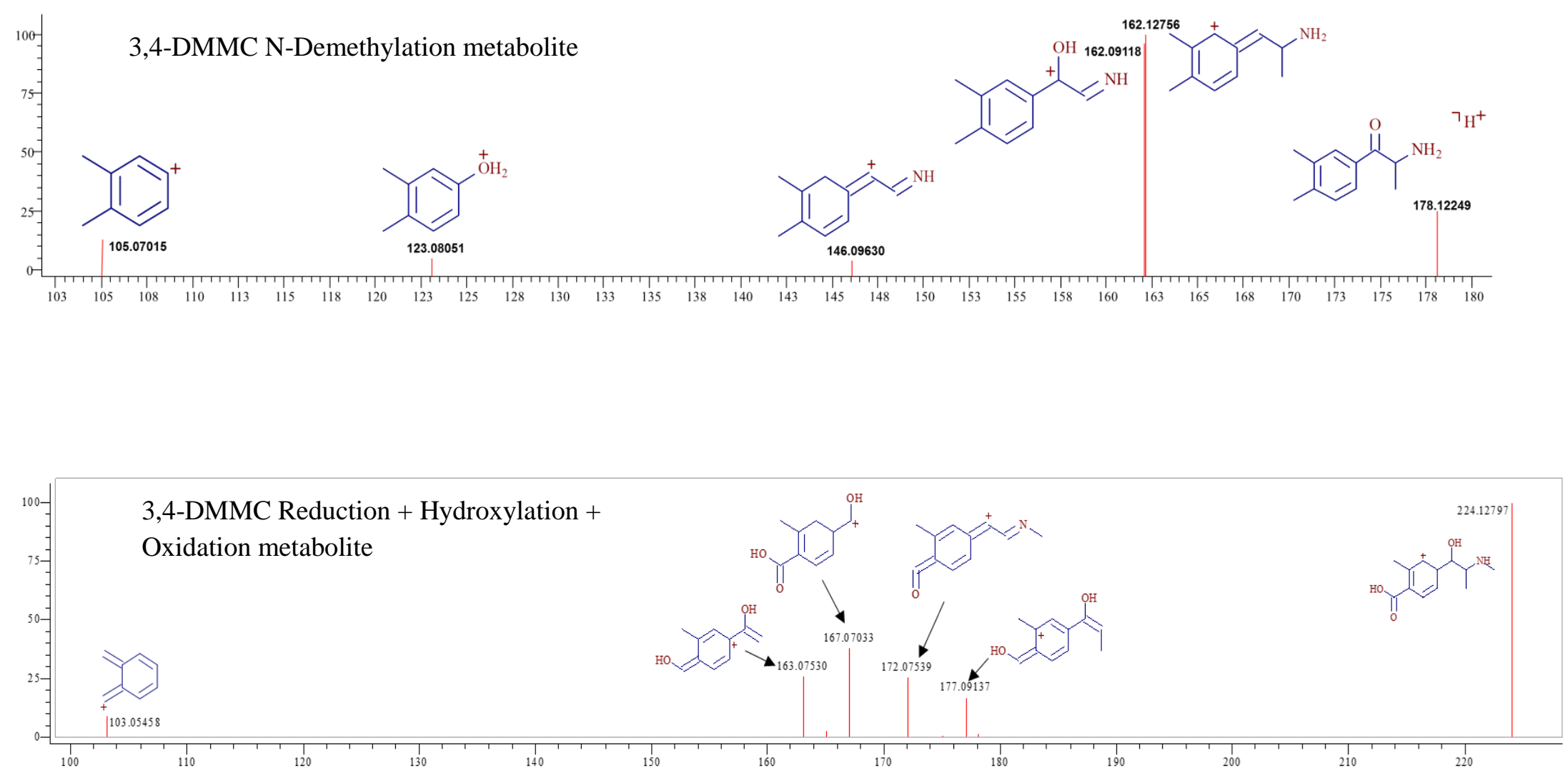

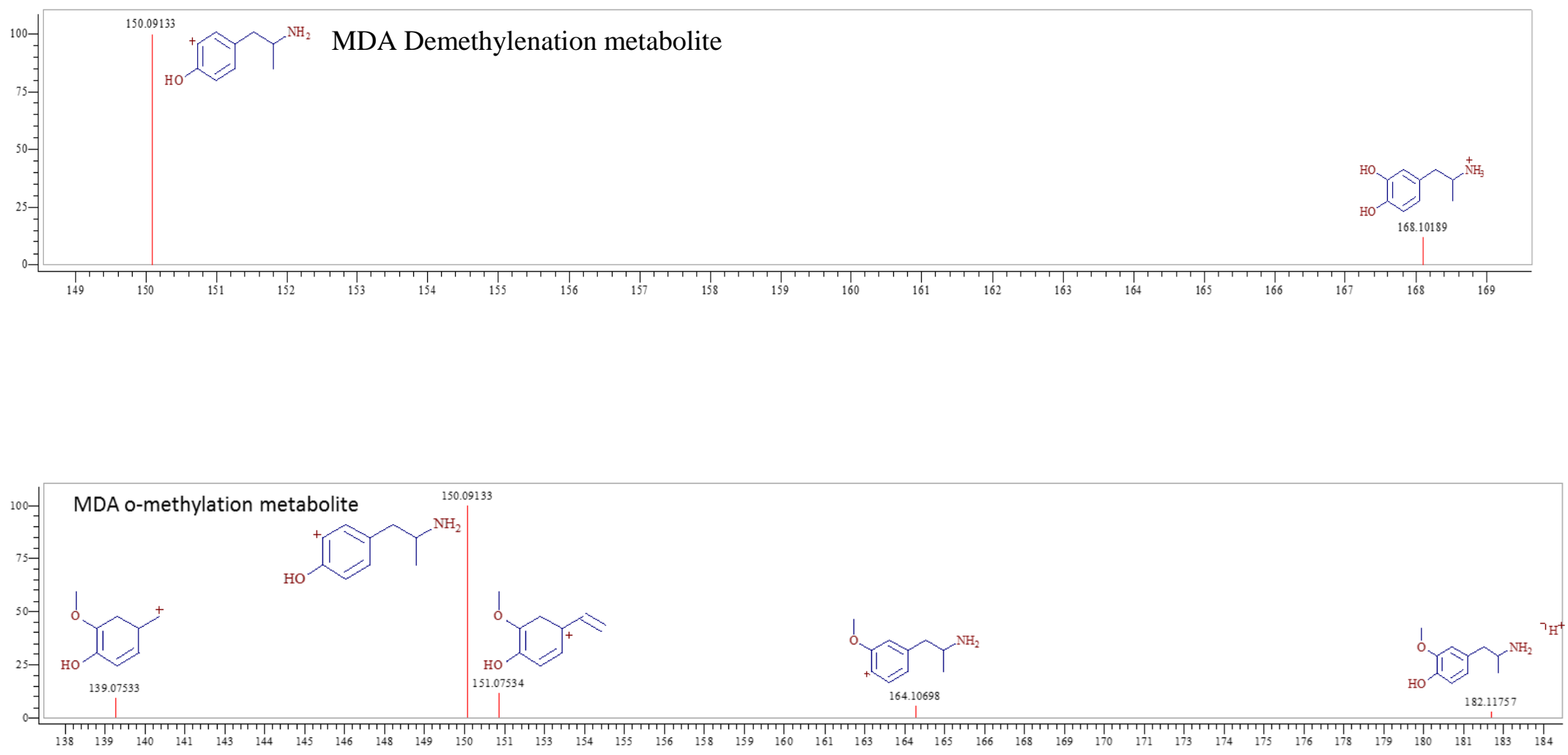


\subsection{COMPARISON OF ACQUISITION MODES}

Both tMS ${ }^{2}$ and ddMS ${ }^{2}$ analyses were conducted to compare the methods. It was determined that $\mathrm{tMS}^{2}$ was more effective at detecting the parent drugs. Fewer fragments were observed using ddMS ${ }^{2}$ which made confirmation difficult. A comparison of the fragments observed in $\mathrm{tMS}^{2}$ and ddMS ${ }^{2}$ is shown in Table 7. A total of 5 parent compounds were confirmed using tMS ${ }^{2}$ and only 2 were confirmed using ddMS ${ }^{2}$. Analysis conducted by ddMS ${ }^{2}$ was deemed to be more efficient in the detection of major metabolites due to the large number of metabolites that were determined through MetWorks.

Table 8. Comparison of target-MS $S^{2}$ and data dependent-MS $S^{2}$ analyses

\begin{tabular}{|l|l|l|}
\hline Compound Name & tMS $^{2}$ (error)* & ddMS $^{2}$ (error)* \\
\hline $3,4-D M M C$ & $192.13823(-0.316)$ & $192.13819(-0.524)$ \\
& $133.06485(0.440)$ & \\
& $105.07019(2.980)$ & \\
\hline MMA & $180.13815(-0.781)$ & $180.13824(-0.282)$ \\
& $121.06425(-4.473)$ & $121.06500(1.722)$ \\
\hline
\end{tabular}

*Error in ppm based on the calculated mass of the chemical formula

\subsection{COMPARISON OF WATER SOURCES}

Both parent compounds and major metabolites were detected in the analysis of sewage influents. A total of 5 parent compounds and 4 metabolites were detected in raw sewage, as shown in Tables 5 and 7 . To date, no study has been conducted to detect a comprehensive list of designer drugs. Previous studies have detected illicit drugs and MDMA in wastewater in detectable concentrations (Baker et. al., 2012; Castiglioni et. al., 2006; Chiaia et. al., 2008; Ostman et. al., 2014; Pal et. al., 2013; Senta et. al., 2014; 
Thomas et. al., 2012; Yargeau et. al., 2014). Analysis conducted on the samples collected from the effluent pipes determined that no designer drugs or metabolites were present in detectable concentrations. Analysis of samples collected upstream of the outfall pipe confirmed that designer drugs were not present in the river water prior to the addition of the treated wastewater. Samples collected from the downstream mixing zone, and the drinking water intake and output locations did not contain parent drugs or metabolites in detectable concentrations. In previous studies conducted on the sample set of samples, several pharmaceuticals and personal care products were tentatively identified (Heuett, 2015.) Additional studies have detected MDMA in surface water collected at varying distances downstream from sewage treatment facilities in concentrations ranging from 0.2 to 180 ppt (Bartelt-Hunt et. al., 2009; Postigo et. al., 2010; Valcarcel et. al., 2012; Zuccato et. al., 2008a; Zuccato et. al., 2008b). This indicates that a variety of compounds will survive the wastewater treatment process, but designer drugs are either removed by the treatment processes or are diluted beyond the limit of detection established in this method. The analysis of reclaimed water determined that no parent drugs or metabolites were present in detectable concentrations above 20 ppt. In previous studies of reclaimed water, pharmaceuticals and personal care products were detected, indicating that some of these products survive the entire wastewater treatment process, to be released into the environment with the use of reclaimed water in irrigation (Chen et. al., 2013).

\section{DISCUSSION AND CONCLUSIONS}

It was determined that the non-target screening and detection method developed was effective in the analysis of designer drugs and their associated metabolites. The parent 
drugs and metabolites which were spiked into the samples were detected and identified in each of the investigated water samples, indicating that the method was effective for each water source, and matrix effects did not inhibit the detection of the target compounds. Compounds could be detected in each water source, including raw sewage at concentrations above 20 ppt. This represents the limit of environmental relevance. Additional compounds may be present at lower concentrations, however below $20 \mathrm{ppt}$ those compounds are not likely to have an environmental effect. For optimum detection of compounds, the raw sewage was diluted ten times to minimize the background interference. As seen in the full scan chromatogram, not all compounds were separated by the column. Compounds which co-eluted were easily identified by comparing the observed fragmentation pattern to the predicted fragmentation. Isomers are distinguished using $\mathrm{MS}^{2}$ because different fragmentation patterns will be observed in regions of structural differences. While two isomers have several fragment peaks in common, they differ in one or more fragments, which allows isomers to be distinguished from one another.

Designer drugs are excreted into the sewage system after consumption. Parent drugs, including 3,4-DMMC and CP 55,244, and metabolites, including the N-demethylation metabolite of 3,4-DMMC and the demethylation product of MDA, are present in detectable concentrations in sewage influent. It is interesting to note that the parent drugs detected in raw sewage were not as common as was expected. It was expected to detect drugs that were more commonly used, such as MDMA or MDPV, however those compounds were not detected. The wastewater proceeds through the sewage treatment protocols and is released into the environment via outfall pipes. Samples collected at this 
point did not contain parent drugs or metabolites of designer drugs in detectable concentrations. These findings indicate that designer drugs are either removed by the sewage treatment process, or are so greatly diluted as to be no longer detectable by this method, which has an established limit of detection of $20 \mathrm{ppt}$. This trend continued in the samples collected downstream of the outfall pipe, indicating that there were no additional sources of designer drugs being added to the river water. The absence of designer drugs in the collected water samples indicates that designer drugs are not a significant source of environmental contamination at this time. Additional research should be done to determine if the compounds are present in the environment at lower concentrations, or if they are being effectively removed during the wastewater treatment process. 


\section{REFERENCES}

Baker, David R.; Ocenaskova, Vera; Kvicalova, Magdalena; Kasprzyk-Hordern, Barbara. Drugs of Abuse in wastewater and suspended particulate matter - Further developments in sewage epidemiology. Environ Int. 2012, 48, 28-38

Bartelt-Hunt, Shannon L.; Snow, Daniel D.; Damon, Teyona; Shockley, Johnette; Hoagland, Kyle. The occurrence of illicit and therapeutic pharmaceuticals in wastewater effluent and surface waters in Nebraska. Environ Poll. 2009, 157, 786-791

Blanchut, Dariusz; Wojtasiewicz, Krystyna; Krawczyk, Krzystof; Maurin, Jan; Szawkalo, Joanna; Czarnocki, Zbigniew. Identification and synthesis of by-products found in 4methylthioamphetamine (4-MTA) produced by the Leuckart method. Forensic Sci Int. 2012, 216, 108-120

Boatta, Gianpiero; Nieddu, Maria; Carta, Antonio; Pau, Amedeo; Palomba, Michele; Asproni, Mattistina; Cerri, Riccardo. Determination of amphetamine-derived designer drugs in human urine by SPE extraction and capillary electrophoresis with mass spectrometry detection. J Chromatogr B. 2005, 814,93-98

Brandt, Simon D.; Martins, Claudia P. B. Analytical methods for psychoactive N,Ndialkylated tryptamines. Trends Anal Chem. 2010, 29, 858-869

Castiglioni, Sara; Zuccato, Ettore; Crisci, Elisabetta; Chiabrando, Chiara; Fanelli, Roberto; Bagnati, Renzo. Identification and Measurement of Illicit Drugs and Their Metabolites in Urban Wastewater by Liquid Chromatography - Tandem Mass Spectrometry. Anal Chem. 2006, 78, 8421-8429

Chen, Weiping; Xu, Jian; Lu, Sidna; Jiao, Wentao; Wu, Laosheng; Chang, Andrew C. Fates and transport of PPCPs in soil receiving reclaimed water irrigation. Chemosphere. 2013, 93, 2621-2630

Chiaia, Aurea C.; Banta-Green, Caleb; Field, Jennifer. Eliminating Solid Phase Extraction with Large-Volume Injection LC/MS/MS: Analysis of Illicit and Legal Drugs and Human Urine Indicators in US Wastewaters. Environ Sci Technol. 2008, 42, 88418848

Concheiro, Marta; Anizan, Sebastien; Ellefsen, Kayla; Huestis, Marilyn A. Simultaneous quantification of 28 synthetic cathinones and metabolites in urine by liquid chromatography-high resolution mass spectrometry. Anal Bioanal Chem. 2013, 405, 9437-9448

de Boer, Douwe; Bosman, Ingrid. A new trend in drugs-of-abuse; the $2 \mathrm{C}$-series of phenethylamine designer drugs. Pharm World Sci. 2004, 26, 110-113

de Hoffmann, Edmond; Stroobant, Vincent. Mass Spectrometry: Principles and Applications, $3^{\text {rd }}$ Ed.; John Wiley \& Sons: England, 2007. 
de Jager, Andrew D.; Warner, Janet V.; Henman, Michael; Ferguson, Wendy; Hall, Ashley. LC-MS/MS method for the quantitation of metabolites of eight commonly usedused synthetic cannabinoids in human urine - An Australian perspective. J Chromatogr B. 2012, 897, 22-31

de Paoli, Giorgia; Brandt, Simon D.; Wallach, Jason; Archer, Roland P.; Pounder Derrick J. From the street to the laboratory: Analytical Profiles of Methoxetamine, 3Methoxyeticyclidine and 3-methoxyphencyclidine and their Determination in Three Biological Matrices. J Anal Toxicol. 2013, 37, 277-283

Dean, Be Vang; Stellpflug, Samuel J.; Burnett, Aaron M.; Engebretsen, Kristin M. 2C or Not 2C: Phenethylamine Designer Drug Review. J Med Toxicol. 2013, 9, 172-178

ElSohly, Mahmoud, A.; Gul, Waseem; Wanas, Amira S. Radwan, Mohamed M. Synthetic cannabinoids: Analysis and metabolites. Life Sci. 2014, 97, 78-90

Environmental Protection Agency "Primer for municipal wastewater treatment systems" EPA 832-R-04-001. September 2004.

Heuett, Nubia Vanessa. Target and Non-Target Techniques for the Quantitation of Drugs of Abuse, Identification of Transformation Products, and Characterization of Contaminants of Emergent Concern by High Resolution Mass Spectrometry (2015). FIU Electronic Theses and Dissertations. Paper 2194. http://digitalcommons.fiu.edu/etd/2194

Heuett, Nubia V.; Batchu, Sudha Rani; Gardinali, Piero R. Understanding the magnitude of emergent contaminant releases through target screening and metabolite identification using high resolution mass spectrometry: Illicit drugs in raw sewage influents. J. Hazard. Mater. 2014

Hu, Q.; Noll, R. J.; Li, H.; Makarov, A.; Hardman, M.; Graham Cooks, R. The Orbitrap: a new mass spectrometer. J Mass Spectrom. 2005, 40, 430-443

Jankovics, Peter; Varadi, Andras; Tolgyesi, Laszlo; Lohner, Szilvia; Nemeth-Palotas, Julia; Koszegi-Szalai, Hilda. Identification and characterization of the new designer drug 4'-methylmethcathinone (4-MEC) and elaboration of a novel liquid chromatographytandem mass spectrometry (LC-MS/MS) screening method for seven different methcathinone analogs. Forensic Sci Int. 2011, 210, 213-220

Lin, Huei R.; Lua Ahai C. Detection of Acid-Labile Conjugates of Ketamine and Its Metabolites in Urine Samples Collected from Pub Participants. J Anal Toxicol. 2004, 28, 181-186

Makarov, A.; Denisov, E.; Kholomeev, A.; Balschun, W.; Lange, O.; Horning, S. Performance of a Hybrid Linear Ion Trap/ Orbitrap Mass Spectrometer. Anal Chem. 2006, 78, 2113-2120

Meyer, Markus R.; Du, Peng; Schuster, Frank; Maurer, Hans H. Studies on the metabolism of the $\alpha$-pyrrolidinophenone designer drugs methylenedioxy-pyrovalerone 
(MDPV) in rat and human urine and human liver microsomes using GC-MS and LChigh-resolution MS and its detectability in urine by GC-MS. J Mass Spectrom. 2010a, 45, 1426-1442

Meyer, Markus R.; Vollmar, Christian; Schwaninger, Andrea E.; Wolf, Ehud (Udi); Maurer, Hans H. New cathinone-derived designer drugs 3-bromomethcathinone and 3fluoromethcathinone: studies on their metabolism in rat urine and human liver microsomes using GC-MS and LC-high resolution MS and their detectability in urine. $J$ Mass Spectrom. 2012, 47, 253-262

Meyer, Markus R.; Wilhelm, Jens; Peters, Frank T. Beta-keto amphetamines: studies on the metabolism of the designer drug mephedrone and toxicological detection of mephedrone, butylone, and methylone in urine using gas chromatography - mass spectrometry. Anal Bioanal Chem. 2010b, 397, 1225-1233

Ostman, Marcus; Fick, Jerker; Nasstrom, Elin; Lindberg, Richard H. A snapshot of illicit drug use in Sweden acquired through sewage water analysis. Sci Total Environ. 2014, $472,862-871$

Pal, Raktim; Megharaj, Mallavarapu; Kirkbride, K. Paul; Naidu, Ravi. Illicit drugs and the environment - A review. Sci Total Environ. 2013, 463-464, 1079-1092

Peters, Frank T.; Meyer, Markus R.; Fritschi, Giselher; Maurer Hans H. Studies on the metabolism and toxicological detection of the new designer drug 4'-methyl- $\alpha$ pyrrolidinobutyrophenone (MPBP) in rat urine using gas chromatography-mass spectrometry. J Chromatogr B. 2005, 824,81-91

Postigo, Cristina; Lopez de Alda, Maria Jose; Barcelo, Damia. Drugs of abuse and their metabolites in the Ebro River basin: Occurrence in sewage and surface water, sewage treatment plants removal efficiency, and collective drug usage estimation. Environ Int. $2010,36,75-84$

Ramirez, Cesar E.; Wang, Chengtao; Gardinali, Piero R.; Massi, Jennifer; Beck, Jonathan. Fully Automated, Trace-Level Determination of Parent and Alylated PAHs in Environmental Waters by Online SPE-LC-APPI-MS/MS. ThermoScientific Application Note 598. 2014.

Sauer, Christoph; Peters, Frank T.; Staack, Roland F.; Fritschi, Giselher; Maurer, Hans H. New designer drug N-(1-phenylcyclohexyl)-3-ethoxypropanamine (PCEPA): Studies on its metabolism and toxicological detection in rat urine using gas chromatographic/mass spectrometric techniques. J Mass Spectrom. 2006, 41, 1014-1029

Seely, Kathryn A.; Patton, Amy L.; Moran, Cindy L.; Womack, Mary L.; Prather, Paul L.; Fantegrossi, William E.; Radominska-Pandya, Anna; Endres, Gregory W.; Channell, Kermit B.; Smith, Nathaniel H.; McCain, Keith R.; James, Laura P.; Moran, Jeffery H. Forensic investigation of K2, Spice and "bath salt" commercial preparations: A threeyear study of new designer drug products containing synthetic cannabinoids, stimulant, and hallucinogenic compounds. Forensic Sci Int. 2013, 487, 659-665 
Senta, Ivan; Krizman, Ivona; Ahel, Marijan; Terzic, Senka. Assessment of stability of drug biomarkers in municipal wastewater as a factor influencing the estimation of drug consumption using sewage epidemiology. Sci Total Environ. 2014, 487, 659-665

Shulgin, Alexander and Ann. PiHKAL: A Chemical Love Story. Transform Press: Berkeley, CA, 1991

Shulgin, Alexander and Ann. TiHKAL: The Continuation. Transform Press: Berkeley, CA, 1997

Smolianitski, E.; Wolf, E.; Almog, J. Proactive forensic science: A novel class of cathinone precursors. Forensic Sci Int. 2014, 242, 219-227

Soblevsky, Tim; Prasolov, Ilya; Rodchenkov, Grigory. Detection of urinary metabolites of AM-2201 and UR-144, two novel synthetic cannabinoids. Drug Test Analysis. 2012, 4, $745-753$

Springer, Dietmar; Peters, Frank T.; Fritschi, Giselher; Maurer, Hans H. New designer drug 4'-methyl- $\alpha$-pyrrolidinohexanophenone: studies on its metabolism and toxicological detection in urine using gas chromatography-mass spectrometry. J Chromatogr B. 2002, $773,25-33$

Springer, Dietmar; Peters, Frank T.; Fritschi, Giselher; Maurer, Hans H. Studies on the metabolism and toxicological detection of the new designer drug 4'-methyl- $\alpha$ pyrrolidinopropiophenone in urine using gas chromatography-mass spectrometry. $J$ Chromatogr B. 2003, 789, 27-41

Swortwood, Madeline Jean. Comprehensive Forensic Toxicological Analysis of Designer Drugs (2013). FIU Electronic Theses and Dissertations. Paper 997. http://digitalcommons.fiu.edu/etd/997

Theobald, Denis S.; Putz, Michael; Scheider, Erhard; Maurer, Hans H. New designer drug 4-iodo-2,5-dimethoxy- $\beta$-phenethylamine (2C-I): Studies on its metabolism and toxicological detection in rat urine using gas chromatographic/ mass spectrometric and capillary electrophoretic/ mass spectrometric techniques. J Mass Spectrom. 2006, 41, $872-886$

ThermoScientific. Removing Uncertainty by Applying Science to SPE. Thermo Scientific Hypersep Columns Application Notebook. 1, 2011.

ThermoScientific: Planet Orbitrap. http://planetorbitrap.com/qexactive\#tab:specifications (accessed November 12, 2014)

Thomas, Kevin T.; Bijlsma, Lubertus; Castiglioni, Sara; Covaci, Adrian; Emke, Erik; Grabic, Roman; Hernandez, Felix; Karolak, Sara; Kasprzyk-Hordern, Barbara; Lindberg, Richard H.; Lopez de Alda, Miren; Meierjohann, Axel; Ort, Christopher; Pico, Yolanda; Quintana, Jose B.; Reid, Malcolm; Rieckermann, Jorg; Terzic, Senka; van Nujis, 
Alexander I.N.; de Voogt, Pim. Comparing illicit drug use in 19 European cities through sewage analysis. Sci Total Environ. 2012, 432, 432-439

Uchiyama, Nahoko; Kawamura, Maiko; Kikura-Hanajiri, Ruri; Goda, Yukihiro. URB754: A new class of designer drugs and 12 synthetic cannabinoids detected in illegal products. Forensic Sci Int. 2013, 227, 21-32

UNODC Research. World Drug Report 2015. United Nations: New York, 2015

Valcarcel, Y.; Martinez, F.; Gonzalez-Alsonso, S.; Segura, Y.; Catala, M; Molina, R.; Montero-Rubio, J.C.; Mastroianni, N.; Lopez de Alda, M.; Postigo, C.; Barcelo, D. Drugs of abuse in surface and tap waters of the Targus River basin: Heterogeneous photonFenton process is effective in their degradation. Eviron Int. 2012, 41, 35-43

Wohlfarth, Ariane; Gandhi, Adarsh S.; Pang, Shaokun; Zhu, Mingshe; Scheidweiler, Karl B.; Huestis, Marilyn A. Metabolism of synthetic cannabinoids PB-22 and its 5-fluoro analog, 5F-PB-22, by human hepatocyte incubation and high-resolution mass spectrometry. Anal Bioanal Chem. 2014, 406, 1763-1780

Wohlfarth, Ariane; Scheidweiler, Karl B.; Chen, Xiaohong; Liu, Hua-fen; Huestis, Marilyn A. Qualitative Confirmation of 9 Synthetic Cannabinoids and 20 Metabolites in Human Urine Using LC-MS/MS and Library Search

Yargeau, Viviane; Taylor, Bryanne; Li, Hongxia; Rodayan, Angela; Metcalfe, Chris D. Analysis of drugs of abuse in wastewater from two Canadian cities. Sci Total Environ. 2014, 487, 722-730

Zawilska, Jolanta B.; Wojcieszak, Jakub. Designer cathinones - An emerging class of novel recreational drugs. Forensic Sci Int. 2013, 231, 42-53

Zuba, Dariusz; Seluka, Karolina; Buczek, Agnieszka. 25C-NBOMe - New potent hallucinogenic substance identified on the drug market. Forensic Sci Int. 2013, 227, 7-14

Zuba, Dariusz; Seluka, Karolina; Buczek, Agnieszka. Identification and characterization of 2,5-dimethoxy-4-nitro- $\beta$-phenthylamine (2C-N) - A new member of $2 \mathrm{C}$-series of designer drug. Forensic Sci Int. 2012, 222, 298-308

Zuccato, Ettore; Castiglioni, Sara; Bagnati, Renzo; Chiabrando, Chiara; Grassi, Paola; Fanelli, Roberto. Illicit drugs, a novel group of environmental contaminants. Water Res. 2008a, 42, 961-968

Zuccato, Ettore; Chiabrando, Chiara; Castiglioni, Sara; Bagnati, Renzo; Fanelli, Roberto. Estimating Community Drug Abuse by Wastewater Analysis. Environ Health Perspect. 2008b, 116, 1027-1032 


\section{APPENDICES}

APPENDIX 1. Database of Designer Drugs and Metabolites

APPENDIX 2. In Silico Fragmentation Pattern of Individual Components of Unknown Mixture 


\section{APPENDIX 1. DATABASE OF DESIGNER DRUGS AND METABOLITES}

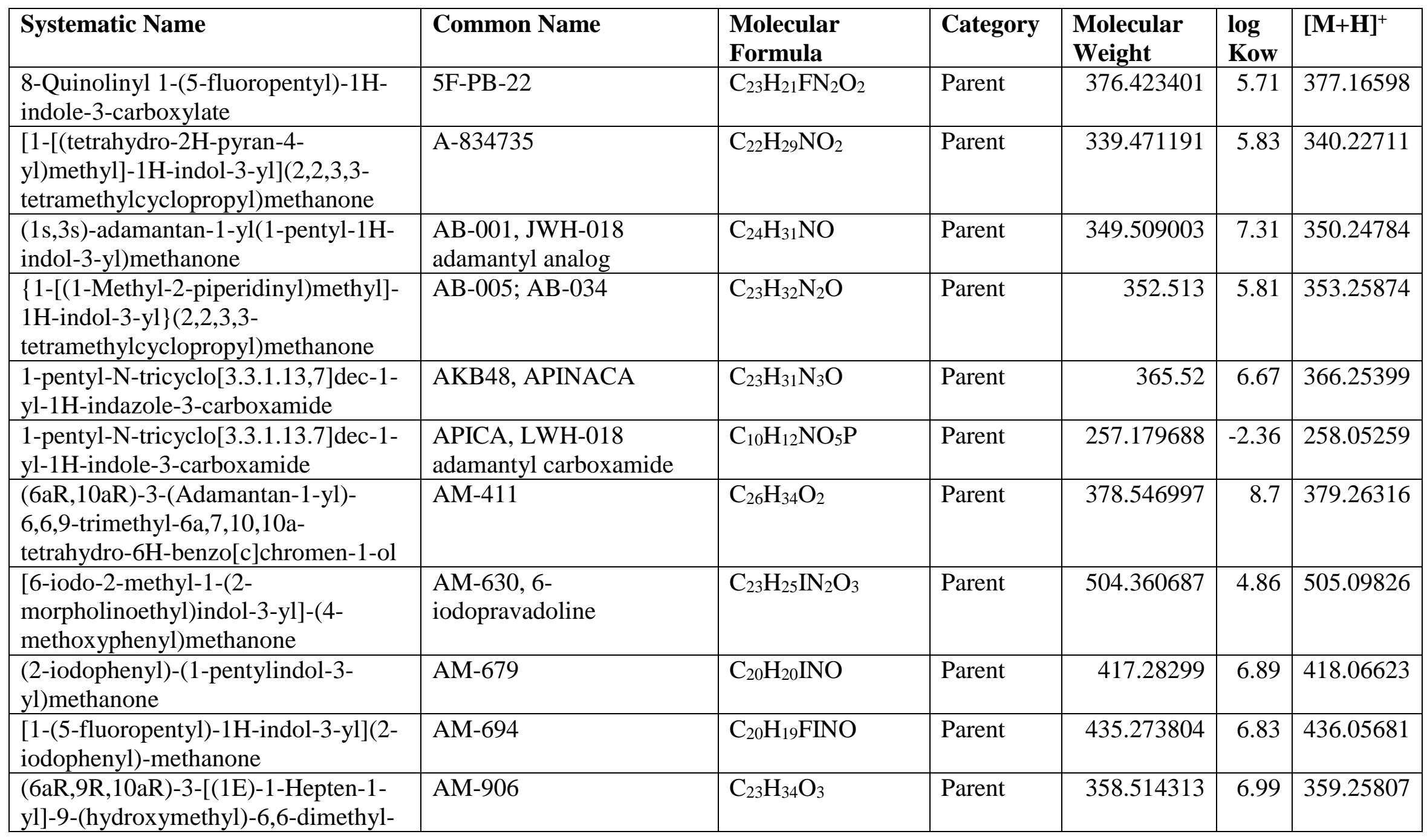




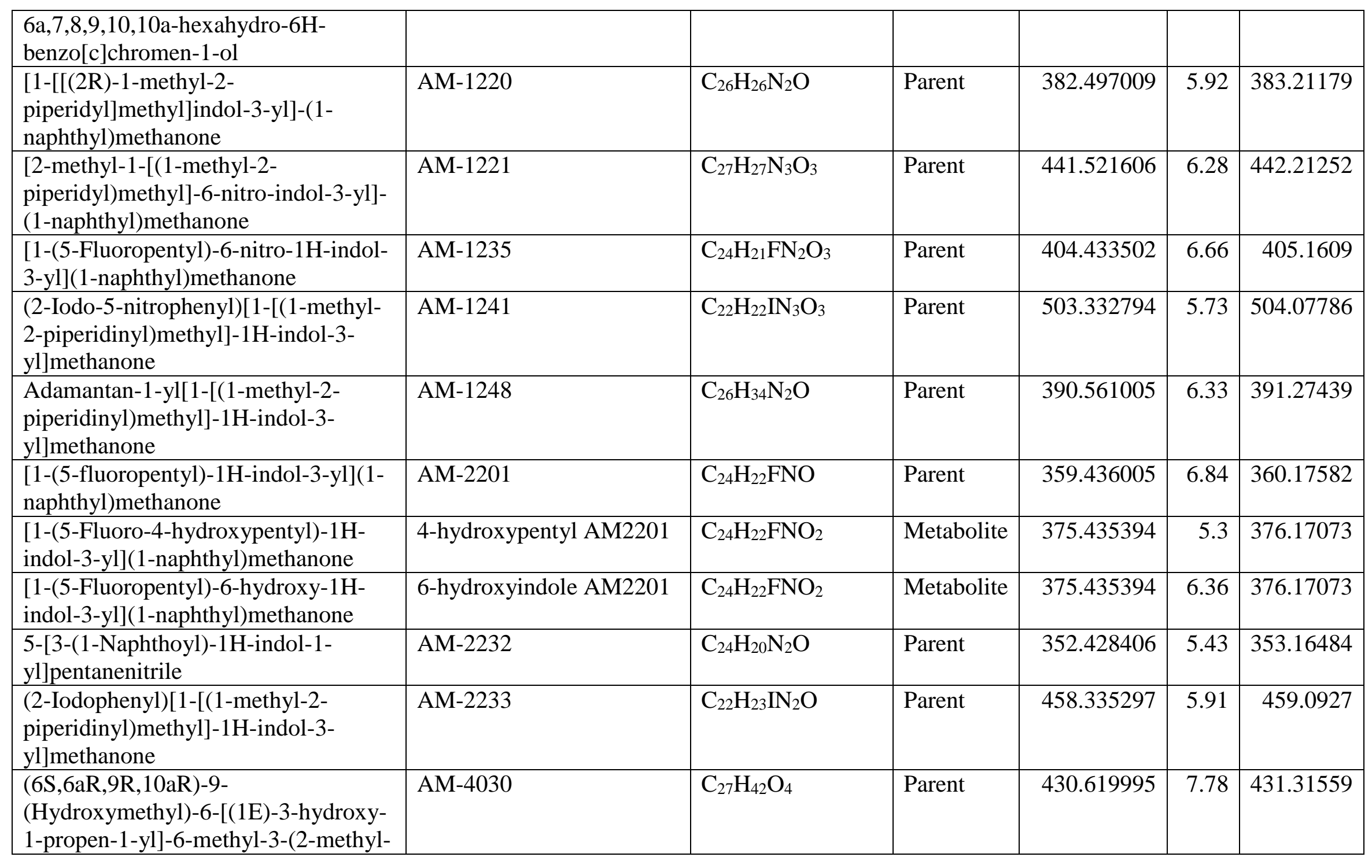




\begin{tabular}{|l|l|l|l|l|l|l|}
\hline $\begin{array}{l}\text { 2-octanyl)-6a,7,8,9,10,10a- } \\
\text { hexahydro-6H-benzo[c]chromen-1-ol }\end{array}$ & & & & & & \\
\hline $\begin{array}{l}\text { 3-\{[(2R)-2-(Hydroxymethyl)-2,3- } \\
\text { dihydro-1H-inden-4-yl]oxy\}phenyl } \\
\text { 4,4,4-trifluoro-1-butanesulfonate }\end{array}$ & BAY 38-7271 & $\mathrm{C}_{20} \mathrm{H}_{21} \mathrm{~F}_{3} \mathrm{O}_{5} \mathrm{~S}$ & Parent & 430.437897 & 4.88 & 431.11346 \\
\hline $\begin{array}{l}\text { 8-Quinolinyl 1-(cyclohexylmethyl)- } \\
\text { 1H-indole-3-carboxylate }\end{array}$ & $\mathrm{BB}-22$; QUCHIC & $\mathrm{C}_{25} \mathrm{H}_{24} \mathrm{~N}_{2} \mathrm{O}_{2}$ & Parent & 384.470306 & 6.56 & 385.19105 \\
\hline $\begin{array}{l}\text { 1-Naphthyl[4-(pentyloxy)-1- } \\
\text { naphthyl]methanone }\end{array}$ & $\mathrm{CB}-13$; CRA-13 & $\mathrm{C}_{26} \mathrm{H}_{24} \mathrm{O}_{2}$ & Parent & 368.46759 & 7.54 & 369.18491 \\
\hline $\begin{array}{l}\text { N-Cyclopropyl-11-(3-hydroxy-5- } \\
\text { pentylphenoxy)undecanamide }\end{array}$ & $\mathrm{CB}-25$ & $\mathrm{C}_{25} \mathrm{H}_{41} \mathrm{NO}_{3}$ & Parent & 403.5979 & 7.79 & 404.31592 \\
\hline $\begin{array}{l}\text { N-Cyclopropyl-11-(2-hexyl-5- } \\
\text { hydroxyphenoxy)undecanamide }\end{array}$ & $\mathrm{CB}-52$ & $\mathrm{C}_{26} \mathrm{H}_{43} \mathrm{NO}_{3}$ & Parent & 417.624512 & 8.28 & 418.33157 \\
\hline $\begin{array}{l}\text { 2-[(1S,3R)-3-Hydroxycyclohexyl]-5- } \\
\text { (2-methyl-2-heptanyl)phenol }\end{array}$ & $\mathrm{CP} 47,497 \mathrm{C} 6$ homologue & $\mathrm{C}_{20} \mathrm{H}_{32} \mathrm{O}_{2}$ & Parent & 304.466888 & 5.97 & 305.24751 \\
\hline $\begin{array}{l}\text { 2-[(1R,3S)-3-Hydroxycyclohexyl]-5- } \\
\text { (2-methyl-2-octanyl)phenol }\end{array}$ & $\mathrm{CP} 47,497 \mathrm{C} 8$ homologue & $\mathrm{C}_{22} \mathrm{H}_{36} \mathrm{O}_{2}$ & Parent & 332.519989 & 7.18 & 333.27881 \\
\hline $\begin{array}{l}\text { 2-[(1S,3R)-3-Hydroxycyclohexyl]-5- } \\
\text { (2-methyl-2-decanyl)phenol }\end{array}$ & $\mathrm{CP} 47,497 \mathrm{C} 9$ homologue & $\mathrm{C}_{23} \mathrm{H}_{38} \mathrm{O}_{2}$ & Parent & 346.5466 & 8.16 & 347.29446 \\
\hline $\begin{array}{l}\text { (2S,4S,4aS,6R,8aR)-6- } \\
\text { (Hydroxymethyl)-4-[2-hydroxy-4-(2- } \\
\text { methyl-2-octanyl)phenyl]decahydro- } \\
\text { 2-naphthalenol }\end{array}$ & $\mathrm{CP} \mathrm{55,244}$ & $\mathrm{C}_{26} \mathrm{H}_{42} \mathrm{O}_{3}$ & Parent & 402.313385 & 7.54 & 403.32067 \\
\hline $\begin{array}{l}\text { 2-[(1R,2R,5R)-5-Hydroxy-2-(3- } \\
\text { hydroxypropyl)cyclohexyl]-5-(2- } \\
\text { methyl-2-octanyl)phenol }\end{array}$ & $\mathrm{CP} 55,940$ & & & & & \\
\hline $\begin{array}{l}\text { (4-Ethyl-1-naphthyl)[1-(5- } \\
\text { fluoropentyl)-1H-indol-3- } \\
\text { yl]methanone }\end{array}$ & $\mathrm{EAM-2201}$ & $\mathrm{C}_{24} \mathrm{H}_{40} \mathrm{O}_{3}$ & Parent & 376.572601 & 6.13 & 377.30502 \\
\hline
\end{tabular}




\begin{tabular}{|c|c|c|c|c|c|c|}
\hline $\begin{array}{l}\text { 3-(1,1'-dimethylheptyl)-6aR,7,10, } \\
\text { 10aR-tetrahydro-1-hydroxy-6,6- } \\
\text { dimethyl-6H-dibenzo[b,d]pyran-9- } \\
\text { methanol }\end{array}$ & HU-210 & $\mathrm{C}_{25} \mathrm{H}_{38} \mathrm{O}_{3}$ & Parent & 386.567413 & 7.44 & 387.28937 \\
\hline $\begin{array}{l}\text { (2-Methyl-1-pentyl-1H-indol-3-yl)(1- } \\
\text { naphthyl)methanone }\end{array}$ & JWH-007 & $\mathrm{C}_{25} \mathrm{H}_{25} \mathrm{NO}$ & Parent & 355.472107 & 7.44 & 356.20089 \\
\hline $\begin{array}{l}\text { (2-Methyl-1-propyl-1H-indol-3-yl)(1- } \\
\text { naphthyl)methanone }\end{array}$ & JWH-015 & $\mathrm{C}_{23} \mathrm{H}_{21} \mathrm{NO}$ & Parent & 327.418915 & 6.46 & 328.16959 \\
\hline $\begin{array}{l}\text { 5-[3-(1-Naphthoyl)-1H-indol-1- } \\
\text { yl]pentanoic acid }\end{array}$ & pentanoic acid JWH-018 & $\mathrm{C}_{24} \mathrm{H}_{23} \mathrm{NO}_{3}$ & Metabolite & 371.428406 & 5.66 & 374.17507 \\
\hline $\begin{array}{l}\text { (5-Hydroxy-1-pentyl-1H-indol-3- } \\
\text { yl)(1-naphthyl)methanone }\end{array}$ & hydroxyindole JWH-018 & $\mathrm{C}_{24} \mathrm{H}_{23} \mathrm{NO}_{2}$ & Metabolite & 357.444885 & 6.42 & 358.18016 \\
\hline $\begin{array}{l}\text { (1-(5-chloropentyl)-1H-indol-3- } \\
\text { yl)(naphthalen-1-yl)methanone }\end{array}$ & $\begin{array}{l}\text { JHW-018 N-(5- } \\
\text { chloropentyl) analog }\end{array}$ & $\mathrm{C}_{24} \mathrm{H}_{22} \mathrm{ClNO}$ & Parent & 375.890594 & 7.15 & 376.14627 \\
\hline $\begin{array}{l}\text { (1-Hexyl-1H-indol-3-yl)(1- } \\
\text { naphthyl)methanone }\end{array}$ & JWH-019 & $\mathrm{C}_{25} \mathrm{H}_{25} \mathrm{NO}$ & Parent & 355.472107 & 7.39 & 357.20872 \\
\hline $\begin{array}{l}\text { 1-Naphthyl[1-(4-penten-1-yl)-1H- } \\
\text { indol-3-yl]methanone }\end{array}$ & JWH-022 & $\mathrm{C}_{24} \mathrm{H}_{21} \mathrm{NO}$ & Parent & 339.429596 & 6.76 & 340.16959 \\
\hline
\end{tabular}




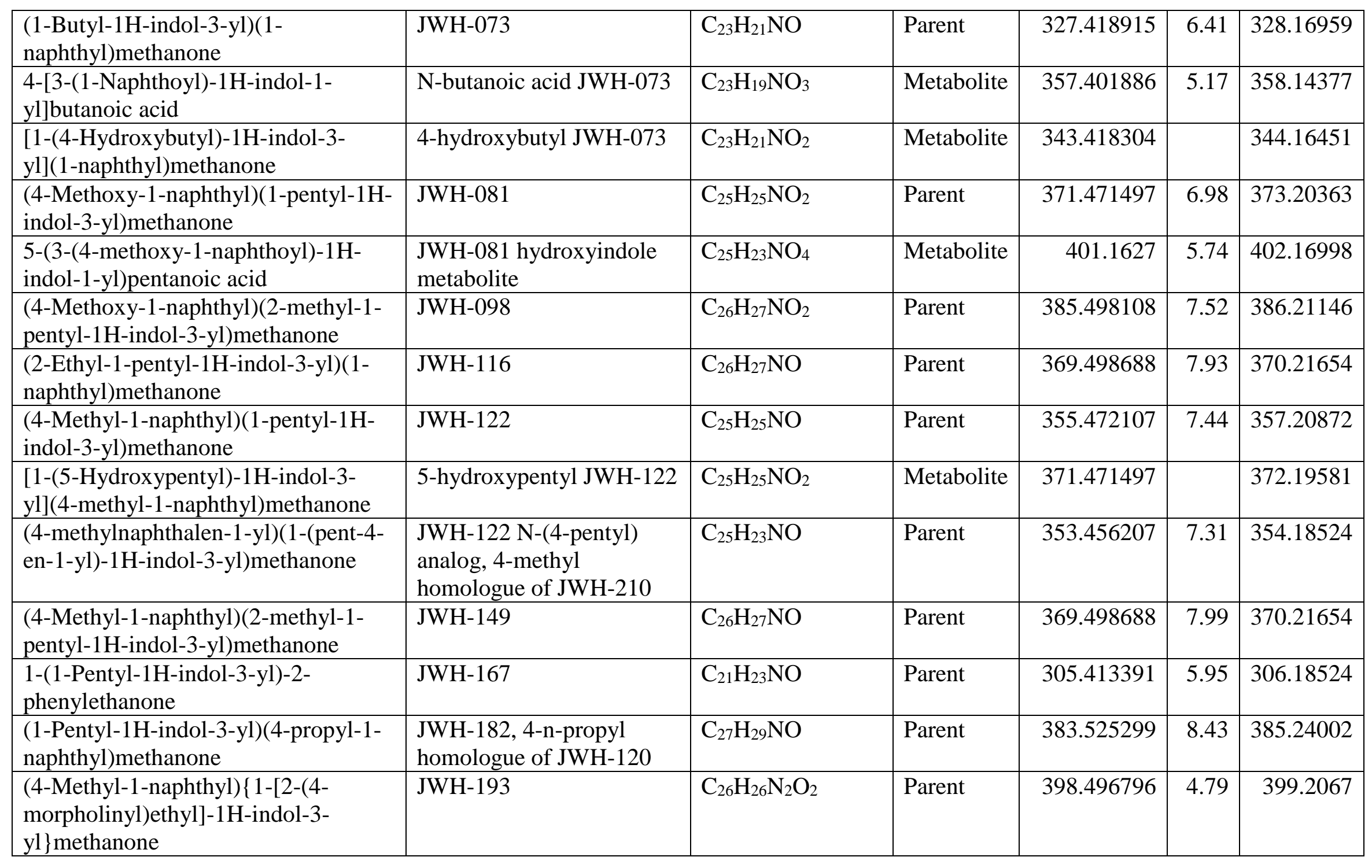




\begin{tabular}{|c|c|c|c|c|c|c|}
\hline $\begin{array}{l}\text { (4-Methoxy-1-naphthyl) }\{1-[2-(4- \\
\text { morpholinyl)ethyl]-1H-indol-3- } \\
\text { yl \}methanone }\end{array}$ & JWH-198 & $\mathrm{C}_{26} \mathrm{H}_{26} \mathrm{~N}_{2} \mathrm{O}_{3}$ & Parent & 414.496185 & 4.32 & 415.20162 \\
\hline $\begin{array}{l}\text { \{1-[2-(4-Morpholinyl)ethyl]-1H- } \\
\text { indol-3-yl }\}(1-\text {-naphthyl)methanone }\end{array}$ & JWH-200 & $\mathrm{C}_{25} \mathrm{H}_{24} \mathrm{~N}_{2} \mathrm{O}_{2}$ & Parent & 384.470306 & 4.24 & 385.19105 \\
\hline $\begin{array}{l}\text { [6-hydroxy-1-(2- } \\
\text { morpholinoethyl)indol-3-yl]-(1- } \\
\text { naphthyl)methanone }\end{array}$ & 6-hydroxyindole JWH-200 & $\mathrm{C}_{25} \mathrm{H}_{24} \mathrm{~N}_{2} \mathrm{O}_{3}$ & Metabolite & 400.178693 & & 401.18597 \\
\hline $\begin{array}{l}\text { 2-(2-Chlorophenyl)-1-(1-pentyl-1H- } \\
\text { indol-3-yl)ethanone }\end{array}$ & JWH-203 & $\mathrm{C}_{21} \mathrm{H}_{22} \mathrm{ClNO}$ & Parent & 339.85849 & 6.6 & 340.14627 \\
\hline $\begin{array}{l}\text { (4-Ethyl-1-naphthyl)(1-pentyl-1H- } \\
\text { indol-3-yl)methanone }\end{array}$ & JWH-210 & $\mathrm{C}_{26} \mathrm{H}_{27} \mathrm{NO}$ & Parent & 369.498688 & 7.93 & 370.21654 \\
\hline $\begin{array}{l}\text { (4-Ethyl-1-naphthyl)[1-(5- } \\
\text { hydroxypentyl)-1H-indol-3- } \\
\text { yl]methanone }\end{array}$ & 5-hydroxypentyl JWH-210 & $\mathrm{C}_{26} \mathrm{H}_{27} \mathrm{NO}_{2}$ & Metabolite & 385.498108 & & 386.21146 \\
\hline $\begin{array}{l}\text { 2-(2-Methoxyphenyl)-1-(1-pentyl-1H- } \\
\text { indol-3-yl)ethanone }\end{array}$ & JWH-250 & $\mathrm{C}_{22} \mathrm{H}_{25} \mathrm{NO}_{2}$ & Parent & 335.439392 & 6.04 & 336.19581 \\
\hline $\begin{array}{l}\text { 1-[1-(5-Hydroxypentyl)-1H-indol-3- } \\
\text { yl]-2-(2-methoxyphenyl)ethanone }\end{array}$ & hydroxypentyl JWH-250 & $\mathrm{C}_{22} \mathrm{H}_{25} \mathrm{NO}_{3}$ & Metabolite & 351.438812 & & 352.19072 \\
\hline $\begin{array}{l}5-\{3-[(2-M e t h o x y p h e n y l) a c e t y l]-1 \mathrm{H}- \\
\text { indol-1-yl\}pentanoic acid }\end{array}$ & pentanoic acid JWH-250 & $\mathrm{C}_{22} \mathrm{H}_{23} \mathrm{NO}_{4}$ & Metabolite & 365.422302 & & 366.16998 \\
\hline $\begin{array}{l}\text { 1-(5-Hydroxy-1-pentyl-1H-indol-3- } \\
\text { yl)-2-(2-methoxyphenyl)ethanone }\end{array}$ & 5-hydroxyindole JWH-250 & $\mathrm{C}_{22} \mathrm{H}_{25} \mathrm{NO}_{3}$ & Metabolite & 351.438812 & & 352.19072 \\
\hline $\begin{array}{l}\text { 2-(2-Methylphenyl)-1-(1-pentyl-1H- } \\
\text { indol-3-yl)ethanone }\end{array}$ & JWH-251 & $\mathrm{C}_{22} \mathrm{H}_{25} \mathrm{NO}$ & Parent & 319.440002 & 6.5 & 320.20089 \\
\hline
\end{tabular}




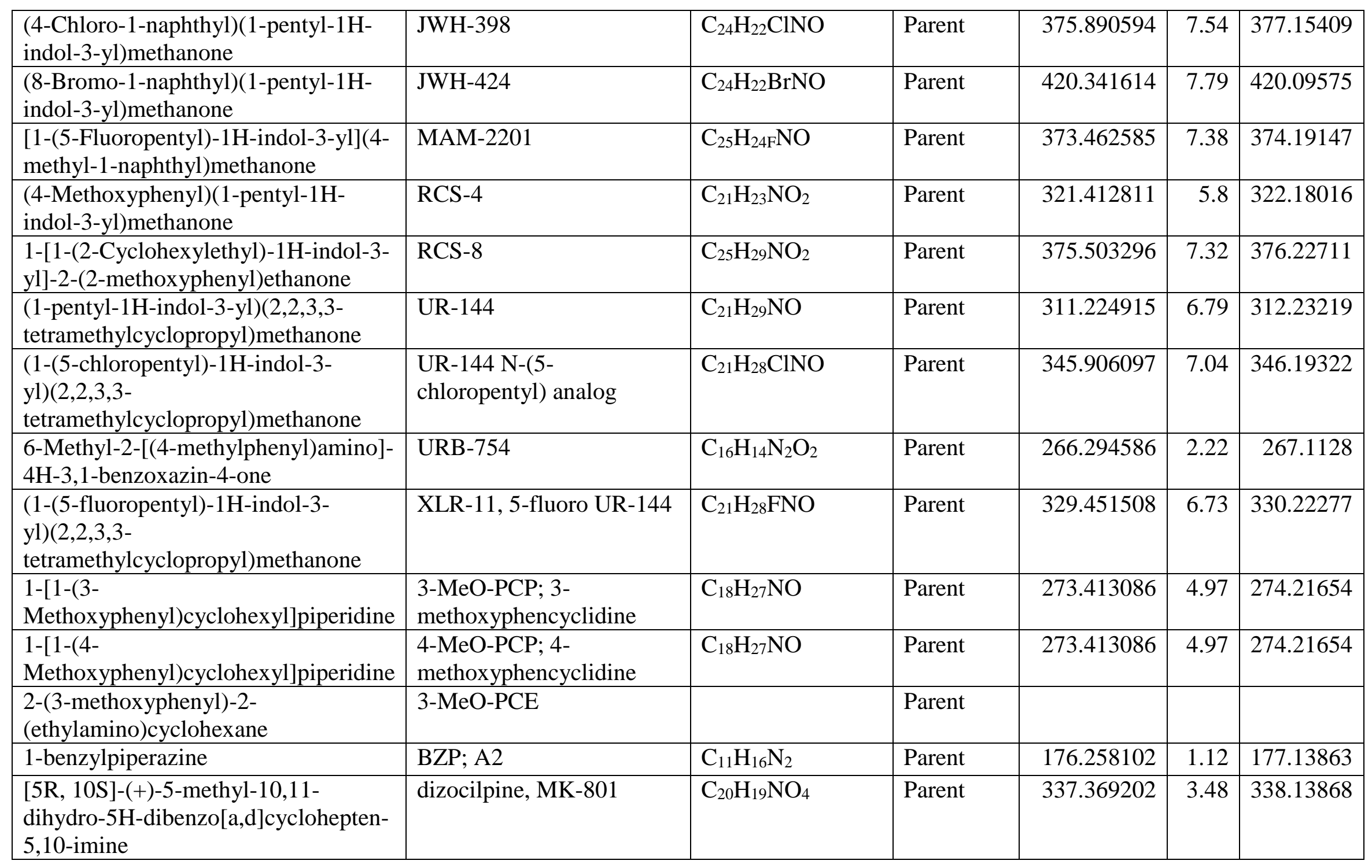




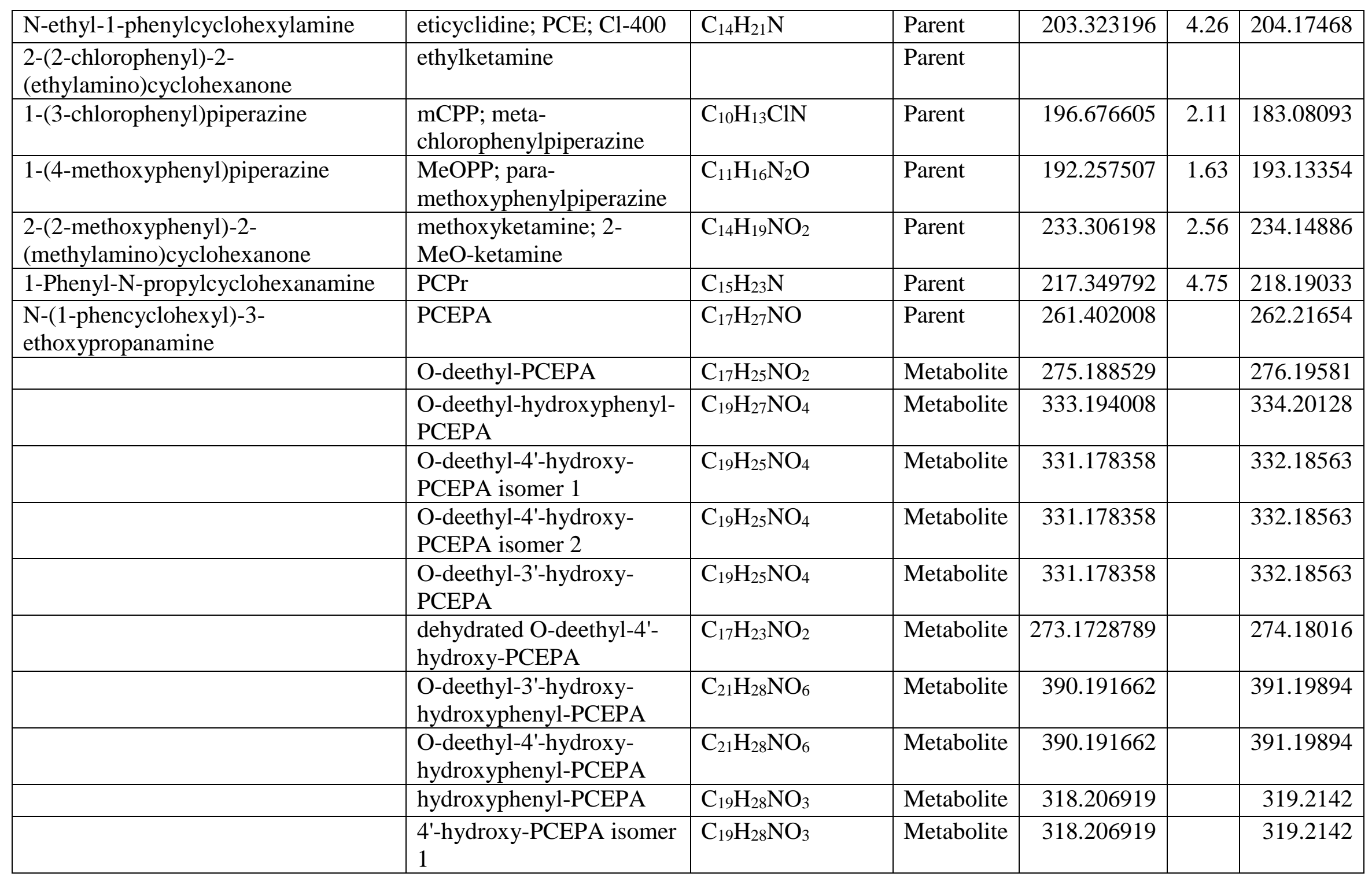




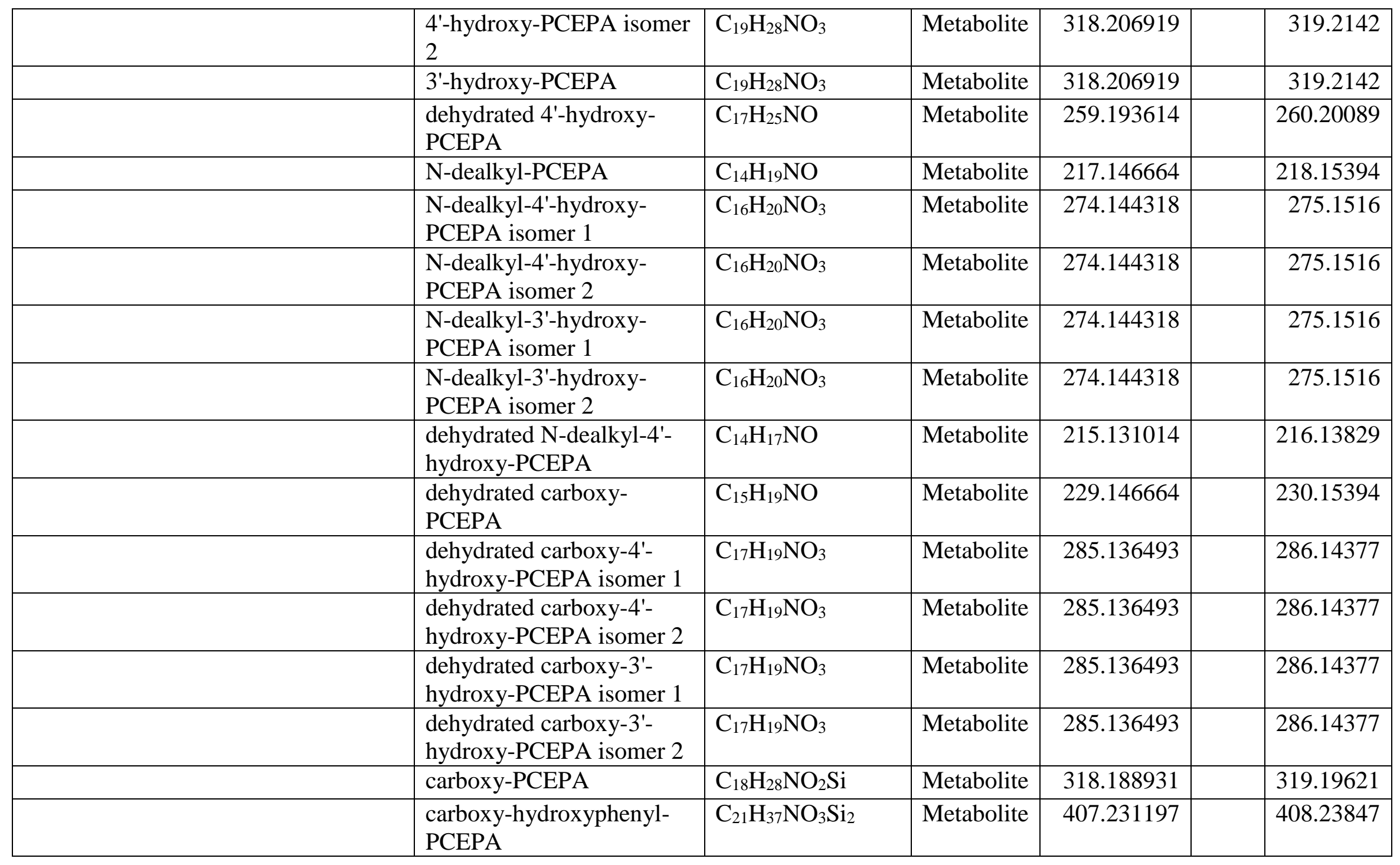




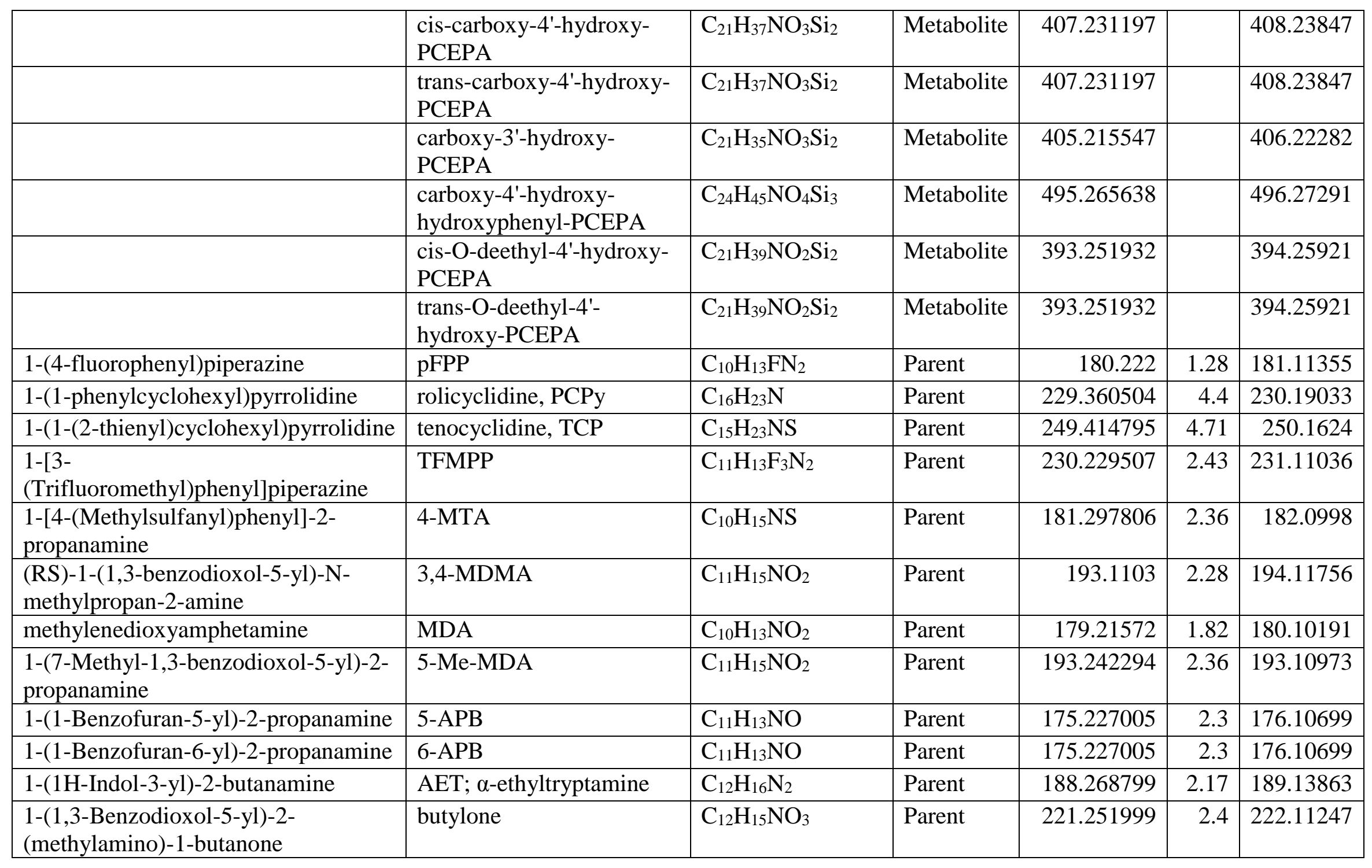




\begin{tabular}{|c|c|c|c|c|c|c|}
\hline $\begin{array}{l}\text { 1-(1,3-Benzodioxol-5-yl)-2- } \\
\text { (ethylamino)-1-propanone }\end{array}$ & ethylone & $\mathrm{C}_{12} \mathrm{H}_{15} \mathrm{NO}_{3}$ & Parent & 221.251999 & 2.4 & 222.11247 \\
\hline $\begin{array}{l}\text { 5,6,7,8-Tetrahydronaphtho[2,3- } \\
\text { d][1,3]dioxol-6-amine }\end{array}$ & MDAT & $\mathrm{C}_{11} \mathrm{H}_{13} \mathrm{NO}_{2}$ & Parent & 191.226395 & 2.25 & 192.10191 \\
\hline $\begin{array}{l}\text { 1-(1,3-Benzodioxol-5-yl)-2- } \\
\text { (methylamino)-1-propanone }\end{array}$ & methylone & $\mathrm{C}_{11} \mathrm{H}_{13} \mathrm{NO}_{3}$ & Parent & 207.2258 & 1.91 & 208.09682 \\
\hline $\begin{array}{l}\text { 1-(3-Methoxy-4-methylphenyl)-2- } \\
\text { propanamine }\end{array}$ & MMA & $\mathrm{C}_{11} \mathrm{H}_{17} \mathrm{NO}$ & Parent & 179.258804 & 2.38 & 180.13829 \\
\hline 1-(4-Methoxyphenyl)-2-propanamine & $\begin{array}{l}\text { PMA; para- } \\
\text { methoxyamphetamine; } \\
\text { Death; Dr. Death }\end{array}$ & $\mathrm{C}_{10} \mathrm{H}_{15} \mathrm{NO}$ & Parent & 165.232193 & 1.77 & 166.12264 \\
\hline $\begin{array}{l}\text { 1-(4-Methoxyphenyl)-N-methyl-2- } \\
\text { propanamine }\end{array}$ & PMMA (AC) & $\mathrm{C}_{13} \mathrm{H}_{19} \mathrm{NO}_{2}$ & Metabolite & 221.141579 & & 222.14886 \\
\hline p-hydroxymethamphetamine & Pholedrine (2AC) & $\mathrm{C}_{14} \mathrm{H}_{19} \mathrm{NO}_{3}$ & Metabolite & 249.136493 & & 250.14377 \\
\hline 1-hydroxypholedrine & Oxilofrine (3AC) & $\mathrm{C}_{16} \mathrm{H}_{21} \mathrm{NO}_{5}$ & Metabolite & 307.141973 & & 308.14925 \\
\hline 1-hydroxypholedrine & $\begin{array}{l}\text { O-demethyl-HO-alkyl- } \\
\text { PMMA (3AC) }\end{array}$ & $\mathrm{C}_{16} \mathrm{H}_{21} \mathrm{NO}_{5}$ & Metabolite & 307.141973 & & 308.14925 \\
\hline p-methoxyamphetamine & $\begin{array}{l}\text { nor-PMMA (AC); PMA } \\
\text { (AC) }\end{array}$ & $\mathrm{C}_{12} \mathrm{H}_{17} \mathrm{NO}_{2}$ & Metabolite & 207.125929 & & 208.13321 \\
\hline p-hydroxyamphetamine & $\begin{array}{l}\text { bis-demethyl-PMMA } \\
\text { (2AC) }\end{array}$ & $\mathrm{C}_{13} \mathrm{H}_{17} \mathrm{NO}_{3}$ & Metabolite & 235.120843 & & 236.12812 \\
\hline 3',4'-dihydroxymethamphetamine & $\begin{array}{l}\text { O-demethyl-HO-aryl- } \\
\text { PMMA; di-HO-MA }\end{array}$ & $\mathrm{C}_{16} \mathrm{H}_{21} \mathrm{NO}_{5}$ & Metabolite & 307.141973 & & 308.14925 \\
\hline
\end{tabular}




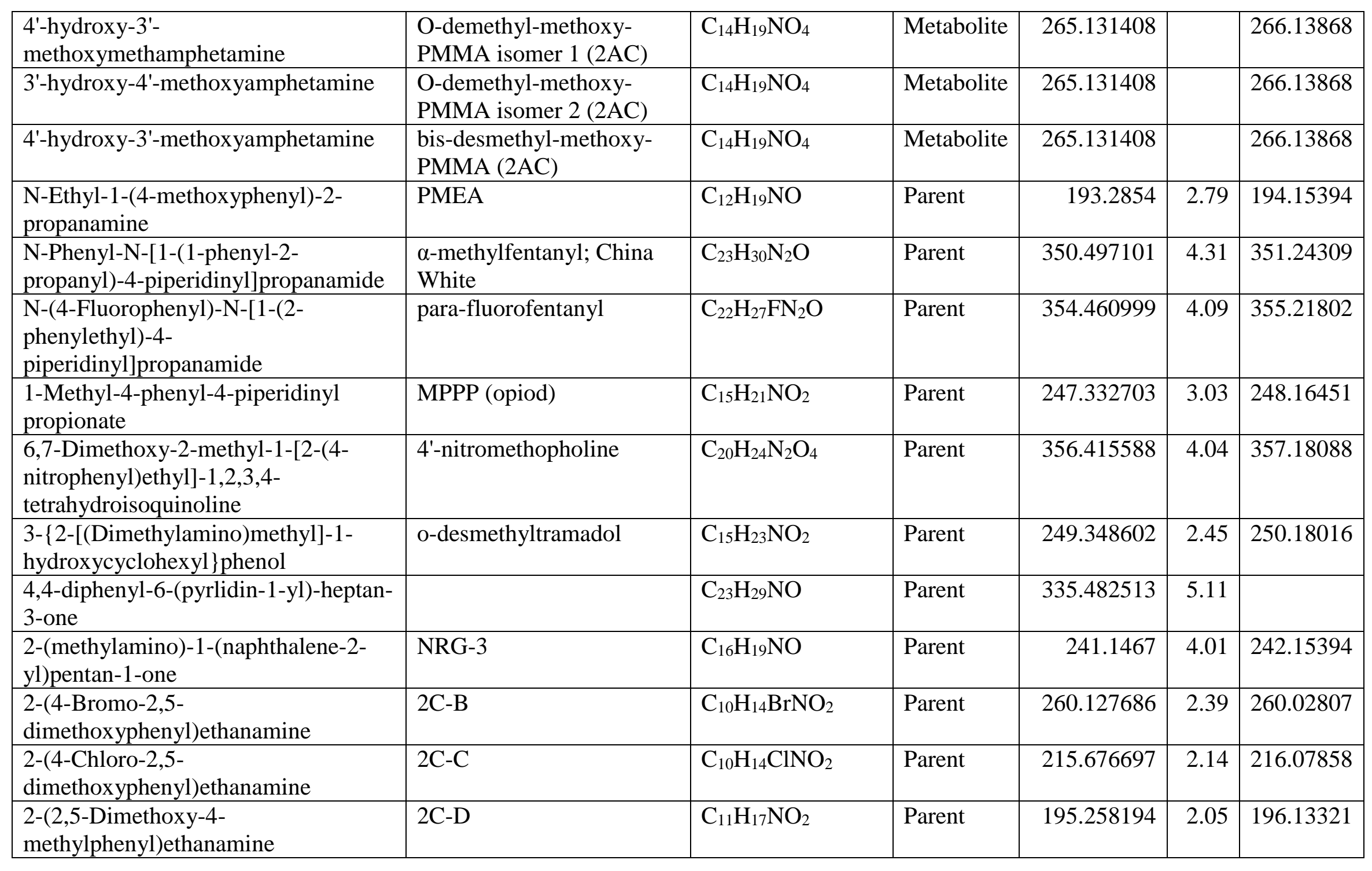




\begin{tabular}{|c|c|c|c|c|c|c|}
\hline $\begin{array}{l}\text { 2-(4-Ethyl-2,5- } \\
\text { dimethoxyphenyl)ethanamine }\end{array}$ & $2 \mathrm{C}-\mathrm{E}$ & $\mathrm{C}_{12} \mathrm{H}_{19} \mathrm{NO}_{2}$ & Parent & 209.284805 & 2.54 & 210.14886 \\
\hline $\begin{array}{l}\text { 2-(4-Iodo-2,5- } \\
\text { dimethoxyphenyl)ethanamine }\end{array}$ & $2 \mathrm{C}-\mathrm{I}$ & $\mathrm{C}_{10} \mathrm{H}_{14} \mathrm{INO}_{2}$ & Parent & 307.128113 & 2.67 & 308.0142 \\
\hline $\begin{array}{l}\text { N-acetyl-2-(4-Iodo-2,5- } \\
\text { dimethoxyphenyl)ethanamine }\end{array}$ & 2C-I (AC) & $\mathrm{C}_{12} \mathrm{H}_{16} \mathrm{INO}_{3}$ & Metabolite & 349.017486 & & 350.02476 \\
\hline $\begin{array}{l}\mathrm{N} \text {-acetyl-acetoxy-4-iodo-methoxy- } \beta \text { - } \\
\text { phenethylamine isomer } 2\end{array}$ & $\begin{array}{l}\text { O-desmethyl-N-acetyl-2C- } \\
\text { I isomer } 2 \text { (AC) }\end{array}$ & $\mathrm{C}_{13} \mathrm{H}_{16} \mathrm{INO}_{4}$ & Metabolite & 377.012401 & & 378.01968 \\
\hline $\begin{array}{l}\text { 2-(4-iodo-2,5-dimethoxyphenyl) ethyl } \\
\text { acetate }\end{array}$ & desamino-HO-2C-I (AC) & $\mathrm{C}_{12} \mathrm{H}_{16} \mathrm{IO}_{4}$ & Metabolite & 351.009327 & & 352.0166 \\
\hline $\begin{array}{l}\text { 2-acetoxy-2-(acetoxy-4-iodo- } \\
\text { methoxyphenyl) ethyl acetate }\end{array}$ & $\begin{array}{l}\text { desamino-di-HO-O- } \\
\text { desmethyl-2C-I (3AC) }\end{array}$ & $\mathrm{C}_{14} \mathrm{H}_{16} \mathrm{IO}_{6}$ & Metabolite & 406.999156 & & 408.00643 \\
\hline $\begin{array}{l}\text { 2-(acetoxy-4-iodo-methoxyphenyl)-2- } \\
\text { oxo-ethyl acetate }\end{array}$ & $\begin{array}{l}\text { desamino-HO-O- } \\
\text { desmethyl-oxo-2C-I } \\
(2 \mathrm{AC})\end{array}$ & $\mathrm{C}_{13} \mathrm{H}_{13} \mathrm{IO}_{6}$ & Metabolite & 391.975681 & & 392.98296 \\
\hline $\begin{array}{l}\mathrm{N} \text {-acetyl-hydroxy-4-iodo-methoxy- } \beta \text { - } \\
\text { phenethylamine isomer } 1\end{array}$ & $\begin{array}{l}\text { O-desmethyl-N-acetyl-2C- } \\
\text { I isomer } 1\end{array}$ & $\mathrm{C}_{11} \mathrm{H}_{14} \mathrm{NIO}_{2}$ & Metabolite & 319.006922 & & 320.0142 \\
\hline $\begin{array}{l}\mathrm{N} \text {-acetyl-hydroxy-4-iodo-methoxy- } \beta \text { - } \\
\text { phenethylamine isomer } 2\end{array}$ & $\begin{array}{l}\text { O-desmethyl-N-acetyl-2C- } \\
\text { I isomer } 2\end{array}$ & $\mathrm{C}_{11} \mathrm{H}_{14} \mathrm{NIO}_{2}$ & Metabolite & 319.006922 & & 320.0142 \\
\hline
\end{tabular}




\begin{tabular}{|c|c|c|c|c|c|c|}
\hline $\begin{array}{l}\text { N-trifluoroacetyl-2-(4-Iodo-2,5- } \\
\text { dimethoxyphenyl)ethanamine }\end{array}$ & 2C-I (TFA) & $\mathrm{C}_{12} \mathrm{H}_{13} \mathrm{NIO}_{3} \mathrm{~F}_{3}$ & Metabolite & 402.989221 & & 403.9965 \\
\hline $\begin{array}{l}\text { N-trifluoroacetyl-trifluoroacetoxy-4- } \\
\text { iodo-methoxy- } \beta \text {-phenethylamine } \\
\text { isomer } 2\end{array}$ & $\begin{array}{l}\text { O-desmethyl-2C-I isomer } \\
2 \text { (2TFA) }\end{array}$ & $\mathrm{C}_{12} \mathrm{H}_{10} \mathrm{NIO}_{4} \mathrm{~F}_{6}$ & Metabolite & 472.955869 & & 473.96315 \\
\hline $\begin{array}{l}\text { methyl-trifluoroacetoxy-4-iodo- } \\
\text { methoxy- } \beta \text {-phenylacetate }\end{array}$ & $\begin{array}{l}\text { desamino-HOOC-O- } \\
\text { desmethyl-2C-I (METFA) }\end{array}$ & $\mathrm{C}_{12} \mathrm{H}_{10} \mathrm{IO}_{5} \mathrm{~F}_{3}$ & Metabolite & 417.952501 & & 418.95978 \\
\hline $\begin{array}{l}\text { 6-iodo-5-methoxy-1-benzofuran- } \\
\text { 2(3H)-one }\end{array}$ & $\begin{array}{l}\text { desamino-HOOC-O- } \\
\text { desmethyl-2C-I }\left(\mathrm{H}_{2} \mathrm{O}\right)\end{array}$ & $\mathrm{C}_{9} \mathrm{H}_{7} \mathrm{IO}_{3}$ & Metabolite & 289.943987 & & 290.95126 \\
\hline $\begin{array}{l}\text { 2-[2,5-Dimethoxy-4- } \\
\text { (methylsulfanyl)phenyl]ethanamine }\end{array}$ & $2 \mathrm{C}-\mathrm{T}$ & $\mathrm{C}_{11} \mathrm{H}_{17} \mathrm{NO}_{2} \mathrm{~S}$ & Parent & 227.323196 & 1.81 & 228.10528 \\
\hline $\begin{array}{l}\text { 2-\{4-[(2-Fluoroethyl)sulfanyl]-2,5- } \\
\text { dimethoxyphenyl }\} \text { ethanamine }\end{array}$ & $2 \mathrm{C}-\mathrm{T}-21$ & $\mathrm{C}_{12} \mathrm{H}_{18} \mathrm{FNO}_{2} \mathrm{~S}$ & Parent & 259.34021 & 2.53 & 260.1115 \\
\hline $\begin{array}{l}\text { 2-(2,5-Dimethoxy-4- } \\
\text { nitrophenyl)ethanamine }\end{array}$ & $2 \mathrm{C}-\mathrm{N}$ & $\mathrm{C}_{10} \mathrm{H}_{14} \mathrm{~N}_{2} \mathrm{O}_{4}$ & Parent & 226.229202 & 1.32 & 227.10263 \\
\hline $\begin{array}{l}\text { 2-(8-Bromo-2,3,6,7- } \\
\text { tetrahydrofuro[2,3-f][1]benzofuran-4- } \\
\text { yl)ethanamine }\end{array}$ & 2CB-FLY & $\mathrm{C}_{12} \mathrm{H}_{14} \mathrm{BrNO}_{2}$ & Parent & 284.149109 & 3.26 & 284.02807 \\
\hline $\begin{array}{l}\text { 3-[2-(Diisopropylamino)ethyl]-1H- } \\
\text { indol-4-yl acetate }\end{array}$ & 4-acetoxy-DiPT & $\mathrm{C}_{18} \mathrm{H}_{26} \mathrm{~N}_{2} \mathrm{O}_{2}$ & Parent & 302.411011 & 3.36 & 303.2067 \\
\hline 4-acetoxy-dimethyltryptamine & 4-acetoxy-DMT & $\mathrm{C}_{14} \mathrm{H}_{18} \mathrm{~N}_{2} \mathrm{O}_{2}$ & Parent & 246.304993 & 1.54 & 247.1441 \\
\hline
\end{tabular}




\begin{tabular}{|c|c|c|c|c|c|c|}
\hline $\begin{array}{l}\text { 3-\{2-[Ethyl(methyl)amino]ethyl }\}-1 \mathrm{H}- \\
\text { indol-4-o }\end{array}$ & 4-HO-MET & $\mathrm{C}_{13} \mathrm{H}_{18} \mathrm{~N}_{2} \mathrm{O}$ & Parent & 218.2948 & 1.95 & 219.14919 \\
\hline $\begin{array}{l}\text { 3-\{2-[Isopropyl(methyl)amino]ethyl }\} \text { - } \\
\text { 1H-indol-4-ol }\end{array}$ & 4-HO-MiPT & $\mathrm{C}_{14} \mathrm{H}_{20} \mathrm{~N}_{2} \mathrm{O}$ & Parent & 232.321396 & 2.37 & 233.16484 \\
\hline $\begin{array}{l}\text { 1-(5-Methoxy-1H-indol-3-yl)-2- } \\
\text { propanamine }\end{array}$ & 5-MeO-AMT & $\mathrm{C}_{12} \mathrm{H}_{16} \mathrm{~N}_{2} \mathrm{O}$ & Parent & 204.126266 & 1.76 & 205.13354 \\
\hline $\begin{array}{l}\mathrm{N} \text {-allyl-N-[2-(5-methoxy-1H-indol-3- } \\
\text { yl)ethyl]prop-2-en-1-amine }\end{array}$ & 5-MeO-DALT & $\mathrm{C}_{17} \mathrm{H}_{22} \mathrm{~N}_{2} \mathrm{O}$ & Parent & 270.368988 & 3.72 & 271.18049 \\
\hline $\begin{array}{l}\text { N-Isopropyl-N-[2-(5-methoxy-1H- } \\
\text { indol-3-yl)ethyl]-2-propanamine }\end{array}$ & $\begin{array}{l}\text { 5-MeO-DiPT, Foxy, Foxy } \\
\text { Methoxy }\end{array}$ & $\mathrm{C}_{17} \mathrm{H}_{26} \mathrm{~N}_{2} \mathrm{O}$ & Parent & 274.401093 & 3.84 & 275.21179 \\
\hline $\begin{array}{l}\text { N-[2-(5-Methoxy-1H-indol-3- } \\
\text { yl)ethyl]-N-methyl-2-propanamine }\end{array}$ & 5-MeO-MiPT & $\mathrm{C}_{15} \mathrm{H}_{22} \mathrm{~N}_{2} \mathrm{O}$ & Parent & 246.348007 & 2.93 & 247.18049 \\
\hline $\begin{array}{l}\text { (8ß)-6-Allyl-N,N-diethyl-9,10- } \\
\text { didehydroergoline-8-carboxamide }\end{array}$ & AL-LAD & $\mathrm{C}_{22} \mathrm{H}_{27} \mathrm{~N}_{3} \mathrm{O}$ & Parent & 349.469299 & 3.11 & 350.22269 \\
\hline $\begin{array}{l}\text { (8ß)-1-Acetyl-N,N-diethyl-6-methyl- } \\
\text { 9,10-didehydroergoline-8- } \\
\text { carboxamide }\end{array}$ & ALD-52 & $\mathrm{C}_{22} \mathrm{H}_{27} \mathrm{~N}_{3} \mathrm{O}_{2}$ & Parent & 365.468689 & 1.95 & 366.2176 \\
\hline $\begin{array}{l}\text { (2R)-1-(8-Bromofuro[2,3- } \\
\text { f][1]benzofuran-4-yl)-2-propanamine }\end{array}$ & Bromodragonfly & $\mathrm{C}_{13} \mathrm{H}_{12} \mathrm{BrNO}_{2}$ & Parent & 294.14389 & 3.74 & 294.01242 \\
\hline $\begin{array}{l}\mathrm{N} \text {-[2-(1H-Indol-3-yl)ethyl]-N- } \\
\text { isopropyl-2-propanamine }\end{array}$ & DiPT & $\mathrm{C}_{16} \mathrm{H}_{24} \mathrm{~N}_{2}$ & Parent & 244.375198 & 3.76 & 245.20123 \\
\hline $\begin{array}{l}\text { 1-(4-Bromo-2,5-dimethoxyphenyl)-2- } \\
\text { propanamine }\end{array}$ & DOB & $\mathrm{C}_{11} \mathrm{H}_{16} \mathrm{BrNO}_{2}$ & Parent & 274.154205 & 2.58 & 274.04372 \\
\hline $\begin{array}{l}\text { 1-(4-Chloro-2,5-dimethoxyphenyl)-2- } \\
\text { propanamine }\end{array}$ & DOC & $\mathrm{C}_{11} \mathrm{H}_{16} \mathrm{ClNO}_{2}$ & Parent & 229.703201 & 2.56 & 230.09423 \\
\hline $\begin{array}{l}\text { 1-(4-Iodo-2,5-dimethoxyphenyl)-2- } \\
\text { propanamine }\end{array}$ & DOI & $\mathrm{C}_{11} \mathrm{H}_{16} \mathrm{INO}_{2}$ & Parent & 321.154694 & 3.08 & 322.02985 \\
\hline $\begin{array}{l}\text { 1-(2,5-Dimethoxy-4-methylphenyl)-2- } \\
\text { propanamine }\end{array}$ & DOM & $\mathrm{C}_{12} \mathrm{H}_{19} \mathrm{NO}_{2}$ & Parent & 209.141586 & 2.46 & 210.14886 \\
\hline
\end{tabular}




\begin{tabular}{|l|l|l|l|l|c|c|}
\hline $\begin{array}{l}\text { N-[2-(1H-Indol-3-yl)ethyl]-N-propyl- } \\
\text { 1-propanamine }\end{array}$ & DPT & $\mathrm{C}_{16} \mathrm{H}_{24} \mathrm{~N}_{2}$ & Parent & 244.375198 & 3.91 & 245.20123 \\
\hline $\begin{array}{l}\text { [(2S,4S)-2,4-Dimethyl-1- } \\
\text { azetidinyl][(83)-6-methyl-9,10- } \\
\text { didehydroergolin-8-yl]methanone }\end{array}$ & $\mathrm{LSZ}$ & $\mathrm{C}_{21} \mathrm{H}_{25} \mathrm{~N}_{3} \mathrm{O}$ & Parent & 335.442688 & 2.5 & 336.20704 \\
\hline $\begin{array}{l}\text { 1-(2,4,5-Trimethoxyphenyl)-2- } \\
\text { propanamine }\end{array}$ & TMA-2 & $\mathrm{C}_{12} \mathrm{H}_{19} \mathrm{NO}_{3}$ & Parent & 225.284195 & 1.74 & 226.14377 \\
\hline $\begin{array}{l}\text { 1-(2,4,6-Trimethoxyphenyl)-2- } \\
\text { propanamine }\end{array}$ & TMA-6 & $\mathrm{C}_{12} \mathrm{H}_{19} \mathrm{NO}_{3}$ & Parent & 225.284195 & 1.57 & 226.14377 \\
\hline $\begin{array}{l}\text { 2-(4-chloro-2,5-dimethoxyphenyl)-N- } \\
\text { (2-methoxybenzyl)ethanamine }\end{array}$ & $\begin{array}{l}\text { 25C-NBOMe, NBOMe- } \\
\text { 2C-C, Pandora }\end{array}$ & $\mathrm{C}_{18} \mathrm{H}_{22} \mathrm{ClNO}_{3}$ & Parent & 335.825195 & 4.4 & 336.1361 \\
\hline $\begin{array}{l}\text { 4-iodo-2,5-dimethoxy-N-[(2- } \\
\text { methoxyphenyl)methyl]- } \\
\text { benzeneethanamine }\end{array}$ & $\begin{array}{l}\text { 25I-NBOMe, NBOMe- } \\
\text { 2C-I, Solaris }\end{array}$ & $\mathrm{C}_{18} \mathrm{H}_{22} \mathrm{INO}_{3}$ & Parent & 427.276611 & 4.92 & 428.07171 \\
\hline $\begin{array}{l}\text { 3-(2,4-Dimethylphenyl)-2-methyl- } \\
\text { 4(3H)-quinazolinone }\end{array}$ & methylmethaqualone & $\mathrm{C}_{17} \mathrm{H}_{16} \mathrm{~N}_{2} \mathrm{O}$ & Parent & 264.321686 & 4.88 & 265.13354 \\
\hline $\begin{array}{l}\text { 3-(2-Bromophenyl)-2-methyl-4(3H)- } \\
\text { quinazolinone }\end{array}$ & GBL; mebroqualone & $\mathrm{C}_{15} \mathrm{H}_{11} \mathrm{BrN}_{2} \mathrm{O}$ & Parent & 315.164612 & 4.67 & 315.01275 \\
\hline $\begin{array}{l}\text { 5-Benzyl-5-butyl-2,4,6(1H,3H,5H)- } \\
\text { pyrimidinetrione }\end{array}$ & GHV; benzylbarbiturate & $\mathrm{C}_{15} \mathrm{H}_{18} \mathrm{~N}_{2} \mathrm{O}_{3}$ & Parent & 274.315002 & 2.8 & 275.13902 \\
\hline $\begin{array}{l}\text { 7-Bromo-5-(2-chlorophenyl)-1,3- } \\
\text { dihydro-2H-1,4-benzodiazepin-2-one }\end{array}$ & GHL; phenazepam & $\mathrm{C}_{15} \mathrm{H}_{10} \mathrm{BrClN}_{2} \mathrm{O}$ & Parent & 349.609711 & 3.2 & 348.97378 \\
\hline $\begin{array}{l}\text { 6,7-Dimethyl-5-phenyl-3,7- } \\
\text { dihydropyrrolo[3,4-e][1,4]diazepin- } \\
\text { 2(1H)-one }\end{array}$ & premazepam & $\mathrm{C}_{15} \mathrm{H}_{15} \mathrm{~N}_{3} \mathrm{O}$ & Parent & 253.299103 & 2.21 & 254.12879 \\
\hline $\begin{array}{l}\text { 4-(2-Chlorophenyl)-2-ethyl-9-methyl- } \\
\text { 6H-thieno[3,2-f][1,2,4]triazolo[4,3- } \\
\text { a][1,4]diazepine }\end{array}$ & etizolam & $\mathrm{C}_{17} \mathrm{H}_{15} \mathrm{ClN}_{4} \mathrm{~S}$ & Parent & 342.845795 & 4.17 & 343.07787 \\
\hline
\end{tabular}




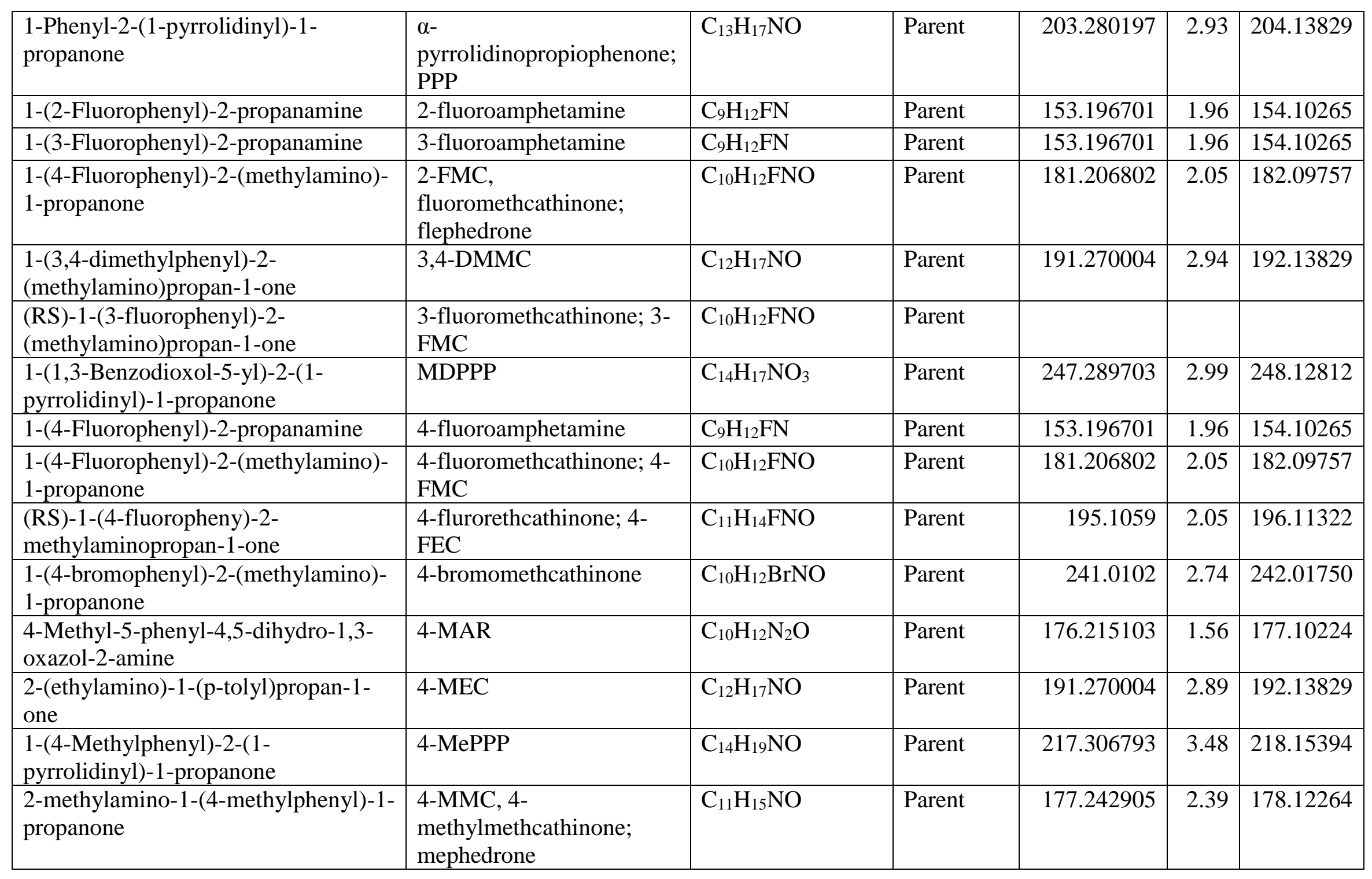




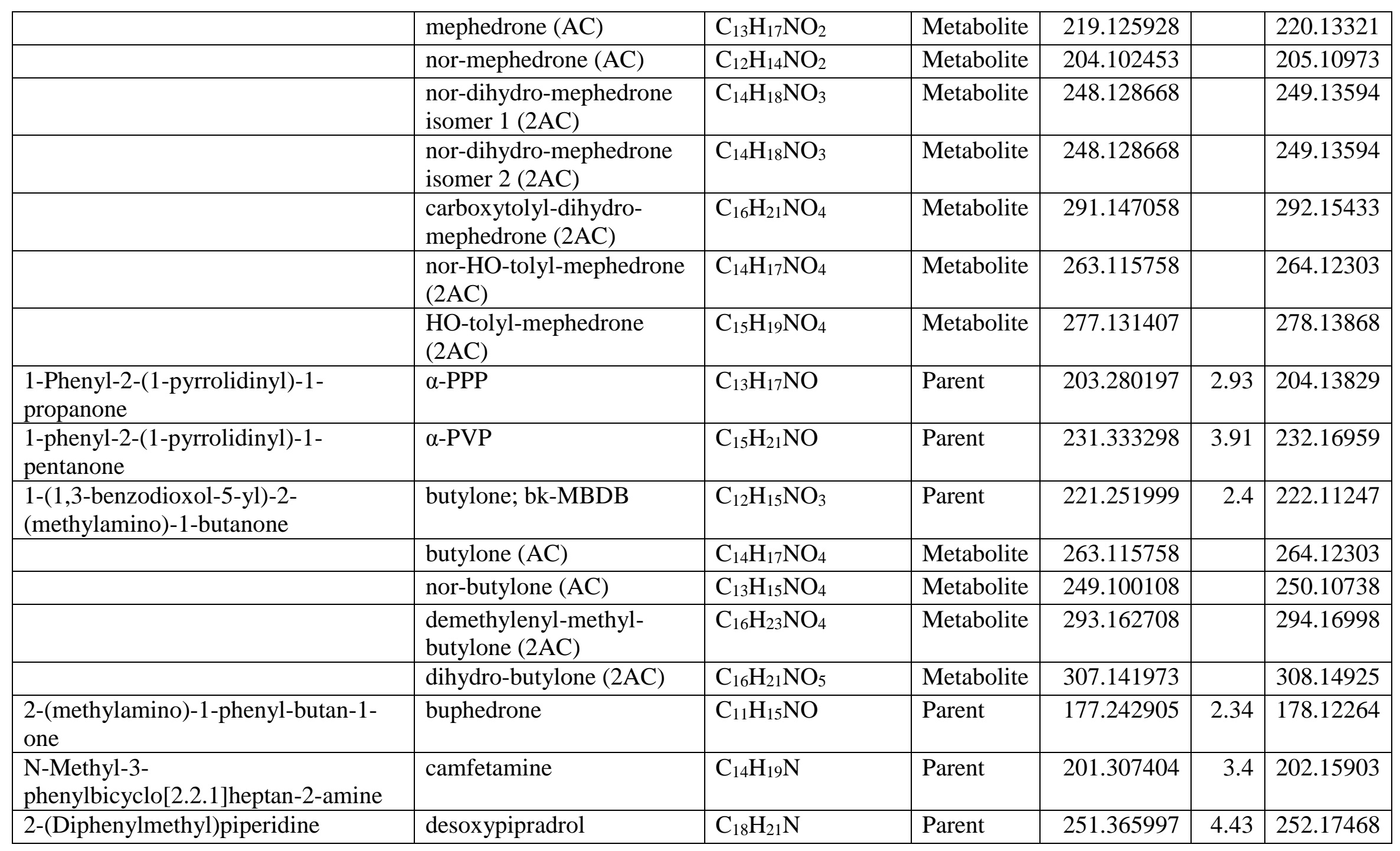




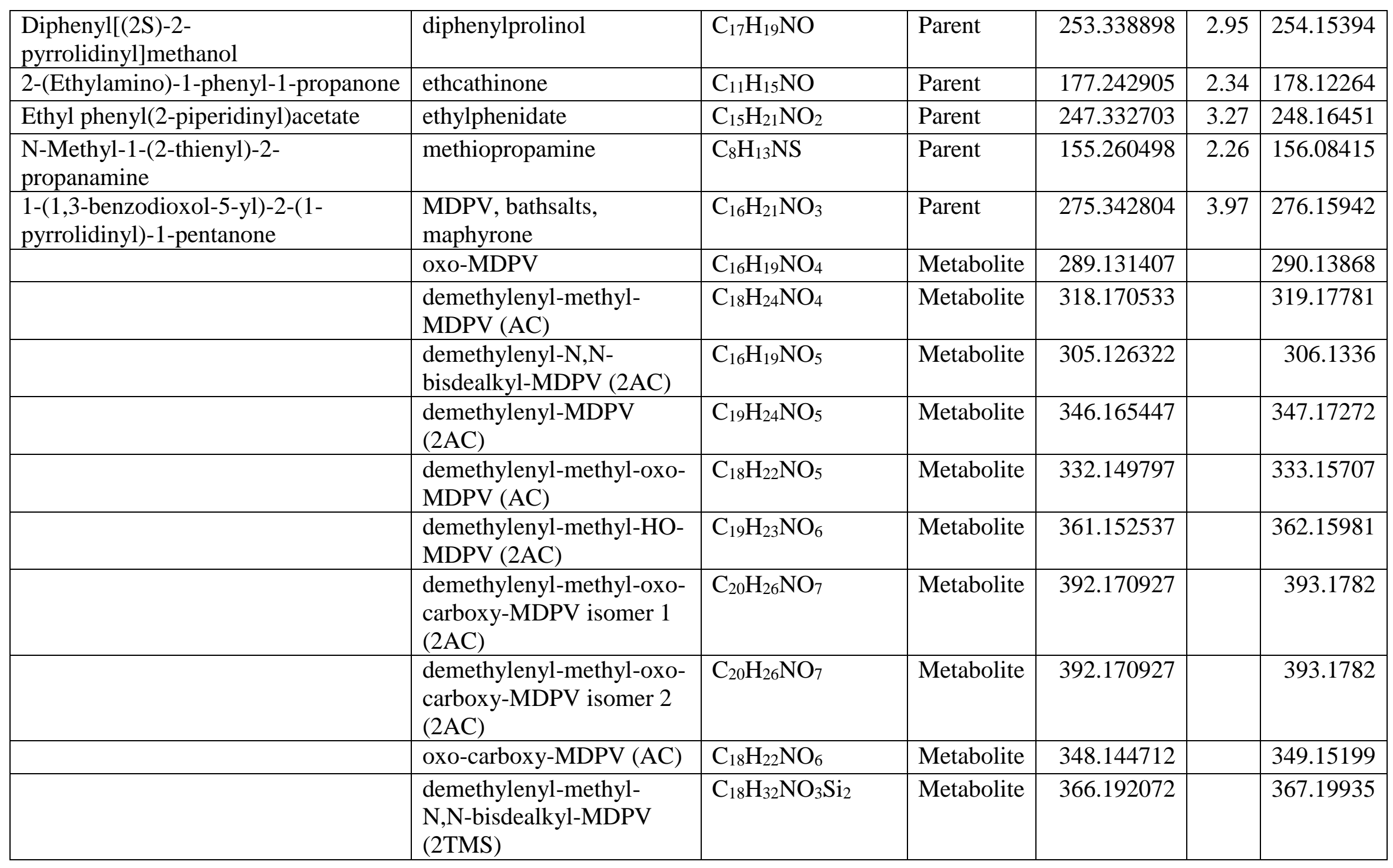









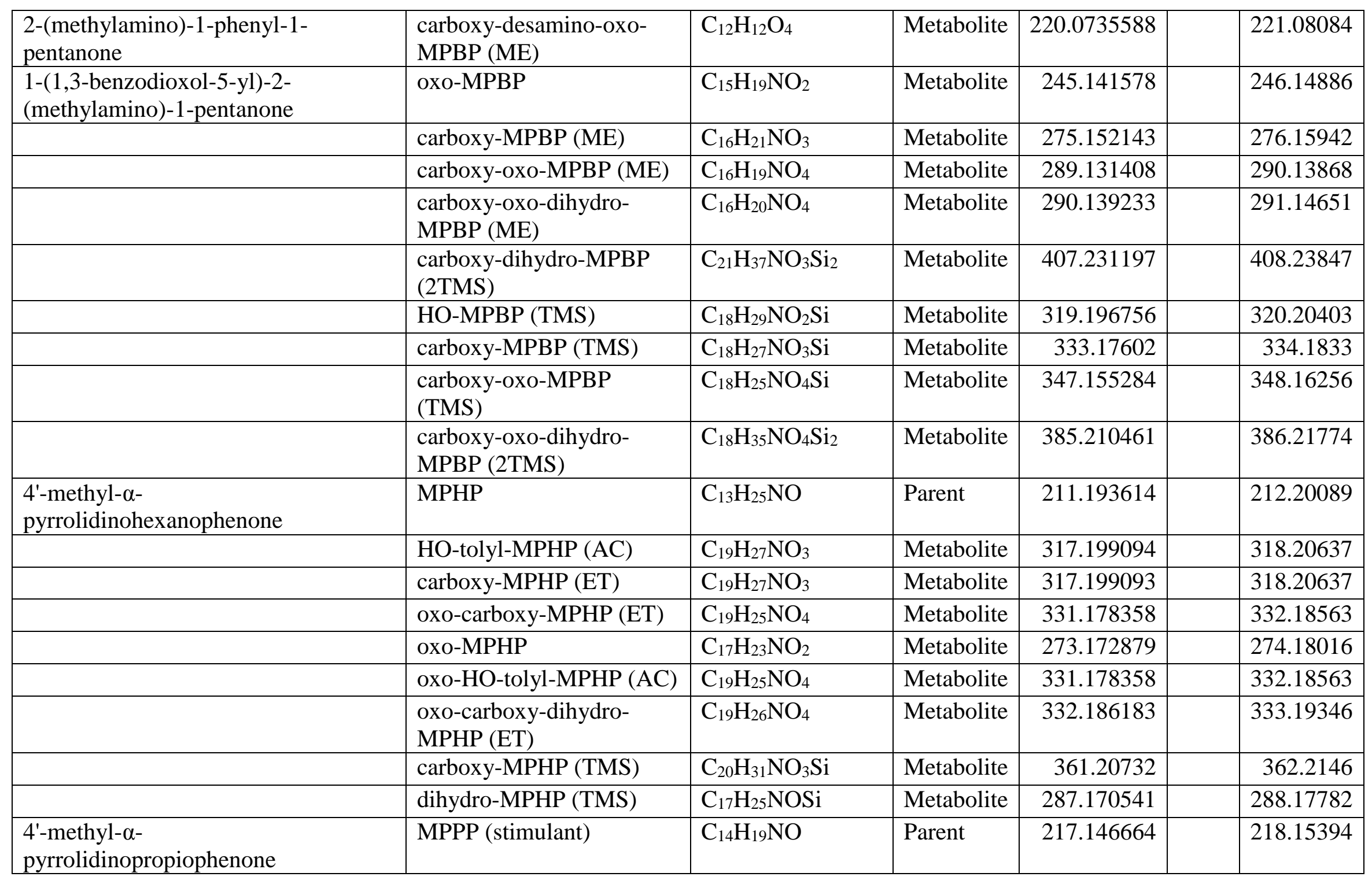




\begin{tabular}{|l|l|l|l|l|l|l|}
\hline & 4'-carboxy-PPP & $\mathrm{C}_{16} \mathrm{H}_{21} \mathrm{NO}_{3}$ & Metabolite & 275.152143 & & 276.15942 \\
\hline & $\begin{array}{l}\text { 2-oxo-4'- } \\
\text { carboxypropiophenone }\end{array}$ & $\mathrm{C}_{12} \mathrm{H}_{12} \mathrm{O}_{4}$ & Metabolite & 220.073558 & & 221.08084 \\
\hline & 4'-carboxybenzoic acid & $\mathrm{C}_{12} \mathrm{H}_{14} \mathrm{O}_{4}$ & Metabolite & 222.089209 & & 223.09649 \\
\hline & 2"-oxo-MPPP & $\mathrm{C}_{14} \mathrm{H}_{17} \mathrm{NO}_{2}$ & Metabolite & 231.125929 & & 232.13321 \\
\hline & 2"-oxo-4'-carboxy-PPP & $\mathrm{C}_{16} \mathrm{H}_{19} \mathrm{NO}_{4}$ & Metabolite & 289.131408 & & 290.13868 \\
\hline
\end{tabular}


APPENDIX 2. IN SILICO PREDICTION OF FRAGMENTATON PATTERNS OF INDIVIDUAL COMPONENTS OF UNKNOWN MIXTURE

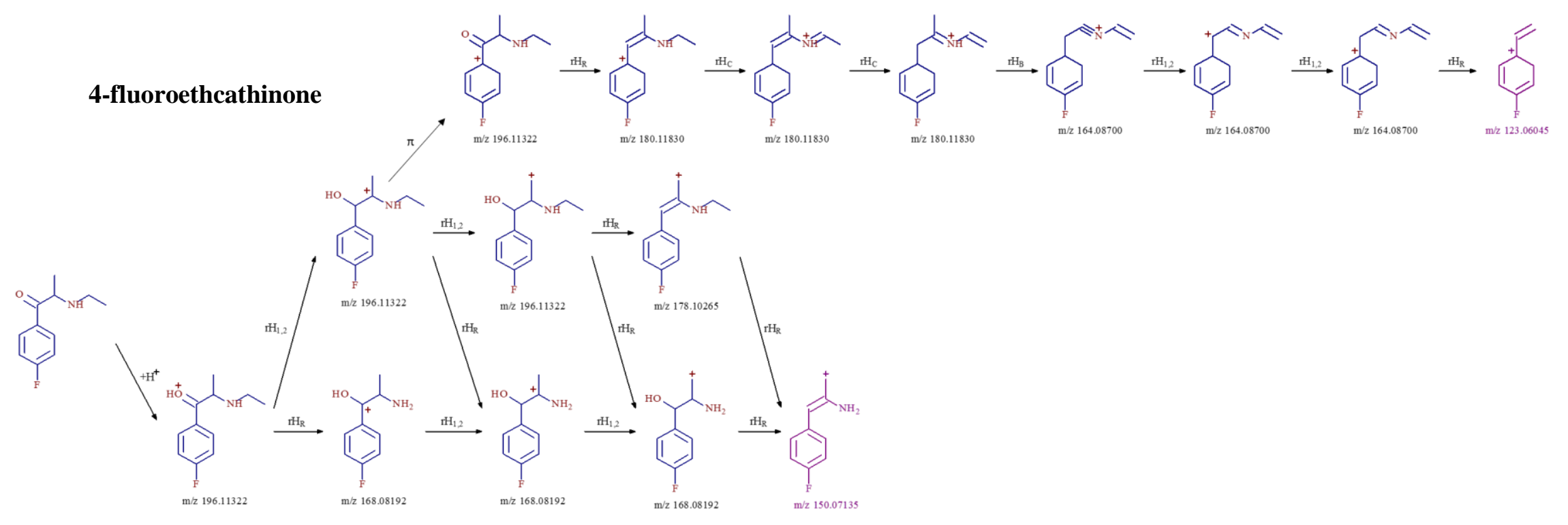




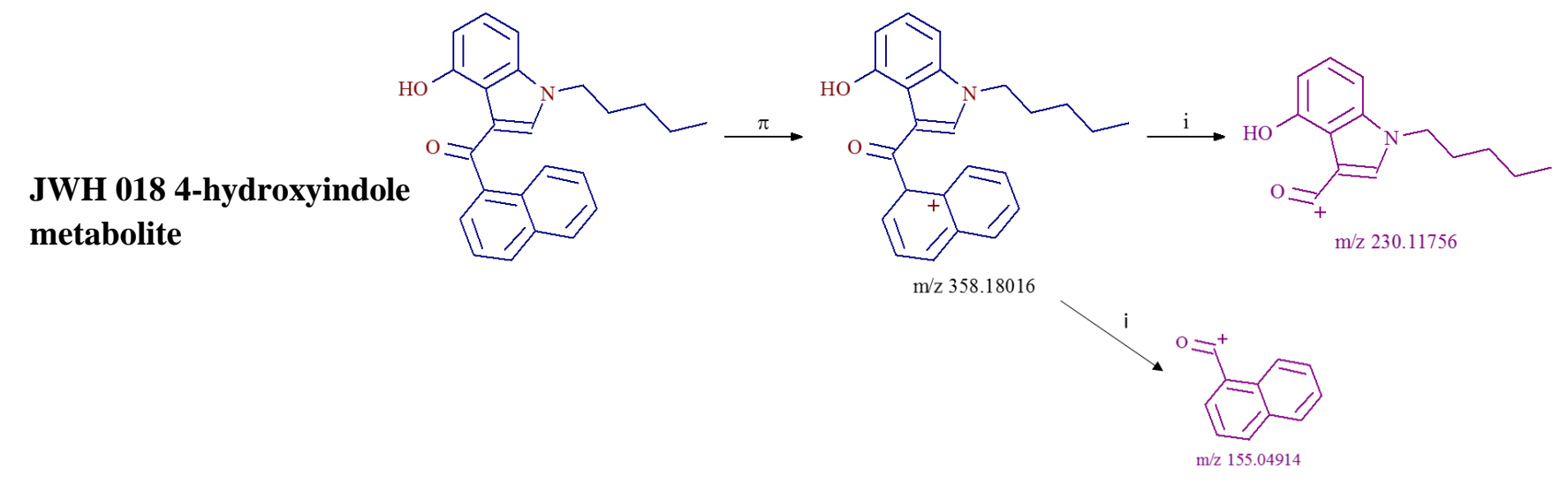




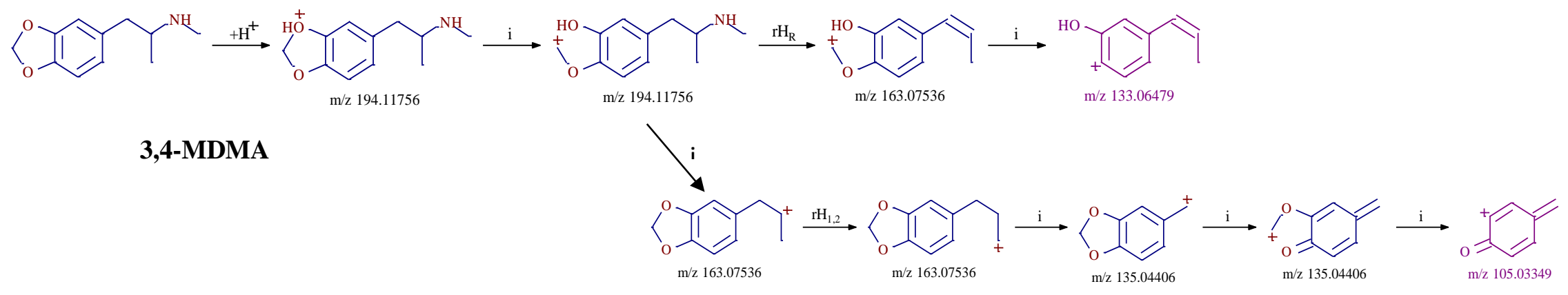




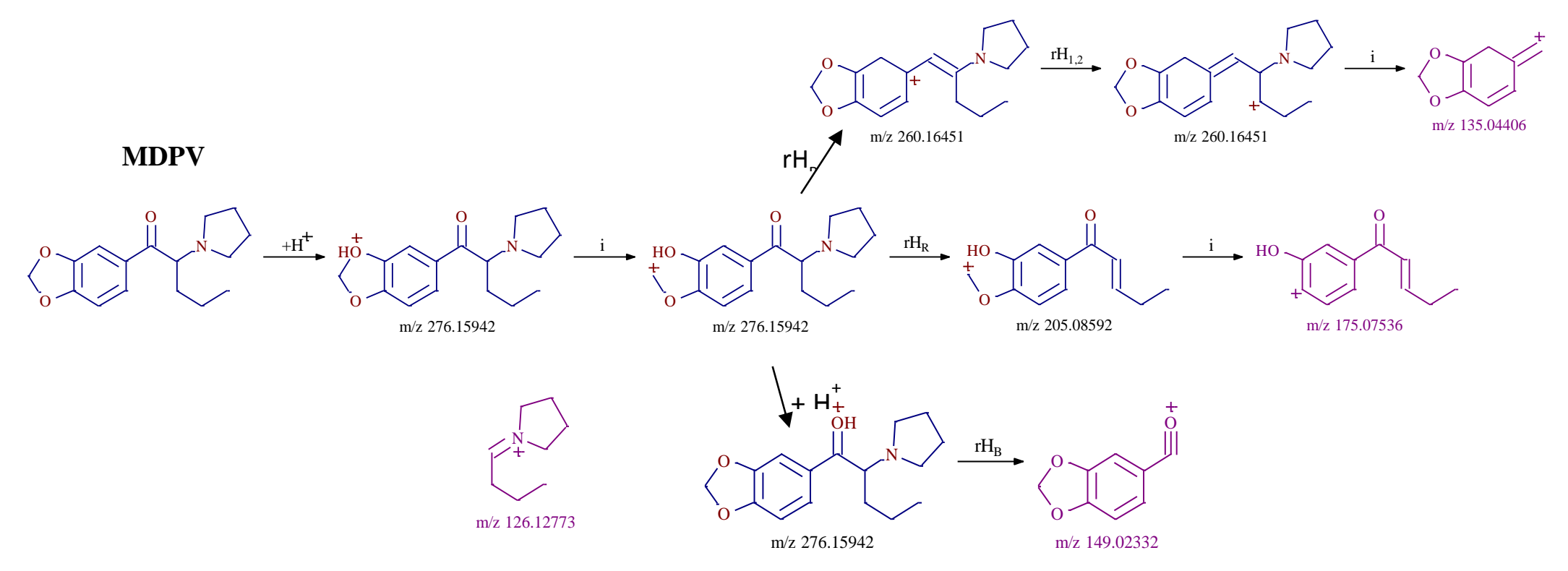




\section{4-Bromomethcathinone}<smiles>C[C+]CNC(C)C(=O)c1ccc(Br)cc1</smiles><smiles>CCCNC(C)C(=[Se])c1ccc(Br)cc1</smiles><smiles>CCCNC(F)C(O)c1ccc(Br)cc1</smiles><smiles>CC(C)[NH2+]CC(C)C(=O)c1ccc(Br)cc1</smiles>

$\mathrm{m} / \mathrm{z} 242.01750$

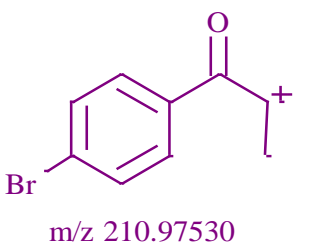




\section{Mephedrone}

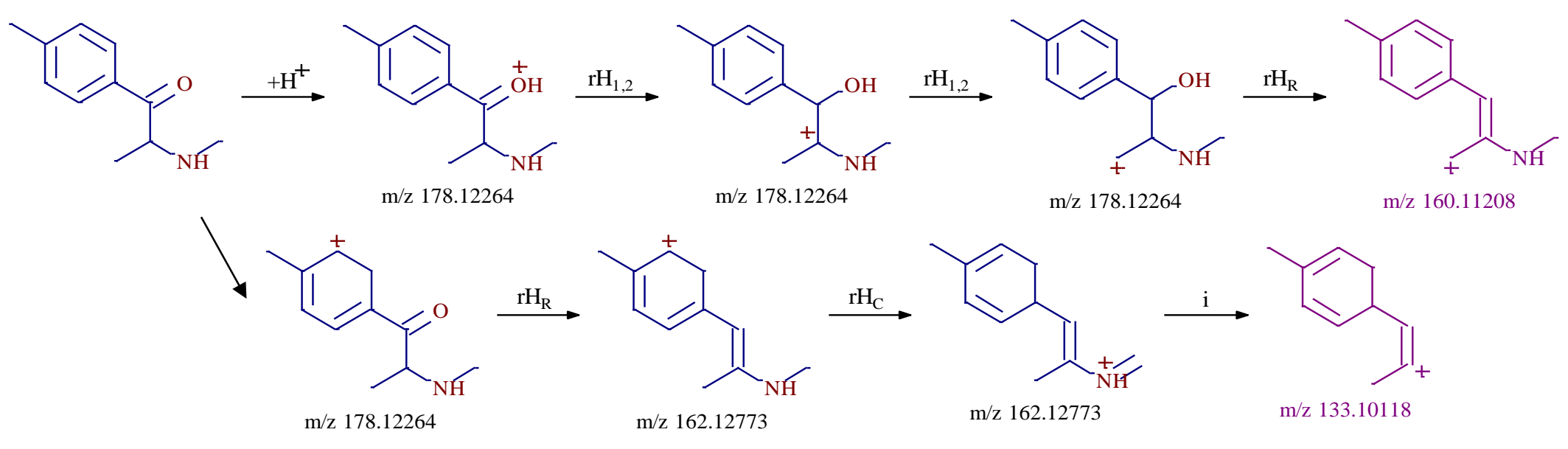


CP 47, 497
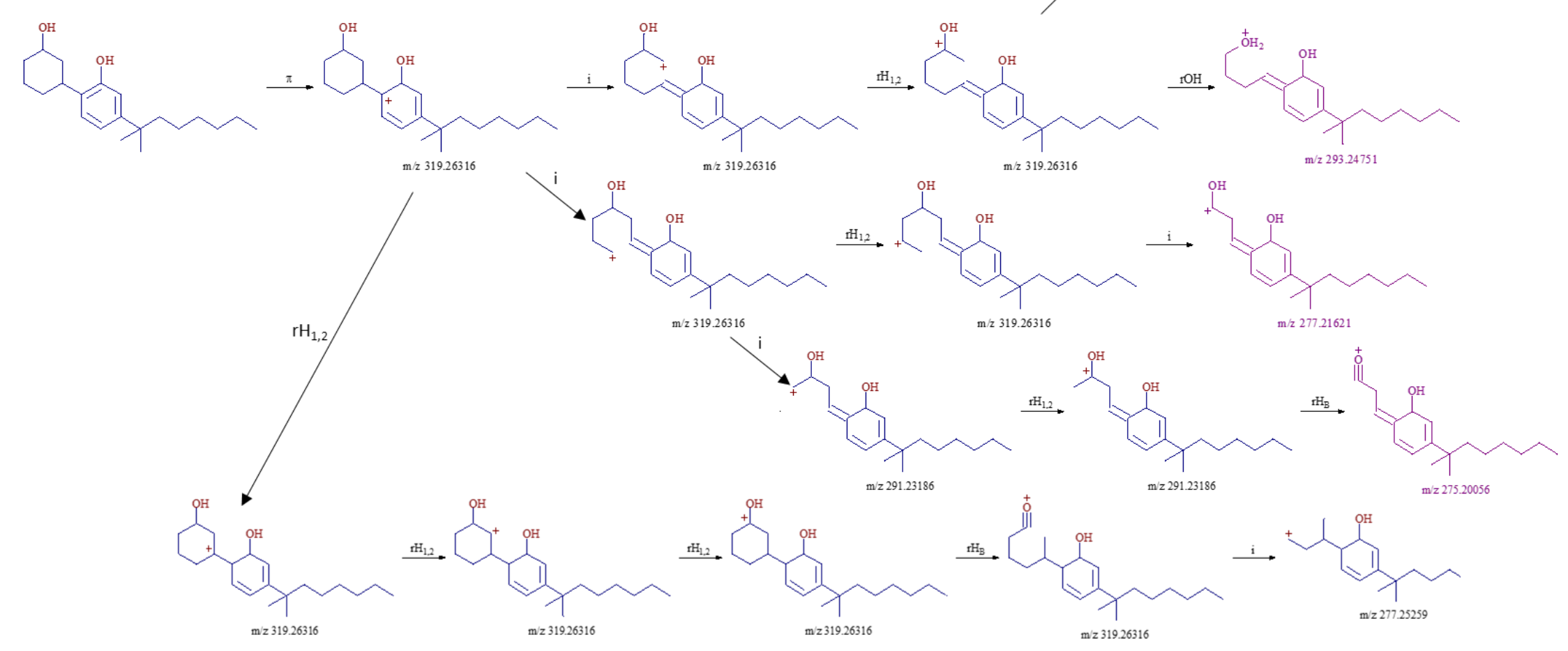


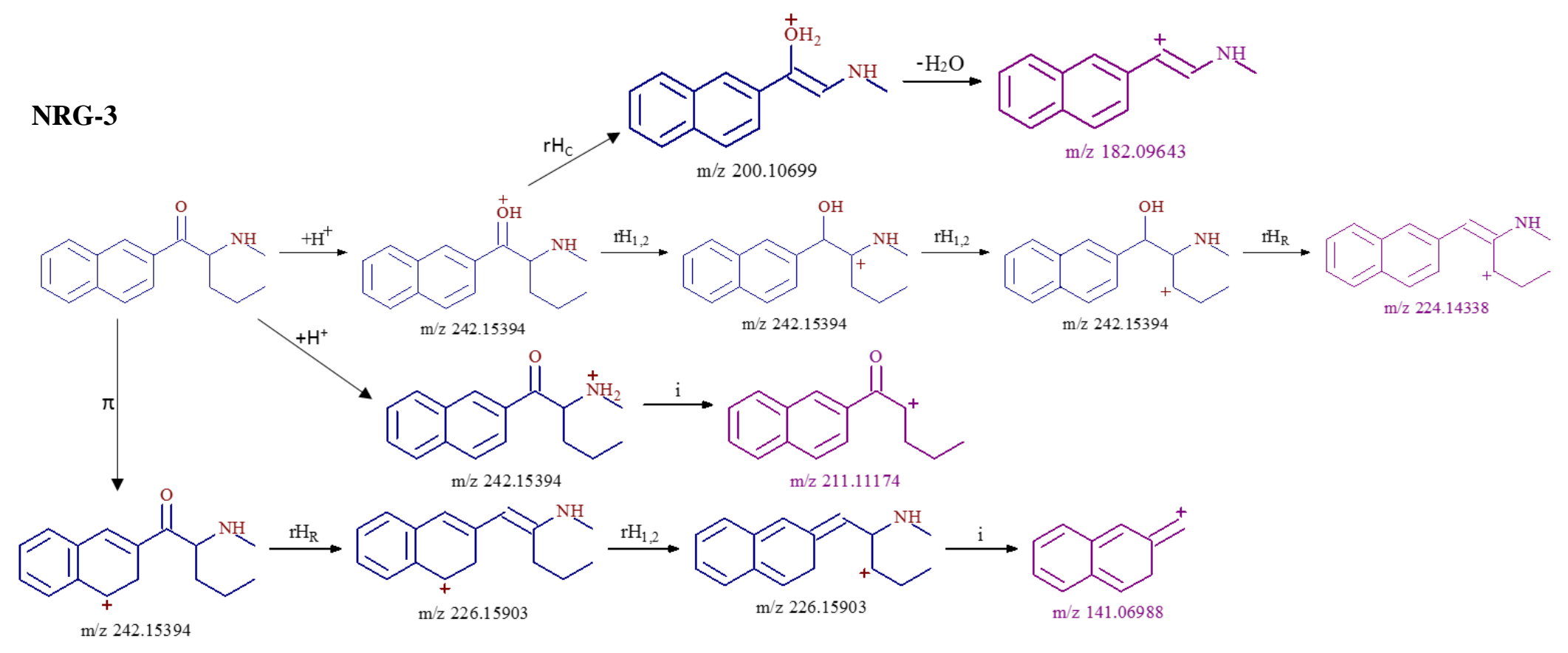




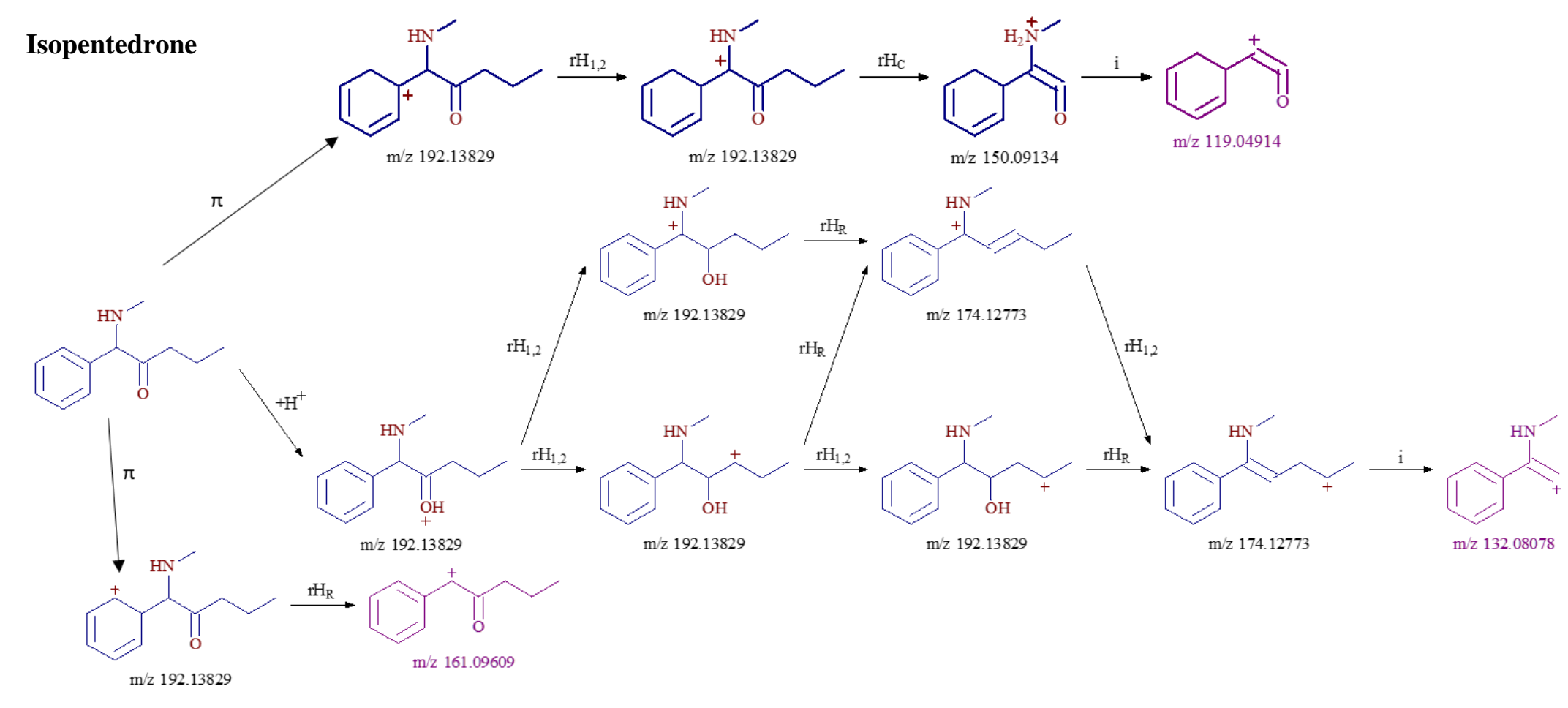




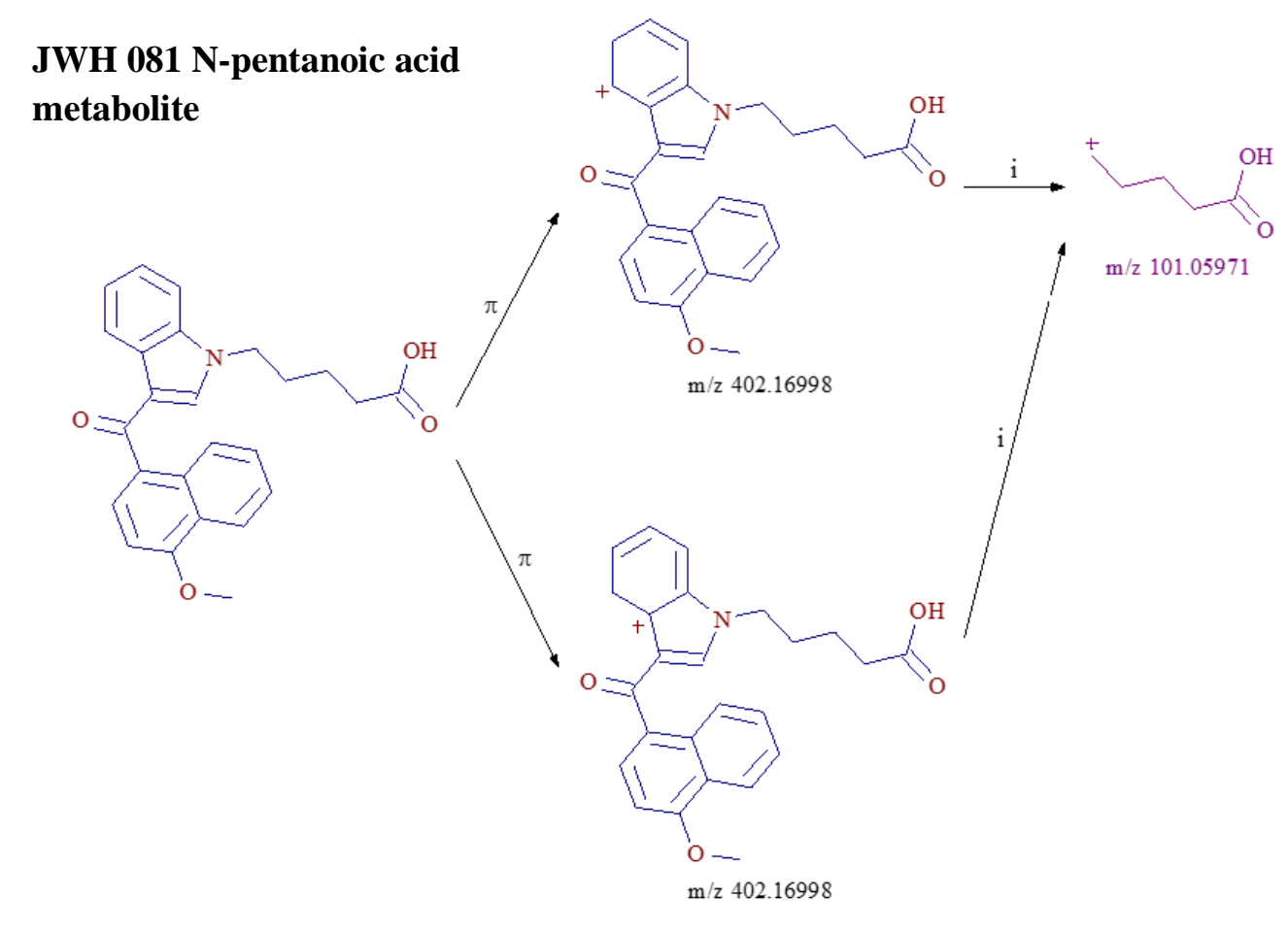




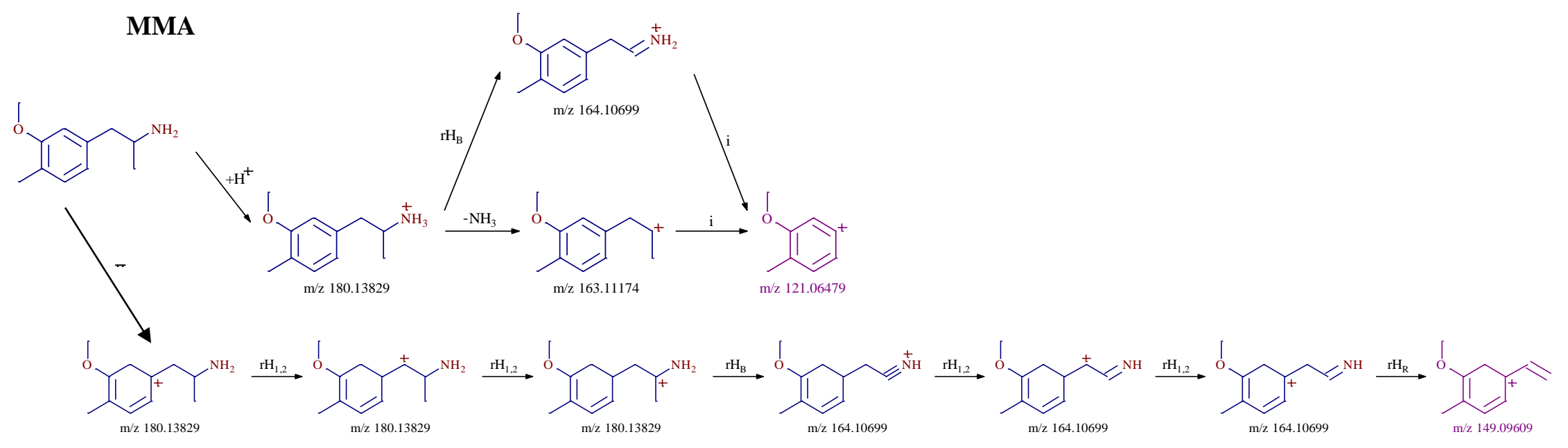




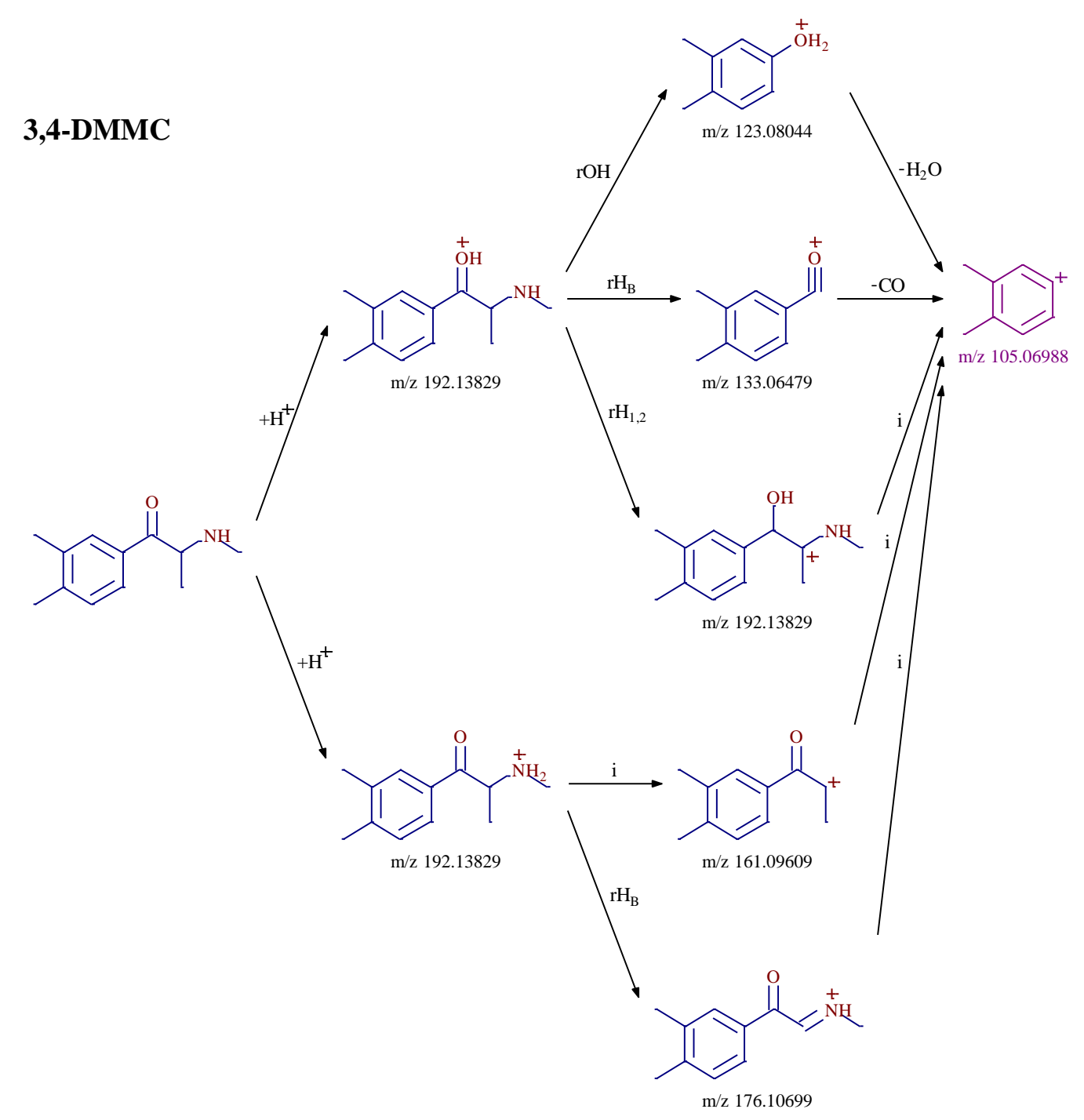




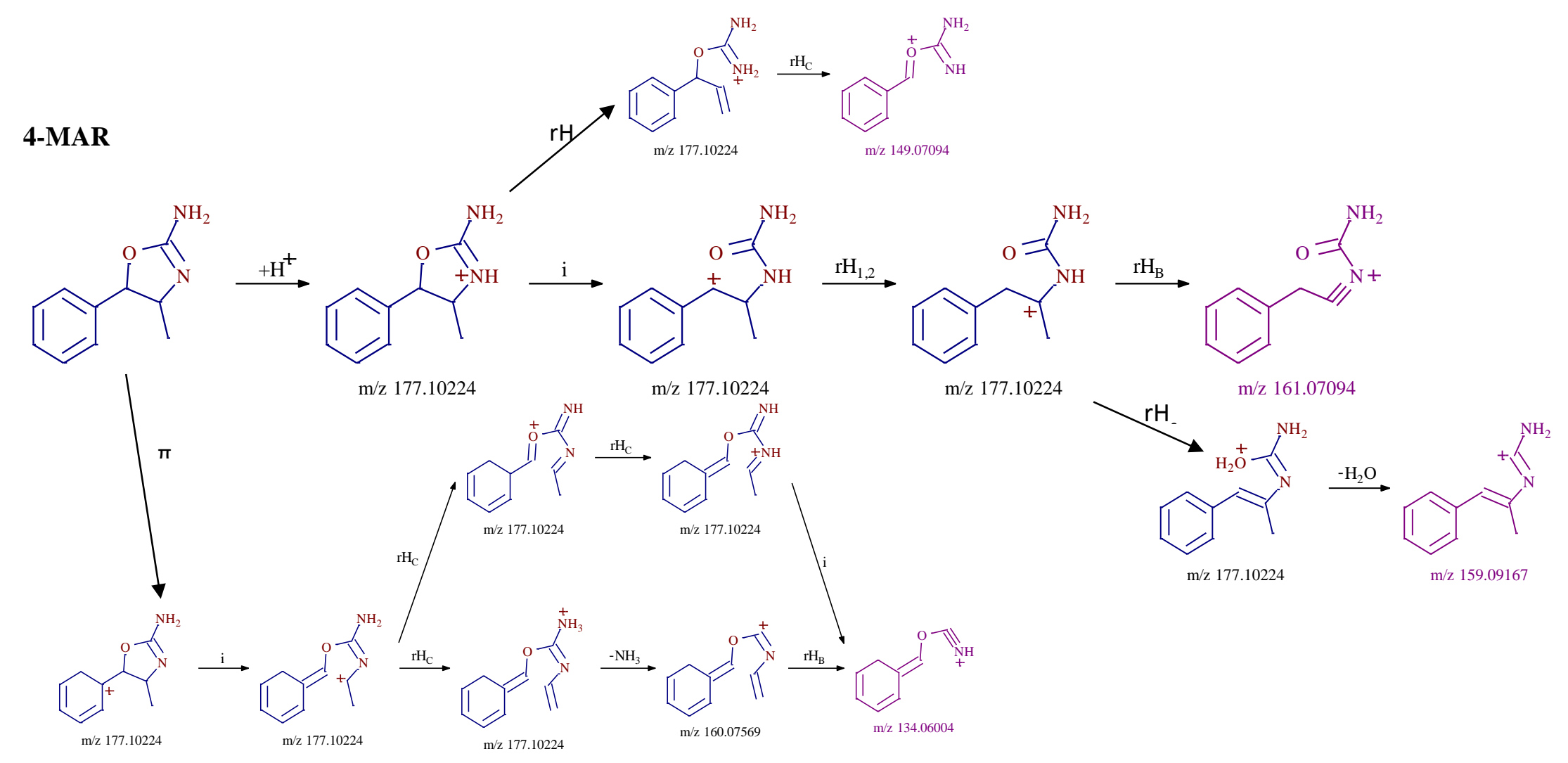




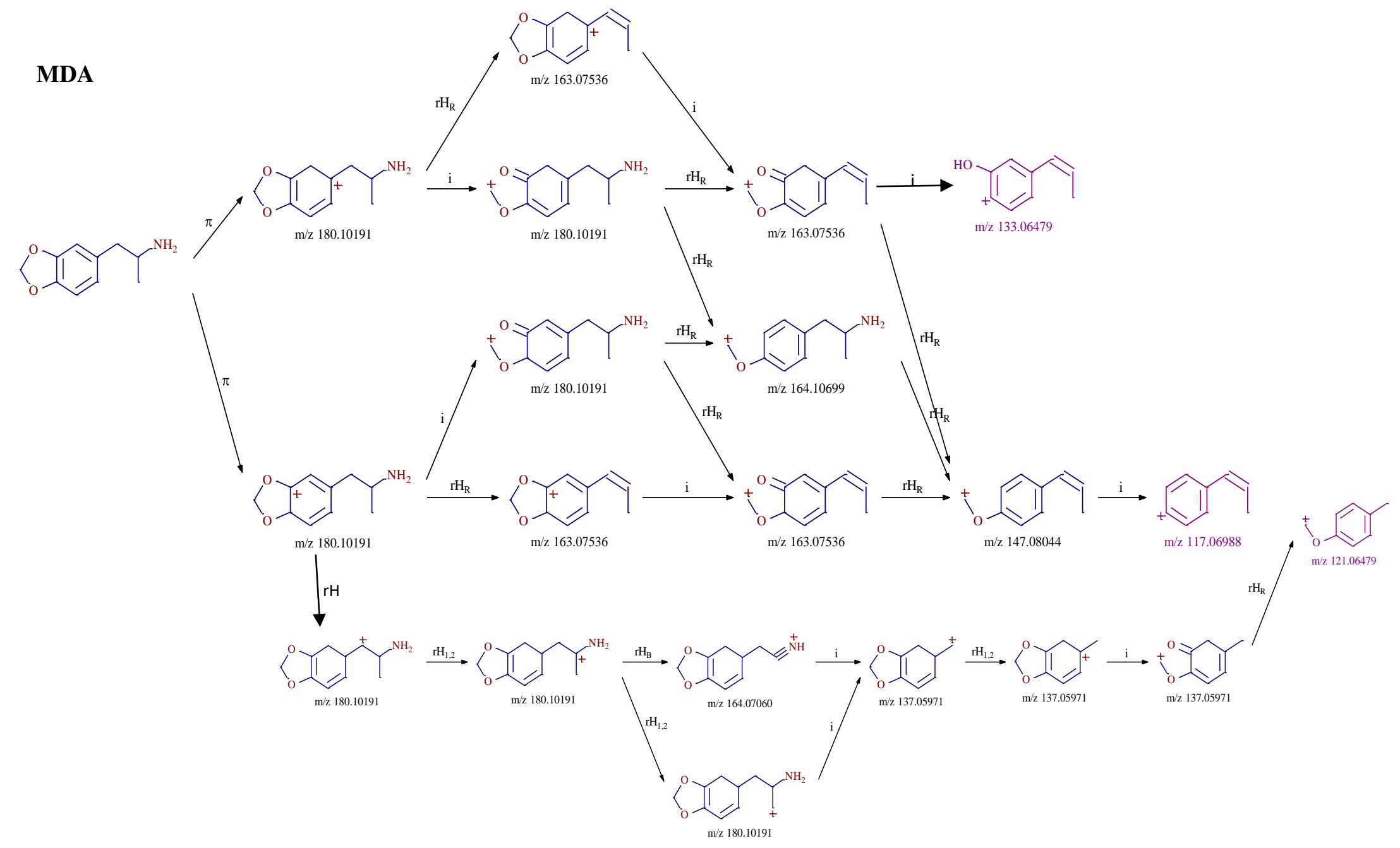




$$
\int_{1}^{\text {CP. } 24}
$$


MDA demethylation metabolite

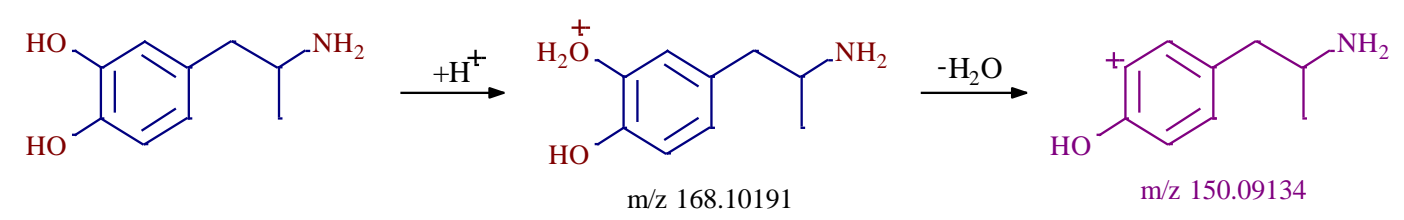




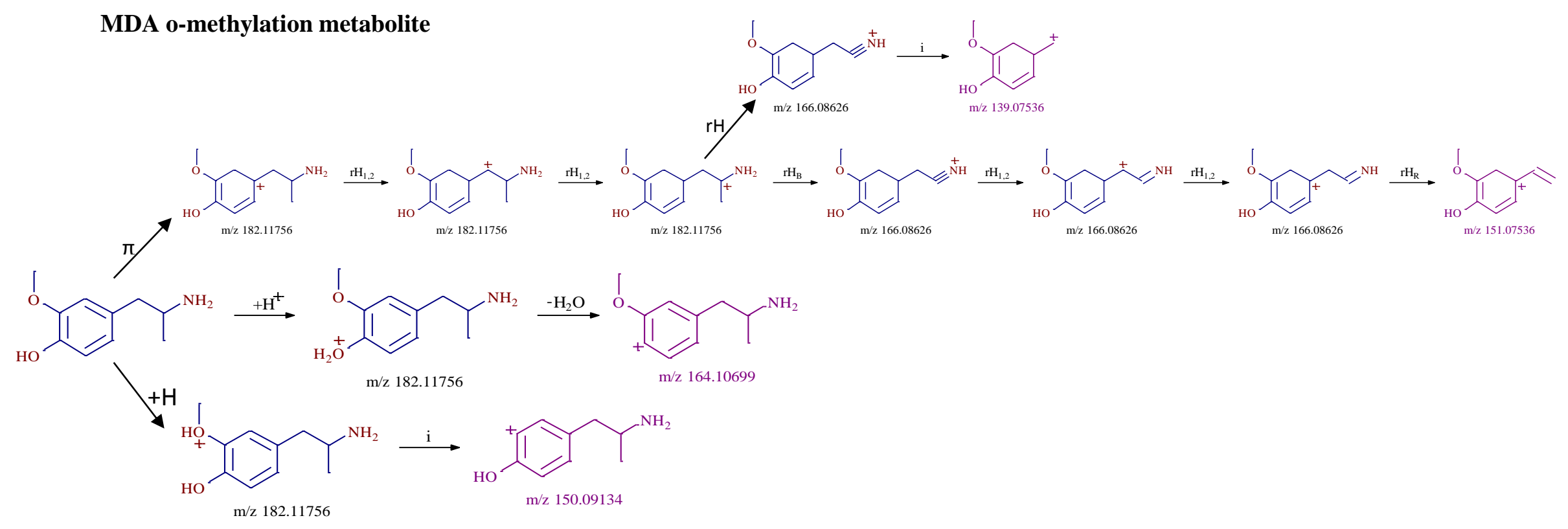




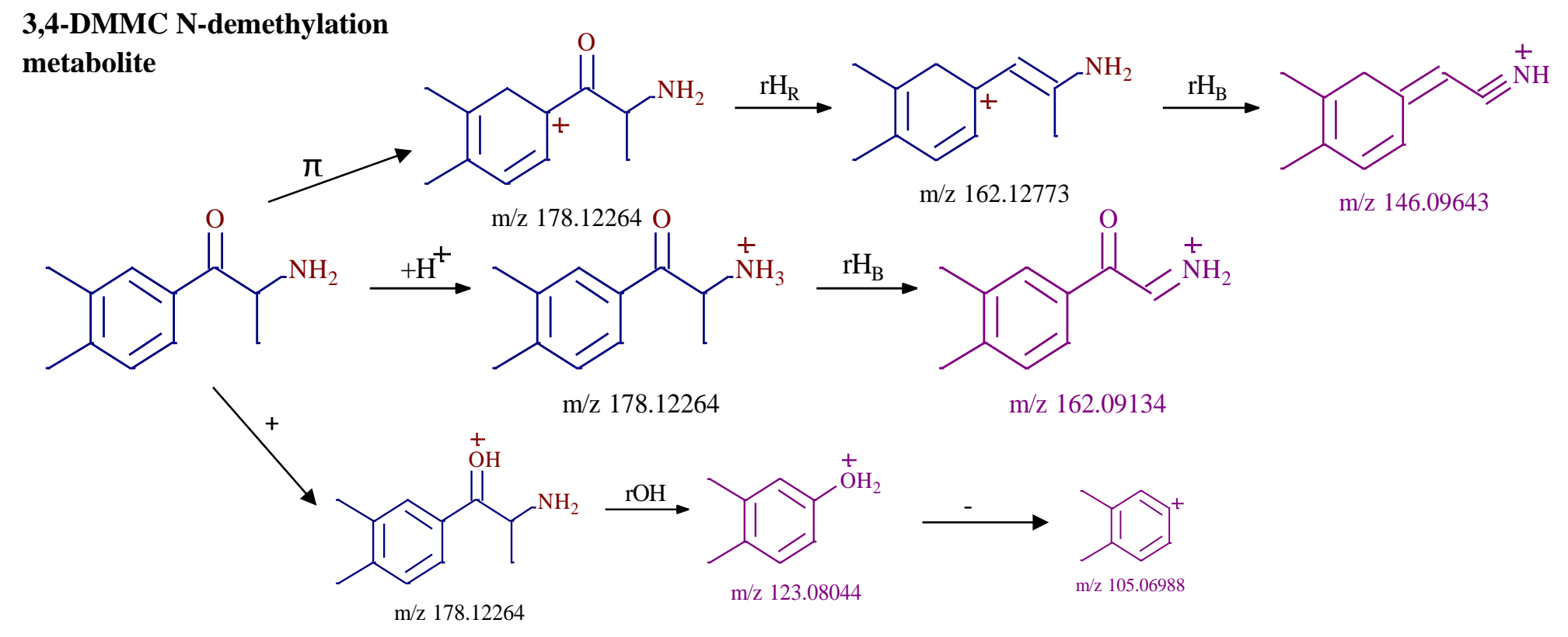




\section{3,4-DMMC reduction +}

hvdroxvlation + oxidation

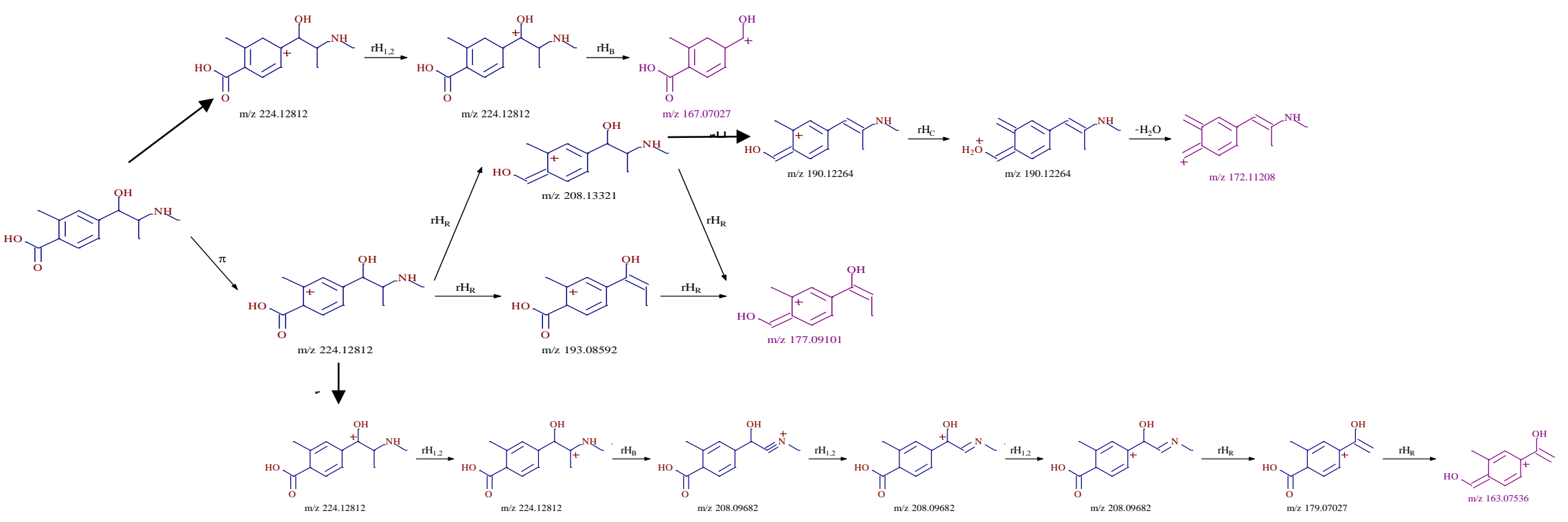

